
UNIVERSIDADE DE SÃO PAULO

ESCOLA DE ENFERMAGEM

\section{QUALIDADE DE VIDA RELACIONADA À SAÚDE E CONDIÇÕES DE TRABALHO DOS ENFERMEIROS DE TERAPIA INTENSIVA DO MUNICÍPIO DE SÃO PAULO}

LUCIANA SOARES COSTA SANTOS 


\section{QUALIDADE DE VIDA RELACIONADA À SAÚDE E CONDICOÕES DE TRABALHO DOS ENFERMEIROS DE TERAPIA INTENSIVA DO MUNICÍPIO DE SÃO PAULO}

Tese apresentada ao Programa de PósGraduação em Enfermagem na Saúde do Adulto - PROESA, da Escola de Enfermagem da Universidade de São Paulo, obtenção do título de Doutor em Ciências.

Orientadora: Profa ${ }^{-}$. Dra. Miako Kimura 


\section{AUTORIZO A REPRODUÇÃO E DIVULGAÇÃO TOTAL OU PARCIAL DESTE TRABALHO, POR QUALQUER MEIO CONVENCIONAL OU ELETRÔNICO, PARA FINS DE ESTUDO E PESQUISA, DESDE QUE CITADA A FONTE.}

Assinatura:

Data:

1
1

Catalogação na publicação (CIP)

Biblioteca "Wanda de Aguiar Horta"

Escola de Enfermagem da Universidade de São Paulo

Santos, Luciana Soares Costa

Qualidade de vida relacionada à saúde e condições de trabalho dos enfermeiros de unidade de terapia intensiva do município de São Paulo / Luciana Soares Costa Santos .-São Paulo, 2012.

$158 \mathrm{p}$.

Tese (Doutorado) - Escola de Enfermagem da Universidade de São Paulo.

Orientadora: $\operatorname{Prof}^{a}$ Dr $^{a}$ Miako Kimura

1. Qualidade de vida 2. Condições de trabalho 3. Enfermeiros 4. Unidade de terapia intensiva I. Título. 
FOLHA DE APROVAÇÃO

Nome: Luciana Soares Costa Santos

Título: QUALIDADE DE VIDA RELACIONADA À SAÚDE E CONDIÇÕES DE TRABALHO DOS ENFERMEIROS DE TERAPIA INTENSIVA DO MUNICÍPIO DE SÃO PAULO

Tese apresentada ao Programa de PósGraduação em Enfermagem na Saúde do Adulto da Escola de Enfermagem da Universidade de São Paulo, obtenção do título de Doutor em Ciências.

Aprovado em:

Banca Examinadora

Prof ${ }^{\mathrm{a}} \mathrm{Dr}^{\mathrm{a}}$ Instituição:

Julgamento: Assinatura:

Prof ${ }^{a} \mathrm{Dr}^{\underline{\underline{a}}}$ Instituição:

Julgamento: Assinatura:

Prof ${ }^{\mathrm{a}} \mathrm{Dr}^{\mathrm{a}}$ Instituição:

Julgamento: Assinatura:

Prof $^{a}{ }^{-a}{ }^{a}$ Instituição:

Julgamento: Assinatura:

Prof $^{a}{ }^{-a}{ }^{a}$ Instituição:

Julgamento: Assinatura: 


\section{Dedicatória}

A Deus que todos os dias me fortaleceu através da sua promessa, da sua fidelidade, do seu amor e da sua misericórdia.

Ao Caio, esposo e amigo, companheiro de todas as horas, obrigada pela paciência, pelo apoio e pelo amor dedicado.

Aos meus amados filhos, Davi e André, que por muitas vezes não entenderam a minha ausência e o meu isolamento, entretanto, na singeleza de seus carinhos me fortaleciam a cada dia.

Aos meus pais, Luciano e Geni, que me ensinaram e me apoiaram a lutar pelos meus sonhos. Mãe, você é a minha maior inspiração. 


\section{Agradecimento especial,}

A Prof ${ }^{a}$ Dr$^{\mathrm{a}}$ Miako Kimura pelo carinho e pela paciência; pelo exemplo como pessoa e profissional, servindo-me de inspiração pela sua competência, sabedoria e ética dedicadas à enfermagem e à pesquisa, o meu muito obrigada! 


\section{Agradecimentos,}

Aos meus sogros, Cesar e Luci, pelos muitos momentos em que suas palavras sábias me fortaleciam para um novo começo.

Aos meus irmãos, Ricardo e Lucimara, cunhados e cunhadas, sobrinhos e sobrinhas, por fazerem parte deste importante momento.

À gerência da UTI HAOC e aos coordenadores de enfermagem pela colaboração nestes anos de estudo.

Aos gerentes das unidades e serviços participantes deste estudo, pela atenção e colaboração.

Aos queridos pastores Rogério e Flávia, pelo apoio espiritual em todo o caminho.

Ao Dr. Sylas Cappi e enfermeira Celeste pelo apoio e colaboração na coleta de dados deste trabalho.

À amiga Acácia, pela convivência de todos estes anos, pelo apoio nos momentos mais difíceis e pela amizade sempre incondicional.

Às amigas Myrcea e Jaqueline pelo apoio nas inúmeras trocas de plantão, muitas vezes exaustivas. Aos amigos, Fábio, Luciana, César, Hérica, Joziane, Sarah, Elda, Edilene, Shirley, Lu Souza, Bia, Nivia e Lu G pela força nesta conquista. Às enfermeiras e colegas da UTI HAOC, pela amizade e apoio.

A todos os enfermeiros das instituições participantes pelo apoio para a realização deste estudo.

Ao Lucas, pela contribuição na análise estatística dos dados e ao Christian pela elaboração gráfica.

A todos vocês, os meus sinceros agradecimentos. 
"Você pode sonhar, criar e construir a ideia mais maravilhosa do mundo, mas são necessárias pessoas para fazer esse sonho virar realidade."

Walt Disney 
Santos, LSC. Qualidade de vida relacionada à saúde e condições de trabalho de enfermeiros de Terapia Intensiva do município de São Paulo [tese]. São Paulo: Escola de Enfermagem, Universidade de Paulo; 2012.

\section{RESUMO}

Considerando a importância de identificar fatores do ambiente de trabalho que afetam a saúde física e mental de enfermeiros em Unidades de Terapia Intensiva (UTI) este estudo teve como objetivos: avaliar a qualidade de vida relacionada à saúde (QVRS) de enfermeiros de UTI em relação a componentes físicos e mentais, descrever as condições do ambiente de trabalho e analisar as associações entre QVRS e condições de trabalho de enfermeiros em UTIs. Um estudo descritivo, com delineamento transversal foi realizado em 31 UTIs de adultos, de 18 hospitais selecionados aleatoriamente nas cinco regiões do município de São Paulo, com uma amostra de 180 enfermeiros $(68,9 \%$ do sexo feminino, idade média de 35,6 anos $(\mathrm{dp}=7,0)$, tempo médio de trabalho em UTI de 7 anos ( $\mathrm{dp}=5,2), 68,0 \%$ trabalhando até 40 horas semanais). O instrumento Nursing Work Index-Revised (NWI-R) foi utilizado para identificar as condições do ambiente de trabalho percebidas pelos enfermeiros (autonomia, controle sobre o ambiente, relacionamento médico-enfermeiro e suporte organizacional) e o Medical Outcomes Study 12 - Item Short Form Health Survey (SF-12), para avaliar a QVRS em seus componentes físico (CF) e mental (CM). Nas análises bivariadas utilizaram-se os testes Qui-Quadrado de Pearson, teste t-Student, ANOVA e o teste pos hoc de Tukey. Análise de Regressão Linear Múltipla, método stepwise forward, foi realizada para examinar o efeito de variáveis selecionadas sobre os CF e CM do SF-12. Na avaliação da QVRS, os escores médios do CF e do CM foram, respectivamente, de $49(\mathrm{dp}=7,6)$ e $46(\mathrm{dp}=10)$, valores próximos aos de referência para a população geral americana (50 pontos). O escore total médio do NWI-R foi de 2,0 (dp=0,5) e dos domínios entre 2,0 e 2,1 (dp entre 0,5 e 07 ), o que sugere condições adequadas de trabalho. Correlações significativas $(p<0,05)$ e de fraca magnitude $(-0,18$ a $-0,34)$ foram encontradas entre os escores do SF-12 (CF e CM) e os do NWI-R (total e domínios), indicando associação entre QVRS e condições de trabalho dos enfermeiros. $\mathrm{Na}$ análise de regressão linear múltipla, o CF esteve associado com gênero masculino, com proporção maior que 8 leitos por enfermeiro e com a subescala suporte organizacional do NWI-R. No CM, foram encontradas associações com idade e com a subescala controle sobre o ambiente do NWIR. Os resultados obtidos sugerem que a QVRS e as condições de trabalho dos enfermeiros deste estudo encontravam-se relativamente preservadas. Gênero masculino, menor idade, maior suporte organizacional e controle sobre o ambiente de trabalho foram fatores independentemente associados à melhor QVRS dos enfermeiros deste estudo.

Descritores: Qualidade de vida, Condições de trabalho, Saúde do trabalhador, Enfermagem, Unidades de Terapia Intensiva. 
Santos, LSC. Health-related quality of life and working conditions of intensive care nurses in Sao Paulo city, Brazil. [thesis]. São Paulo: Escola de Enfermagem, Universidade de Paulo; 2012.

\begin{abstract}
Considering the importance of identifying factors that affect the physical and mental health of nurses in Intensive Care Units (ICU), this study aimed to assess the health-related quality of life (HRQOL) physical and mental components of ICU nurses, to describe the conditions of the work environment and to examine the associations between HRQOL and working conditions of ICU nurses. A descriptive and cross-sectional study was performed in 31 adult ICUs, of 18 hospitals randomly selected in the five regions of Sao Paulo city, Brazil, with a sample of 180 nurses (68.9\% female, mean age 35.6 years (SD $=7.0$ ), average working time in the ICU for 7 years $(S D=5.2), 68.0 \%$ up to 40 working hours per week). The instrument Nursing Work Index-Revised (NWIR) was used to identify the nurses' perceptions of the working environment (autonomy, control over the environment, physician-nurse relationship and organizational support) and the Medical Outcomes Study 12 - Item Short Form Health Survey (SF-12) to assess the physical (PC) and mental (MC) HRQOL components. The chi-square Pearson test, Student's t-test, ANOVA and post hoc Tukey test were used in bivariate analyzes. Multiple Linear Regression Analysis, stepwise forward method, was performed to examine the effect of selected variables on the SF-12 PC and MC. In the assessment of HRQOL, the average scores of PC and CM were, respectively, $49(\mathrm{SD}=7.6)$ and 46 $(S D=10)$, values close to that of reference for the general U.S. population (50 points). The mean total score of NWI-R was $2.0(\mathrm{SD}=0.5)$ and between 2.0 and 2.1 for the subscales (SD from 0.5 to 07 ), suggesting adequate work conditions. Significant correlations $(p<0.05)$ and of low magnitude $(r=-0.18$ to -0.34) were found between the scores of the SF-12 and NWI-R (total and subscales), indicating association between $\mathrm{HRQOL}$ and working conditions of nurses. In the Multiple Linear Regression Analysis, the PC was associated with male gender, ratios beds per nurse greater than 8 and with the organizational support subscale of the NWI-R. For the MC, significant associations were found with age and the subscale control over the environment. The results of this study suggest that the HRQOL and the working conditions of nurses were relatively preserved. Male gender, younger age, greater organizational support and control over the work environment were factors independently associated with better HRQOL of the nurses in this study.
\end{abstract}

Descriptors:Quality of Life, Working Conditions, Occupational Health, Nursing, Intensive Care Units. 


\section{LISTA DE GRÁFICOS}

Gráfico 1- Distribuição das respostas do SF-12 por componentes e dimensões. São Paulo, 2012 ............................................. 84

Gráfico 2- Distribuição das respostas dos enfermeiros para o NWI-R.

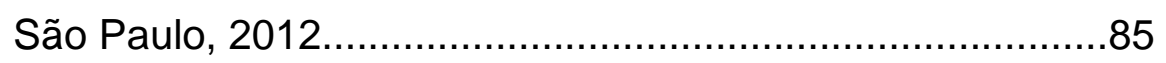

Gráfico 3- Distribuição do modelo final de regressão para o CF fixando as referências sexo feminino e leitos por enfermeiro até oito, com intervalo de confiança de 95\%. São Paulo, 2012 .96

Gráfico 4- Distribuição do modelo final de regressão para o CM fixando a idade média dos enfermeiros e variando o escore NWI-RControle, com intervalo de confiança de 95\%. São Paulo, 2012. 98

Gráfico 5- Distribuição do modelo final de regressão para o CM fixando o escore médio do NWI-R-Controle e variando a idade dos enfermeiros, com intervalo de confiança de 95\%. São Paulo, 2012 .99

Anexo IV- Resíduos do modelo estatístico final e da distribuição normal do CF e CM SF 12. São Paulo, 2012 


\section{LISTA DE QUADROS}

Quadro 1 - Distribuição dos itens, dimensões e componentes do instrumento SF 12. São Paulo, 2012 ..................................64 


\section{LISTA DE TABELAS}

Tabela 1 - Distribuição do total de hospitais com UTI do município de São Paulo, por região e vinculação administrativa. São Paulo, 2010.

Tabela 2 - Distribuição da amostra de hospitais com UTI de adultos do município de São Paulo, por região e tipo de vinculação administrativa. São Paulo, 2010. .55

Tabela 3 - Distribuição dos hospitais com UTI do município de São Paulo planejados (P) e obtidos (O) para a amostra, segundo região do município e tipo de vinculação administrativa. São Paulo, 2012.

Tabela 4 - Distribuição da amostra de enfermeiros de UTI do município de São Paulo, por região e tipo de hospital.

São Paulo, 2012 .59

Tabela 5 - Distribuição das variáveis de caracterização dos hospitais. São Paulo, 2012. .74

Tabela 6 - Distribuição das UTIs segundo o número de leitos, tipo e proporção paciente - enfermeiro. São Paulo, 2012. .75

Tabela 7 - Caracterização sociodemográfica e de trabalho dos enfermeiros de UTI. São Paulo, 2012.

Tabela 8 - Distribuição dos enfermeiros de UTI segundo respostas aos itens do SF-12. São Paulo, 2012. .80

Tabela 9 - Média e desvio-padrão das dimensões dos Componentes Físico e Mental do SF-12. São Paulo, 2012 
Tabela 10 - Distribuição dos enfermeiros de UTI segundo respostas às questões do NWI - R. São Paulo, 2012.

Tabela 11 - Consistência interna do instrumento NWI - R. São Paulo, 2012

Tabela 12 - Estatística descritiva dos escores dos instrumentos SF 12 e NWI-R. São Paulo, 2012. ( $n=180)$ .88

Tabela 13 - Associações entre o escore do SF-CF e variáveis sociodemográficas e de trabalho dos enfermeiros e dos hospitais. São Paulo, 2012 .90

Tabela 14 - Associação entre o escore do SF - CM e variáveis sociodemográficas e de trabalho dos enfermeiros e dos hospitais. São Paulo, 2012

Tabela 15 - Coeficiente de correlação entre o NWI-R e os componentes do SF-12. São Paulo, 2012.

Tabela 16 - Lista de variáveis candidatas aos modelos de regressão linear múltipla para os componentes físico e mental do SF-12 e NWI-R por ordem decrescente de significância. São Paulo, 2012 94

Tabela 17- Regressão linear múltipla para o componente físico do SF-12. São Paulo, 2012 


\section{LISTA DE SIGLAS}

AMIB - Associação de Medicina Intensiva Brasileira

ANVISA - Agência Nacional de Vigilância Sanitária

CF - Componente Físico

CM - Componente Mental

DATASUS - Departamento de Informática do Sistema Único de Saúde

GM - Gabinete do Ministério

MS - Ministério da Saúde

NWI-R - Nursing Work Index - Revised

OMS - Organização Mundial de Saúde

QV - Qualidade de Vida

QVRS - Qualidade de Vida Relacionada à Saúde

RDC - Resolução da Diretoria Colegiada

SF - 12 - Versão do Medical Outcomes Study 12- Item Short Form Health Survey

SF - 36 - Versão do Medical Outcomes Study 36 - Item Short Form Health Survey

UTI - Unidade de Terapia Intensiva

WHOQOL - The World Health Organization Quality Of Life Assessment Instrument 


\section{SUMÁRIO}

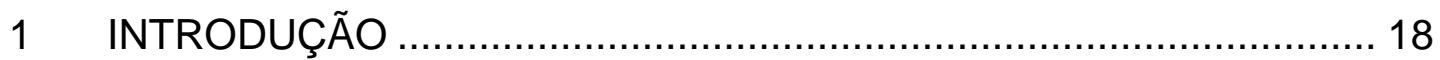

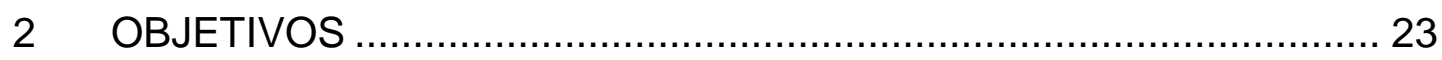

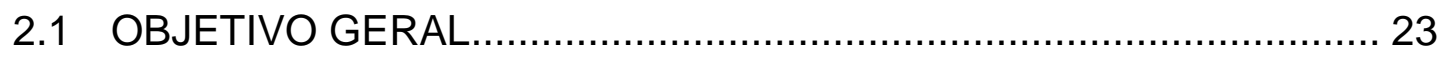

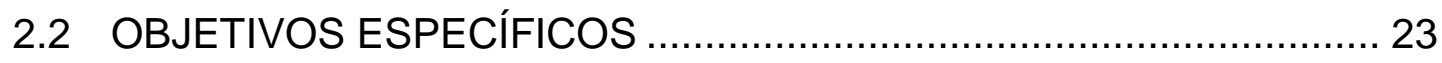

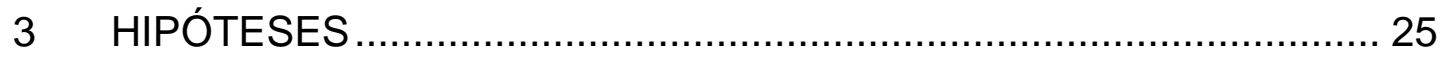

4 REFERENCIAL TEÓRICO ………………............................ 27

4.1 CONTEXTO DO CUIDADO E A INSERÇÃO DO ENFERMEIRO NO CUIDADO INTENSIVO.

4.2 CARACTERÍSTICAS E CONDIÇÕES DE TRABALHO DO ENFERMEIRO NA UTI

4.3 QUALIDADE DE VIDA, QUALIDADE DE VIDA RELACIONADA À SAÚDE

4.3.1. Qualidade de vida e saúde dos enfermeiros ................................... 47

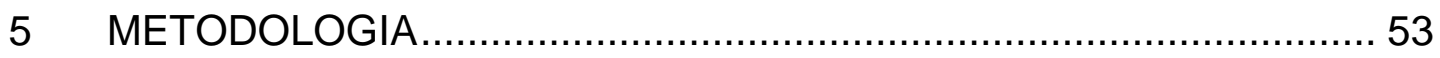

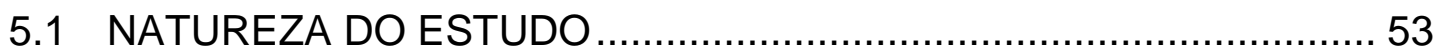

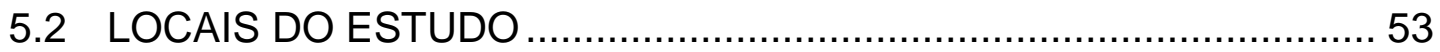

5.3 AMOSTRA DE HOSPITAIS COM UTI - CRITÉRIOS DE INCLUSÃO E

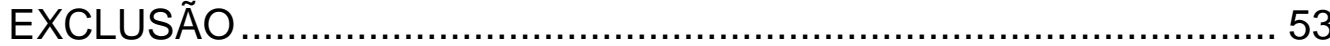

5.3.1 Procedimentos de amostragem dos hospitais com UTI ...................... 54

5.3.2 Dificuldades de composição da amostra ............................................... 56

5.3.3 Amostra de enfermeiros de UTI - critérios de inclusão e exclusão ..... 58

5.4 PRÉ-TESTE ………………………………….......................

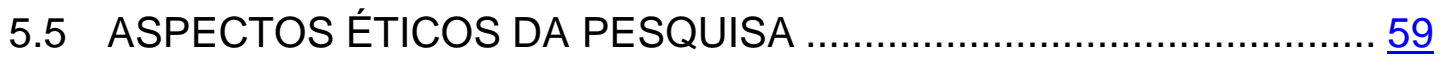

5.6 INSTRUMENTOS DE COLETA DE DADOS ..................................... 60

5.6.1 Ficha de caracterização sociodemográfica e profissional dos enfermeiros 
5.6.2 Instrumento Nursing Work Index - Revised 60

5.6.3 Instrumento de Avaliação de Qualidade de Vida Relacionada à Saúde Medical Outcomes Study 12 - Item Short Form Health Survey (SF-12) 62

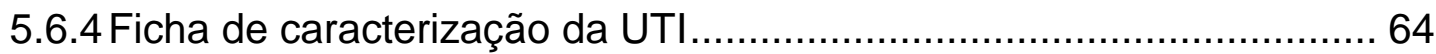

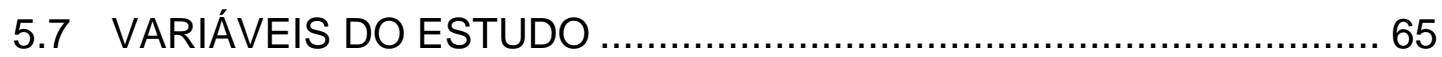

5.7.1 Variáveis sociodemográficas e do trabalho dos enfermeiros ...............65 65

5.7.2 Variáveis relacionadas às condições de trabalho dos enfermeiros ..... 66

5.8 PROCEDIMENTOS PARA COLETA DE DADOS ............................... 66

5.9 OPERACIONALIZAÇÃO DA COLETA DE DADOS …......................... 67

5.10 TRATAMENTO E ANÁLISE ESTATÍSTICA DOS DADOS ................... 68

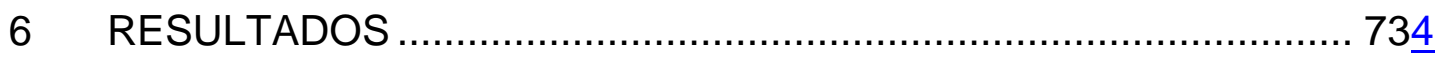

6.1 CARACTERIZAÇÃO DOS HOSPITAIS E UTIS................................ $73 \underline{4}$

6.2 CARACTERIZAÇÃO DOS ENFERMEIROS …………................... 75므

6.3 QUALIDADE DE VIDA RELACIONADA À SAÚDE E DAS CONDIÇÕES DE TRABALHO DOS ENFERMEIROS …........................................ 78

6.3.1 Análise descritiva dos itens do SF 12 ............................................. 78

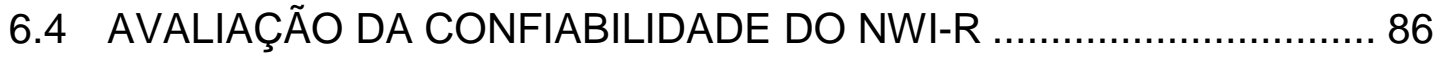

6.5 ASSOCIACCÕES ENTRE QUALIDADE DE VIDA RELACIONADA À SAÚDE E VARIAVEIS SELECIONADAS ....................................... 87

6.5.1 Associações entre os Componentes Físico e Mental do SF-12 e variáveis

6.6 ANÁLISE DE REGRESSÃO LINEAR MÚLTIPLA ............................93

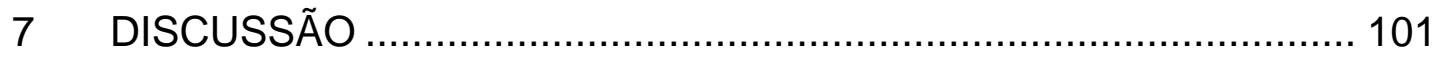

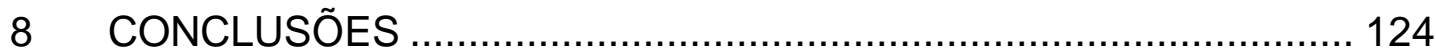

9 CONSIDERAÇÕES FINAIS ………………….......................... 127

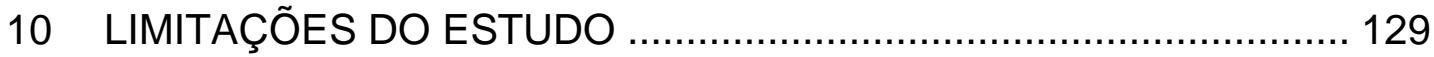

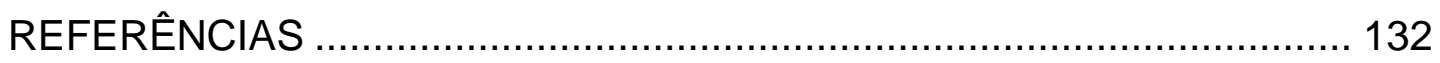

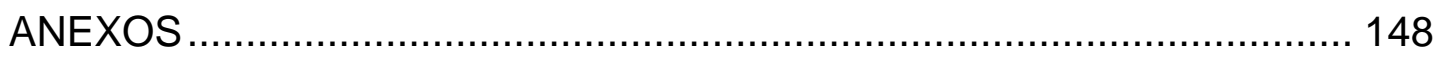




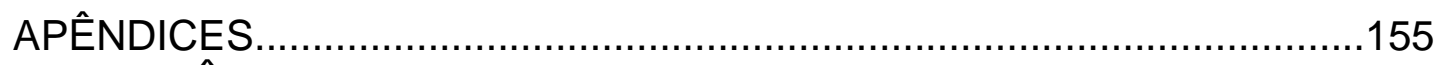

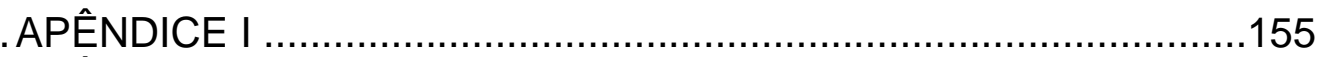

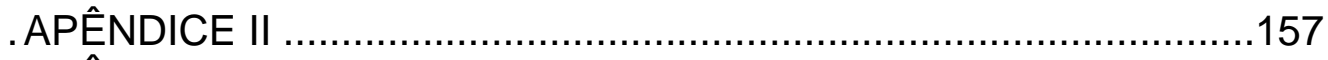

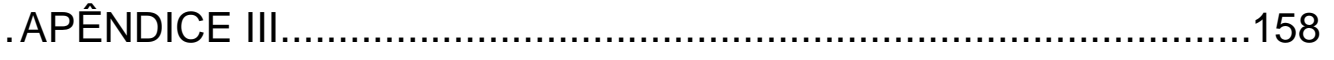


Introduçãa 


\section{INTRODUÇÃO}

Entender o contexto de trabalho dos enfermeiros em Unidade de Terapia Intensiva (UTI) e como ele influencia os próprios profissionais e os resultados do cuidado é uma preocupação que veio crescendo desde o início das atividades como enfermeira intensivista, há dezesseis anos. Inúmeros questionamentos instigavam a busca de novos conhecimentos sobre a realidade vivenciada. Com os conhecimentos aprimorados nos cursos de Especialização e no Mestrado, foram sendo construídas as percepções e experiências que direcionaram a proposição desta tese de Doutorado.

No Mestrado, em pesquisa realizada com 158 enfermeiros de um hospital privado e filantrópico do município de São Paulo (Santos, 2004), já se pôde observar que as condições do ambiente de trabalho e as diversas demandas presentes na prática assistencial dos enfermeiros podem representar uma ameaça à saúde física e mental desses profissionais. Fatores como excesso de carga de trabalho, horário de descanso insuficiente ou inexistente, o lidar com situações como sofrimento, tomada de decisão imediata, falta de tempo para atender familiares com importantes necessidades emocionais e dar apoio aos pacientes foram destaques nos achados do estudo.

A preocupação com as condições de trabalho da enfermagem encontra-se em ascensão em nível global, sobretudo nos Estados Unidos e em países da Europa, em função da escassez de enfermeiros para a prática assistencial em hospitais, com impacto direto sobre os processos operacionais e financeiros das instituições e sobre a qualidade dos cuidados prestados aos pacientes (Kelley, Chalfin, Ingbar, Sessler, 2006; Warshawsky, Havens, 2011). 
Leplat, Cuny (1977) definem condições de trabalho como "o conjunto de fatores que determinam o comportamento do trabalhador". Por outro lado, as condições de trabalho podem caracterizar uma determinada situação que permite ou impede a atividade laboral, podendo ser influenciadas por condições físicas do ambiente, temporais, organizacionais e pelo contexto do trabalho propriamente dito.

Segundo Marziale (2001) há muito tempo as condições de trabalho dos enfermeiros nos hospitais tem sido considerada inadequada devido às especificidades do ambiente e das atividades insalubres executadas. Destaca ainda, o desgaste físico e emocional, a baixa remuneração e o desprestígio social como fatores associados às condições de trabalho do enfermeiro o que pode levar ao abandono da profissão, escassez de profissionais no mercado de trabalho e a deterioração da qualidade da assistência prestada.

Desta forma, é importante que consigamos identificar os fatores que se relacionam com as condições de trabalho dos enfermeiros e repercutem na sua QVRS, principalmente para os enfermeiros de UTI.

A UTI é tratada como uma unidade diferenciada do ponto de vista de recursos materiais e humanos. Requer uma dinâmica de trabalho especializada, ágil e imediata, devido à complexidade do cuidado dos pacientes atendidos na unidade. $O$ processo de trabalho na UTI pode ser desgastante, gerador de sofrimento e muitas vezes insalubre. Ressalta-se a relação entre o ambiente de trabalho, bastante peculiar, impactando diretamente os profissionais que ali atuam.

A interferência de aspectos físicos e psíquicos do trabalho na saúde e na qualidade de vida $(\mathrm{QV})$ nem sempre é claramente percebida pelos profissionais, mas ela pode se manifestar como uma queda de produtividade, sentimentos negativos de desprazer, fadiga e tensão, envelhecimento precoce e como doenças físicas e emocionais (Rocha e Felli, 2004; Elias e Navarro, 2006; Kurgant, Tonchin e Melleiro,2006). 
Saúde é uma dimensão consistentemente importante da QV (Moons, 2004). Ao definir Saúde como um estado de bem estar físico, mental e social e não apenas a ausência de doença ou enfermidade, a Organização Mundial da Saúde (OMS) relacionou, indiretamente, saúde ao conceito multidimensional de qualidade de vida.

Relacionando a condição de saúde ao seu impacto em aspectos significativos da vida em geral, encontra-se na literatura o conceito de Qualidade de Vida Relacionada à Saúde (QVRS), uma vertente de abordagem da QV diretamente ligada a questões de saúde-doença. $\mathrm{Na}$ avaliação da QVRS considera-se essencial a experiência subjetiva em relação a determinados estados ou problemas de saúde e o seu impacto no funcionamento físico, social e psicológico (Minayo, Hartz, Bussl, 2000; Seidl, Zannon, 2004; Moons, 2004).

As relações entre saúde e condições de trabalho vêm sendo desenvolvidas desde a década de 1970, pautadas inicialmente no referencial da ergonomia. A partir da década de 1990, tiveram início as pesquisas sobre questões relacionadas à organização do trabalho, condições ocupacionais e riscos do ambiente de trabalho, estresse, qualidade de vida, adoecimento dos trabalhadores, saúde mental, prazer e sofrimento no trabalho, evidenciando a importância dos aspectos subjetivos e psicossociais para a saúde dos profissionais de enfermagem (Oliveira, Lisboa, 2004).

$\mathrm{Na}$ enfermagem, as condições objetivas do trabalho, assim como as percepções sobre estas condições podem diferir entre os trabalhadores de diferentes áreas de atuação e influenciar os desfechos na saúde. Observa-se na literatura que algumas lacunas ainda permanecem, quando se trata de estudos sobre as relações entre condições de trabalho em UTIs e QVRS de enfermeiros que atuam nessa área.

O conceito de UTI agrega a especialização do cuidado, o uso da tecnologia em saúde e a capacitação profissional constante. As próprias características do trabalho intensivo remetem à reflexão sobre o quanto 
estas condições podem interferir na QVRS dos enfermeiros. QVRS pode ser afetada pelas condições de trabalho, pelo aumento dos esforços e pela baixa recompensa no trabalho quando comparada a um alto desgaste da sua prática. Reforça-se a necessidade da discussão sobre os papéis profissionais, das condições de trabalho e da QVRS dos profissionais de saúde (Silva, Souza, Borges, Fischer, 2010).

Um estudo sobre QVRS de profissionais de enfermagem atuando em UTIs observou que os escores eram piores para os envolvidos com erros de medicação e entre as classes trabalhadoras, os mais acometidos eram os técnicos de enfermagem quando comparados aos enfermeiros (Pellicioti, 2009). Os maiores escores de QVRS foram observados no domínio capacidade funcional e os menores, para vitalidade e dor. De maneira geral, o estado de saúde da equipe de enfermagem foi considerado regular.

Outro estudo realizado com 62 trabalhadores de enfermagem de cinco hospitais universitários investigou as cargas psíquicas e processos de desgaste destes trabalhadores. Os resultados demonstraram que todos os trabalhadores referiram sofrer algum tipo de carga psíquica e apresentavam desgastes originados por eles. Este desgaste psíquico era traduzido pelo maior impacto nas situações e relações sociais da sua QV, quando relacionado à natureza do trabalho de enfermagem propriamente dito. Os achados evidenciam o papel das estruturas organizacionais do trabalho como um fator colaborador da saúde do trabalhador em enfermagem (Mininel, Baptista, Felli, 2011).

A identificação dos fatores que podem interferir na QVRS dos enfermeiros de UTI pode permitir subsidiar uma melhor assistência de enfermagem, em um menor impacto na sua condição física e mental, direcionando assim, a melhores resultados. Diante desse panorama, faz-se pertinente a investigação das associações entre as condições de trabalho e a QVRS dos enfermeiros de UTI, principalmente por causa da escassez dos estudos relacionados ao tema, pautando assim novas discussões sobre melhorias para o trabalho e para a saúde destes profissionais. 
Objetivas 


\section{OBJETIVOS}

\subsection{OBJETIVO GERAL}

Analisar as relações entre condições de trabalho e qualidade de vida relacionada à saúde (QVRS) de enfermeiros em Unidades de Terapia Intensiva (UTI) no município de São Paulo.

\subsection{OBJETIVOS ESPECÍFICOS}

- Avaliar a QVRS de enfermeiros de UTI, em relação aos componentes físico e mental.

- Descrever as condições de trabalho de enfermeiros de UTI, em relação à autonomia, controle sobre o ambiente, relacionamento médico-enfermeiro e suporte organizacional.

- Analisar as associações entre condições de trabalho e os componentes da QVRS dos enfermeiros, ajustando por covariáveis sociodemográficas e profissionais selecionadas. 
Hipóteses 


\section{HIPÓTESES}

- As condições de trabalho (autonomia, controle sobre o ambiente, relacionamento médico-enfermeiro e suporte organizacional) estarão associadas ao componente físico da QVRS, independente das covariáveis sociodemográficas e profissionais.

- As condições de trabalho (autonomia, controle sobre o ambiente, relacionamento médico-enfermeiro e suporte organizacional) estarão associadas ao componente mental da QVRS, independente das covariáveis sociodemográficas e profissionais. 
Referencial teárica 


\section{REFERENCIAL TEÓRICO}

\subsection{CONTEXTO DO CUIDADO E A INSERÇÃO DO ENFERMEIRO NO CUIDADO INTENSIVO}

Nas últimas décadas, nota-se um interesse crescente na avaliação da qualidade dos cuidados de saúde, não apenas entre os administradores do setor, mas também entre os profissionais e os próprios usuários dos sistemas de saúde.

Esse crescente interesse pode ser atribuído ao aumento de custos diretos relacionados à saúde, bem como às mudanças ocorridas nos processos do cuidar em saúde, da economia e do processo produtivo como um todo, o que permite aperfeiçoar a qualidade dos recursos que dispomos para o atendimento destas novas demandas.

A busca por melhorias contínuas da qualidade do cuidado e da determinação de mecanismos para uma avaliação objetiva em saúde é um grande desafio para os profissionais da área.

A qualidade pode ser interpretada como conformidades de normas não absolutas que variam de uma sociedade para outra. Ressaltamse ainda três componentes importantes: atenção técnica, manejo das relações interpessoais e o ambiente físico em que acontece o processo de saúde. Essa qualidade pode ser influenciada pelo ambiente físico, pela relação interpessoal, pela atenção técnica-científica, pelos recursos humanos e materiais, pelas características e preferências dos pacientes e pelos objetivos sociais que envolvem a eficiência e a equidade relacionada à saúde (Donabedian, 1990). 
A avaliação de estratégias relacionadas ao cuidado envolve atividades que proporcionem mensurar principalmente os resultados como uma forma de assegurar sua qualidade. Dependendo do nível e do alcance das responsabilidades que são preestabelecidas, os resultados podem incluir aspectos físicos, fisiológicos, sociais, além de medidas individuais e populacionais (Donabedian, 2000).

Nos últimos anos, tem-se observado a expansão dos processos de melhorias e avaliação da qualidade do cuidado através das certificações de qualidade em saúde, visando o alcance de níveis superiores de qualidade no atendimento ao público geral.

Atualmente, os serviços de saúde no geral, buscam a efetividade da qualidade do cuidado em todos os ambientes da área hospitalar através do aperfeiçoamento dos recursos humanos, materiais, ambientais e, sobretudo, da tecnologia. Uma das unidades que mais empregam tecnologia é a UTI. Entretanto, o uso de tecnologia sem estar agregado a recursos humanos qualificados para sua utilização não é suficiente para certificar uma assistência de qualidade, devido às circunstâncias em que este cuidado é prestado.

A Portaria $n^{\circ} 3.432 / 98$, do Ministério da Saúde, con ceitua UTI como a unidade hospitalar destinada ao atendimento de pacientes graves ou de risco que dispõe de assistência médica e de enfermagem ininterruptas, com equipamentos específicos próprios, recursos humanos especializados e que tenha acesso a outras tecnologias destinadas a diagnóstico e terapêutica. De acordo com a faixa etária atendida, as UTIs podem ser classificadas em neonatal, pediátrica e adulta. Podem ainda ser destinadas para atendimento geral ou especializado, como as unidades cardiológica, coronariana, neurológica, para trauma, entre outras.

O Ministério da Saúde determina a obrigatoriedade de UTI em todo hospital secundário ou terciário com capacidade igual ou superior a 100 leitos, que devem corresponder entre $4 \%$ e $10 \%$ do total de leitos existentes 
no hospital. Já os hospitais gerais que realizam cirurgias complexas (neurológicas, cardíacas) e com atendimento a trauma e queimaduras, esta taxa sobe para $10 \%$ dos leitos disponíveis (Brasil, 1998).

Segundo a Portaria $\mathrm{n}^{\circ} 3.432 / 98$, as UTIs podem ser c lassificadas em tipo I, II e III, de acordo com a incorporação de tecnologia, especialização dos recursos humanos e área física disponível. Também dispõe sobre a necessidade de um enfermeiro assistencial para cinco leitos ou fração em UTIs tipo II e III.

As UTIs do tipo I são aquelas que estão em processo de adequação à legislação vigente cadastradas no DATASUS até 1998; as do tipo II são as unidades de tratamento Intensivo, credenciadas em conformidade com a Portaria GM no $3.432 / 98$, onde constam os critérios minimamente aceitáveis para atendimento a pacientes graves. Já as UTls do tipo III devem atender aos mesmos critérios das UTIs tipo II, uma vez que são critérios mínimos. No entanto, são mais qualificadas, incluindo recursos tecnológicos e humanos adicionais, como, por exemplo, a ampliação do número de exames no hospital e maior número de equipamentos por paciente ou grupo de pacientes e enfermeiro exclusivo (um para cada cinco leitos), e fisioterapeuta exclusivo.

Em relação aos recursos humanos, a $\operatorname{RDC} n^{\circ}-7$, de 24 de fevereiro de 2010 (ANVISA, 2010) estabelece a obrigatoriedade, na UTI, de um enfermeiro coordenador, exclusivo da unidade, especialista em UTI e com experiência de, no mínimo, três anos de trabalho na área e um enfermeiro assistencial, exclusivo da unidade, para, no máximo, oito leitos ou fração, por turno, além de outros profissionais, como técnicos de enfermagem, fisioterapeutas e médicos. A relação enfermeiro/leito recomendada pela Associação de Medicina Intensiva Brasileira (AMIB, 2009) é de um enfermeiro para cada cinco pacientes. Já a RDC n 26 de 11 de maio de 2012 (ANVISA, 2012) altera a RDC $n^{\circ} 7$, aume ntando a relação para, no mínimo, um enfermeiro a cada 10 leitos ou fração. 
Para atender o alto nível de complexidade do cuidado em UTI, torna-se imprescindível a presença de profissionais preparados para responder às diferentes demandas e necessidades do paciente crítico e ao mesmo tempo capacitados para lidar com o acúmulo de informações decorrentes das inovações tecnológicas, uma constante no ambiente de UTI.

Um fator que pode influenciar a qualidade do cuidado é a equipe de enfermagem. Atualmente, associam-se diferentes indicadores de qualidade da assistência aos profissionais que executam os cuidados. Sob essa ótica, a equipe multiprofissional torna-se responsável pelos resultados relacionados aos pacientes. As avaliações de qualidade incluem itens como nível de atualização profissional (especializações) e associação com eventos adversos, iatrogenias medicamentosas, erros médicos e complicações diversas (Cho, Kefian, Barkauskas, Smith, 2003).

Outro estudo identificou a associação de alguns fatores, como erros de medicação, queda do paciente, lesões e erros de diagnósticos ou intervenções como possíveis causas da deterioração da qualidade do cuidado quando associados com a equipe de enfermagem. $\mathrm{O}$ que chama atenção nos resultados é a questão do nível educacional da equipe de enfermagem, influenciando fortemente os resultados relacionados aos pacientes (Abdolmohsin, Thomas, 1991).

Nos EUA, outro estudo investigou a influência das ações de enfermagem nos eventos adversos, morbidade, mortalidade e custos médicos em 232 hospitais da Califórnia, com mais de 120 mil pacientes cirúrgicos. Os achados revelaram que o nível educacional das enfermeiras pode ser um importante determinante da qualidade do cuidado e parcialmente responsável pelo resultado final dos pacientes (Cho, Kefian, Barkauskas, Smith, 2003). 
Este estudo evidenciou ainda que, quanto maior o número de horas de cuidados de enfermagem (pela enfermeira), menores as complicações para os pacientes. A presença de eventos adversos nos pacientes cuidados por enfermeiras foi evidenciada em apenas $6,8 \%$ dos pacientes; $5,6 \%$ dos pacientes experienciaram apenas um dos eventos adversos, sendo que a pneumonia foi o mais frequente. Cabe ressaltar que a pneumonia é o principal e mais frequente fator de complicação em pacientes críticos e, para alguns autores (Cho, Kefian, Barkauskas, Smith, 2003) o papel do enfermeiro na sua prevenção é de fundamental importância.

Outro estudo identificou a associação do nível educacional das enfermeiras hospitalares e as taxas de mortalidade de pacientes cirúrgicos de 168 hospitais do estado da Pensilvânia. Neste estudo foram avaliados mais de 230.000 pacientes, de três especialidades cirúrgicas: geral, ortopédica e vascular. Quanto às enfermeiras, 10.184 participaram do estudo e as variáveis estudadas incluíam o seu nível educacional e a proporção pacientes por enfermeiro. Os achados demonstraram que 0 número de enfermeiras influenciou diretamente nos resultados dos pacientes, minimizando complicações ou detectando-as precocemente. Os resultados foram estatisticamente significantes para a relação entre a proporção de enfermeiras nos hospitais que tinham maiores níveis educacionais (bacharelado e mestrado) com as taxas de mortalidade e risco de morte dos pacientes, após controle das variáveis dos hospitais e dos pacientes. Outro resultado estatisticamente significante em relação à mortalidade foi a proporção de médicos com título de especialista em cirurgia (Aiken, Clarke, Cheung, Sloane, Silber, 2003).

Os resultados indicam que o nível educacional dos enfermeiros desses hospitais pode estar diretamente relacionado a menores taxas de mortalidade dos pacientes e de complicações decorrentes de procedimentos cirúrgicos, o que reforça a importância do enfermeiro no cuidado crítico. (Aiken, Clarke, Sloane, Sochalski, Silber, 2002; Aiken, Clarke, Cheung, Sloane, Silber, 2003 e Aiken, Clarke, Sloane, Lake,2009). 
O cuidado ao paciente crítico requer habilidade técnica, conhecimento fisiopatológico, atenção, agilidade e exatidão na tomada de decisão ou em momentos de intercorrências. Tais particularidades são essenciais ao profissional que assiste a este tipo de paciente e um nível educacional diferenciado do enfermeiro poderá influenciar diretamente na qualidade do cuidado prestado e no resultado final do paciente (Miller, 2000).

Para que uma UTI atenda as normatizações estabelecidas pelos órgãos competentes, é necessária uma gestão do cuidado que aborde aspectos mais abrangentes que o próprio cuidado, como dimensionamento de pessoal qualificado, disposição do espaço físico apropriado para o cuidado crítico, investimentos em equipamentos e tecnologia, recursos financeiros e interações com demais setores do serviço hospitalar, colocando-se à disposição como setor de apoio à terapêutica e tratamento dos pacientes que necessitam deste tipo de cuidado.

Ressalta-se que, para um cuidado de qualidade, é necessário que os profissionais também estejam satisfeitos com as condições de trabalho impostas pelo sistema de saúde, onde possuam uma condição de saúde que permita "cuidar" do outro, que seu trabalho seja reconhecido e remunerado adequadamente, pois, a todo o momento nossa capacidade técnica científica nos é testada, porque na UTI a tomada de decisão é imediata, requisitando cada vez mais dos enfermeiros sua capacitação contínua e efetiva a fim de minimizar erros.

\subsection{CARACTERÍSTICAS E CONDIÇÕES DE TRABALHO DO ENFERMEIRO NA UTI}

O conceito de UTI é traduzido como uma unidade hospitalar que agrupa pacientes com alta complexidade de cuidados, que necessitam ser monitorizados ininterruptamente e acompanhados por profissionais especializados no atendimento ao paciente crítico. Ressaltamos que se trata 
de uma unidade onde são atendidos os pacientes passíveis de cura, envolvendo uma equipe multiprofissional (médicos, enfermeiros, fisioterapeutas, técnicos de enfermagem, nutricionista, farmacêutico entre outros) durante o processo de recuperação.

Apresenta "características sensoriais específicas como ruídos, odores, claridade intensa, janelas fechadas e cobertas, além da temperatura fria" (Chavaglia, Borges, Amaral, Iwamoto, 2011). Contudo, ainda oferece um dos ambientes mais agressivos, tensos e traumatizantes dos hospitais (Ferrareze, Ferreira, Carvalho, 2006).

A dinâmica do trabalho na UTI é diferenciada em relação a outras unidades dos serviços de saúde. A percepção dos enfermeiros em relação a seu ambiente de trabalho muitas vezes, é encarada como hostil e assustadora, onde vidas frágeis necessitam de vigilância e cuidado contínuo, o que requer elevado nível de conhecimento, habilidade e competência para o cuidado a pacientes e familiares (Bucchi, Mira, Santos, 2010).

Segundo Bulhões (1994), o trabalho dos enfermeiros pode não ser apenas insalubre e perigoso para quem o executa como preconiza a legislação brasileira, mas também um trabalho penoso, característica ainda não contemplada na legislação. Este trabalho penoso é composto por fatores como carga física, mental e psíquica.

O conhecimento das condições de trabalho dos profissionais de enfermagem e das atividades desenvolvidas pode refletir nos resultados relacionados à pratica do enfermeiro (Padilha, 2001).

Para Bucchi, Mira, Santos (2010) a evolução de estudos e do conhecimento sobre a prática assistencial permitiu avaliar a influência do ambiente da UTI sobre os profissionais e pacientes. A influência negativa de fatores ambientais sobre os profissionais pode resultar em conflitos interpessoais (até de natureza ética) criando um estado de tensão que pode 
comprometer o discernimento e a habilidade, levar a exaustão pela carga de trabalho e gerar frustração profissional.

A crise vivenciada pelos países de primeiro mundo em busca de profissionais qualificados, principalmente para unidades de cuidados críticos (Ewart, Marcus, Gaba, Bradner, Medina, Chandler, 2004; Kelley, Chalfin, Ingbar, Sessler, 2004) tem suscitado questões pertinentes à prática da enfermagem, como a influência negativa do seu ambiente de trabalho sobre a qualidade do cuidado prestado.

As altas demandas de profissionais na área de saúde vêm sendo discutidas na literatura, entretanto, as maiores discussões estão em volta dos profissionais que atuam nas UTls devido às características e condições bastante especializadas da unidade, além do inter-relacionamento com outros fatores como a pressão do tempo, o trabalho multidisciplinar e os confrontos com os limites da medicina moderna. Apesar do trabalho na UTI ser realizado por uma equipe multiprofissional os estudos ao longo dos anos, separa tal investigação por classe profissional, o que pode repercutir sobre o cuidado crítico (Jasper, Stephan, Al-Khalafa, Rennekampff, Vogt, Mirastschihski, 2011).

Muitos encaram o papel do enfermeiro na UTI como fragmentado, sem a nítida percepção do todo. Esta fragmentação para o enfermeiro é pertinente às suas atribuições profissionais como coordenar, realizar e avaliar as atividades da enfermagem, bem como implementar e utilizar o processo de enfermagem. Desta forma, na ótica dos enfermeiros, o gerenciamento em UTI significa prestar cuidados ao paciente, administrar a assistência de enfermagem a administrar a equipe de saúde, além de articular os meios de trabalho entre a equipe multiprofissional (Martins, Robazzi, Marziale, Garanhani, Haddad, 2009).

A gestão do cuidado crítico é baseada em diversos fatores que incluem a estrutura como aspectos físicos, equipamento e tecnologia e uma equipe multidisciplinar, destacando neste item a quantidade e qualidade da 
equipe, o papel das lideranças profissionais, o que faz diferença nos momentos de tomada de decisão. No fator processo, destaca que a qualidade é essencial para o tipo de cuidado prestado e destaca o uso de protocolos, rouparias e capacidade de otimização. Os protocolos baseados em evidências são conhecidos por minimizar erros e efeitos adversos mesmo em simples procedimentos, o que permite controlar melhor os resultados. Já os resultados, o ponto final do processo de melhoria da qualidade assistencial, destacam a relação com a mortalidade, com a QV após internação na UTI e os custos (Barbieri, Carson, Amaral, 2008).

Para o fator custos, o serviço de cuidados críticos representa um grande e crescente negócio em expansão na área da saúde, principalmente por serem influenciados pela gravidade e severidade das doenças, complicações, nível de atendimento hospitalar, custos de medicamentos e o nível das equipes multiprofissionais. Ressalta-se que nos próximos anos, a gestão das UTIs não será realizada sem que seja incluída qualidade, segurança e gestão de custos (Barbieri, Carson, Amaral, 2008).

Segundo Mark, Hagenmueller (1994), as características do ambiente e da tecnologia no trabalho de enfermeiros na UTI podem ser divididas em quatro conceitos que se inter-relacionam como a estrutura social, os profissionais, a tecnologia e o ambiente. Quando falamos em UTI, logo nos vem a ideia de que o cuidado crítico é baseado na tecnologia, porém, a tecnologia funciona como ferramenta da assistência, como um complemento do conhecimento profissional e parte do direcionamento do cuidado. Envolve ainda o ambiente onde o cuidado é prestado, as condições de trabalho e principalmente os profissionais que participam deste cenário.

A relação enfermeiro - médico, o nível de gestão da enfermagem nas unidades, a direção e suporte hospitalar podem levar a exaustão emocional, a despersonalização profissional e alteração da realização pessoal influenciando a qualidade dos serviços de enfermagem e a satisfação dos resultados (Bogaert, Clarke, Vermeyen, Meulemans, Heyning, 2009). Destaca-se a importância dos enfermeiros se envolverem nas 
políticas de funcionamento da unidade de trabalho, o que contribui para se distanciarem do burnout, além de servir como estímulo de melhoria no trabalho.

Um estudo comparou médicos e enfermeiros de UTI e destacou a alta deterioração da saúde mental dos enfermeiros e um grande desequilíbrio entre esforço e recompensa para a equipe médica, além de evidenciar um aumento de doenças psiquiátricas nesses profissionais (Jasper, Stephan, Al-Khalafa, Rennekampff, Vogt, Mirastschihski, 2011).

A necessidade de entendermos a interação profissional com ambiente de trabalho vem sendo crescentemente investigada por refletir no comportamento das pessoas, nos custos, na estrutura organizacional e principalmente nos resultados. Estas associações positivas são destacadas nos estudos de Aiken, Clarke, Sloane et al (2008), Friese, Lake, Silber, Sochalski (2008), Stone, Larson, Mooney-kane, Smolowitz, Lin, Dick (2006) e Gershon, Stone, Zeltser, Faucett, Macdavitt, Chou (2007).

Como um dos possíveis meios de mensurar a percepção dos atributos relacionados ao ambiente de trabalho do enfermeiro destaca-se 0 Nursing Work Index - Revised (NWI-R) desenvolvido por Aiken e Patrician (2000), que objetiva mensurar a presença de características do ambiente de trabalho que favorecem a prática profissional, ou seja, podem indicar possíveis condições de trabalho que refletem na prática do enfermeiro. Este instrumento derivou do Nursing Work Index desenvolvido por Kramer, Hafner (1989), porém, com o objetivo de mensurar a satisfação dos enfermeiros no ambiente hospitalar.

Um estudo realizado na Austrália em 21 hospitais públicos, com 2.141 enfermeiras de unidades cirúrgicas e clínicas, utilizando o NWI-R e associando questões relacionadas à satisfação profissional, satisfação com a enfermagem e intenção de mudar de emprego. Os achados destacaram a importância da liderança em enfermagem na inter-relação com a sua equipe de trabalho, de maneira onde os problemas da prática são discutidos e por 
meio de um feedback resultam em soluções rápidas e otimizadas, o que permitiu uma melhoria na satisfação com o trabalho e com a enfermagem destes enfermeiros (Duffield, Roche, Stasa, 2010).

Fatores como trabalhar com enfermeiros competentes, manutenção de um bom relacionamento enfermeiro-médico, poder de decisão e autonomia profissional, controle da prática de enfermagem, suporte educacional, identificação das prioridades da equipe e a importância da inserção do paciente para o nosso trabalho, são definidos como fontes essenciais para uma melhor satisfação profissional e serve como estímulo para um ambiente de trabalho produtivo. Isto se repercute ainda na forma de magnetismo profissional, ou seja, uma forma de apreensão profissional na prática assistencial da enfermagem (Kramer, Schmalenberg, 2008).

Um estudo investigou as diferenças do ambiente no trabalho de UTI utilizando o NWI-R. Avaliaram as percepções de 817 enfermeiros de 39 UTIs com atendimento para adultos de 15 hospitais coreanos. Como conclusões, destacou que o ambiente de trabalho, o nível de autonomia do enfermeiro, o relacionamento entre as equipes, o tipo de hospital e atendimento podem influenciar diretamente a dinâmica de trabalho dos enfermeiros e os resultados relacionados ao cuidado (Cho, Mark, Yun, June, 2011).

A satisfação com o trabalho é um importante fator para manter o magnetismo profissional dos enfermeiros, ou seja, para que o profissional mantenha-se inserido no processo do cuidar é necessário que ele encontre boas condições de trabalho. Sengin (2003) destaca dez atributos consistentemente identificados na literatura que influenciam a satisfação profissional dos enfermeiros. São eles: autonomia, comunicação e colaboração interpessoal, prática profissional, prática e gestão administrativa, status e reconhecimento, requisitos de tarefas e trabalho, oportunidades de avanços profissionais, condições de trabalho e ambiente físico, além da remuneração salarial. Esses atributos podem ser influenciados por outras variáveis, principalmente por ser um conceito 
multidimensional, entretanto, destaca-se a sua influência sobre os profissionais e seus resultados.

O nível profissional dos enfermeiros, o relacionamento com as lideranças em enfermagem, os fatores do ambiente e a força de trabalho podem interferir nos resultados relacionados aos pacientes, na incidência de eventos adversos e na dinâmica de trabalho dos enfermeiros (Duffield, Roche, Stasa, 2010).

Entretanto, os fatores relacionados às condições de trabalho e do ambiente da prática assistencial podem repercutir em alterações físicas e emocionais nos profissionais como sintomas de depressão (Jolivet et al, 2010), exposição à violência (Nachreiner, Gerberich, Ryan, McGovern, 2007), racismo e bullyng (Allan, Cowie, Smith, 2009) e alterações do estilo de vida (Zapka, Lemon, Magner, Hale, 2009).

Além das características ambientais da UTI, o lidar com situações críticas como a morte, gravidade dos pacientes, conflitos interpessoais, problemas éticos, resolução de problemas administrativos, inadequado conhecimento e habilidades, carga de trabalho e frustrações de seus ideais de trabalho, podem ocasionar danos ao profissional e se estender aos pacientes (Cronin-Stubbs, Rooks, 1985; Buerhaus, Staiger, Auerbach, 2000).

Outras características como trabalho gratificante e penoso, limitante, gerador de sofrimento, sentimentos de onipotência, estressante e desgastante podem alterar a qualidade de vida no trabalho dos enfermeiros (Martins, Robazzi, 2009; Beccaria, Pereira, Contrin, Lobo, Trajano, 2009; Bianchi, 2000; Guerrer, Bianchi, 2008; Rocha, De Martino, 2010).

Avaliando o impacto das características dos hospitais (tamanho, certificações e padrão de ensino), dos enfermeiros (idade, tempo de experiência em UTI e nível educacional), das condições de trabalho (peso dos pacientes, número de profissionais por paciente, hora extra, salário e condições de execução do trabalho) e da segurança ocupacional em 
unidades de cuidado intensivo (incidência de doença musculoesquelética e exposição a sangue e fluidos) evidenciou-se que as condições de trabalho dos enfermeiros na UTI são um importante elemento para a segurança do paciente, destacando a relação entre equipe de enfermagem e os resultados obtidos junto aos pacientes (Stone, Gershon, 2009).

Outro estudo avaliou a segurança do paciente e a qualidade do cuidado junto a enfermeiros e pacientes na Europa (488 hospitais em 12 países) e Estados Unidos (617 hospitais) e identificou que o investimento na equipe de enfermagem resulta em melhores resultados para os pacientes. Destacou ainda a influência do ambiente de trabalho sobre os resultados junto aos pacientes (Aiken et al, 2012).

Os excessos de trabalho e carga horária extensa favorecem o comprometimento não só da saúde do trabalhador, mas também dos resultados relacionados a esta prática. Estudo realizado com 2.200 enfermeiros destacou a vulnerabilidade deste profissional quando submetido a períodos de trabalho prolongados. Esta vulnerabilidade se concretiza na forma de fatiga física ou risco de, além de colocar em risco a segurança do paciente e a sua própria, na forma de eventos adversos e resultados indesejados para os pacientes (Trinkoff, Geiger-Brown, Brady, Lipscomb, Muntaner, 2006).

Outra investigação da relação dos modelos assistenciais de enfermagem, custos e os resultados relacionados aos pacientes como falhas, erros de medicação e taxas de infecção (trato urinário e úlceras) mostrou que a capacitação profissional dos enfermeiros estava relacionada às horas de enfermagem, quanto menor a capacitação, maior era a quantidade de horas trabalhadas, o que gerava alto custo para o cuidado. Destacou também, que a proporção de pacientes por enfermeiro está diretamente relacionada com os resultados. Isto reforça a ideia de que a exposição do enfermeiro na prestação de cuidados em situações com alto número de pacientes, de alta complexidade e intensa carga horária de trabalho e sem uma capacitação adequada, pode comprometer a qualidade 
do cuidado prestado e consequentemente expor o profissional ao erro (Hall, Doran, Pink, 2004).

Quanto aos erros cometidos pelos enfermeiros, os fatores que mais se destacaram foram relacionados à equipe de trabalho $(60 \%)$ e alto volume de trabalho e estresse (56\%), o que permitiu refletir sobre a incapacidade dos enfermeiros em gerenciar um alto número de pacientes, de alta complexidade levando a maior chance de erro. Quanto aos fatores relacionados aos pacientes, o que o autor destaca é a questão da comunicação enfermeiro-paciente, ressaltando sua importância para o desenvolvimento de estratégias de comunicação e otimização do tempo, minimizando assim a chance de erros (Thomas, 2010).

Outro estudo analisou a postura dos enfermeiros de UTI frente ao erro, do ponto de vista ético, e concluiu que a responsabilidade diante do erro supõe o reconhecimento das próprias vulnerabilidades e assumir o erro com responsabilidade supõe, ainda, condições éticas nas relações entre as pessoas envolvidas, que se reflete na questão da comunicação e autonomia da ação. Além do que, na opinião dos autores, o erro está diretamente atrelado ao contexto da situação e o ambiente em que se deu. Ressalta-se ainda, que é necessário repensar a prática da enfermagem dentro de contextos mais amplos e diretos sempre pautados na bioética, principalmente pela vulnerabilidade deste profissional em seu ambiente de trabalho (Coli, Anjos, Pereira, 2010).

A inserção do enfermeiro no cuidado crítico nos remete a refletir sobre as condições deste trabalho, do seu reconhecimento na equipe multiprofissional, da sua autonomia, da importância do conhecimento não somente técnico, mas baseado na ciência, além das estratégias utilizadas para conduzir e gerenciar o cuidado na UTI. Entretanto, devemos também aprofundar sob os reflexos que são resultantes desta inserção do enfermeiro no cuidado crítico como o estresse, o coping, o distresse e o burnout. 
Estudo realizado em 2008 investigou o nível de estresse de enfermeiros de UTI e a sua correlação com repercussões na saúde destes profissionais através de sintomas cardiovasculares, digestivos e musculoesqueléticos, além da evidência de insatisfação do enfermeiro com a sua atividade profissional, associada aos agentes estressores e um possível quadro de burnout (Cavalheiro, Moura Junior, Lopes, 2008).

Outra pesquisa avaliou a relação de estresse do enfermeiro de diferentes setores do hospital e a sua relação com a qualidade do sono. Este estudo comprovou o efeito do estresse sobre o sono, com repercussões negativas para o enfermeiro, dos diferentes turnos e setores do hospital. Destaca-se uma forte relação entre o alto nível de estresse e uma qualidade ruim do sono para os enfermeiros do turno da manhã e Clínica Médica Cirúrgica, o que demonstra a necessidade de mudanças comportamentais, condições de repouso, dinâmica e motivação para o trabalho, adequação de quadro de pessoal e suporte técnico/científico como subsídio para um cuidado com qualidade (Rocha, De Martino, 2010).

Um estudo realizado com enfermeiros na UTI evidenciou um alto nível de estresse dos enfermeiros com pós-graduação para situações como administração de pessoal e assistência de enfermagem, porém, reafirmam a necessidade de se reconhecer os estressores que estão presentes no trabalho e da necessidade de se estabelecer mecanismos e estratégias de enfrentamento individual e grupal para diminuir a ocorrência de estresse profissional (Guerrer, Bianchi, 2008).

Destaca-se na literatura que o enfermeiro é um profissional que vive sob condições estressantes na prática do seu trabalho. Para Batista, Bianchi (2006), os fatores mais estressantes estão relacionados às condições de trabalho, disponibilidade de recursos materiais e humanos para uma boa prática do cuidado.

Um estudo com 3.000 enfermeiros, em 80 diferentes UTIs, de 12 países da Europa avaliou a susceptibilidade dos enfermeiros ao burnout. Os 
resultados destacaram que os enfermeiros que trabalhavam com outros colegas que já apresentavam os sintomas do burnout, estavam mais susceptíveis à síndrome, porém, a probabilidade de desenvolverem estes sinais quando os controlavam e conheciam os fatores estressores da sua prática de trabalho, diminuía-se consideravelmente sua exposição. Entretanto, a exaustão emocional e despersonalização são percebidas entre os enfermeiros como um forte preditor de desenvolvimento da síndrome, além da demanda de trabalho e limitado poder de decisão são os mais importantes estressores organizacionais que podem influenciar o burnout (Bakker, Blanc, Schaufeli, 2005).

Entendermos o contexto em que o enfermeiro está inserido na UTI, avaliarmos o panorama do seu trabalho e principalmente as condições que influenciam este cenário são de extrema importância, principalmente porque um profissional capacitado, com boas condições de trabalho nos revela resultados assistenciais de qualidade e minimamente livre de erros.

\subsection{QUALIDADE DE VIDA e QUALIDADE DE VIDA RELACIONADA À SAÚDE}

Atualmente os termos qualidade de vida (QV) e qualidade de vida relacionada á saúde (QVRS) vêm sendo empregados em diferentes áreas profissionais e contextos diversos, abordando um conceito mais generalizado o de QV e outro mais específico, o de QVRS.

O conceito de QV pode ser utilizado em duas vertentes: uma para o cotidiano, onde o conceito é utilizado por pessoas em geral e de diferentes profissões e outra para o contexto da pesquisa científica, forma esta, utilizada pelas ciências sociais, humanas e da saúde (Seidl, Zannon, 2004).

$\mathrm{Na}$ área de saúde, o interesse pela temática é crescente e já dispõe de conceitos bastante sólidos, em função dos determinantes e 
condicionantes do processo saúde-doença serem multifatoriais e complexos.

QV é tida como um conceito subjetivo, multidimensional e dinâmico, podendo ser influenciada por aspectos culturais, religiosos, éticos e valores pessoais. Por ser considerada um conceito multidimensional compreende aspectos sociais, materiais, físicos, mental e espiritual (Minayo, Hartz, Buss, 2000). Baseia-se na percepção do significado que as pessoas atribuem as suas experiências de vida de forma subjetiva, positiva ou negativa, determinando assim o nível de satisfação ou felicidade em relação aos vários domínios considerados importantes para elas (Oleson, 1990).

A Organização Mundial de Saúde (OMS) teve um papel importante nos estudos relacionados à $\mathrm{QV}$, a partir da década de 50 , quando definiu que "a saúde é um estado de bem estar físico, mental e social e não apenas a ausência de doença ou enfermidade", destacando indiretamente $o$ conceito multidimensional da qualidade de vida.

Pode ser percebida como detentora de um potencial variável de condições que podem afetar o comportamento do indivíduo e suas percepções em relação a sua vida diária geral, não se limitando somente a sua condição de saúde. Destacam-se três aspectos fundamentais quando relacionamos este conceito: subjetividade, multidimensionalidade e presença de dimensões positivas como, por exemplo, a mobilidade, e as dimensões negativas, a dor (Fleck et al, 1999).

Segundo WHOQOL Group (1994), QV é a "percepção do indivíduo de sua posição na vida no contexto da cultura e sistema de valores nos quais ele vive e em relação aos seus objetivos, expectativas, padrões e preocupações".

Uma das mais utilizadas definições do conceito geral é apresentada pela OMS que define QV como "a percepção do indivíduo de sua posição na vida, no contexto da cultura e sistema de valores nos quais 
ele vive e em relação aos seus objetivos, expectativas, padrões e preocupações" (WHO, 1995).

Neste contexto científico, observou-se um crescente interesse em avaliar não mais a QV na saúde de uma maneira ampla e generalizada, e sim de uma maneira mais específica junto a determinados grupos e populações. A QVRS inclui a saúde como ponto central e não mais como um dos componentes da QV. Excluem-se conceitos mais genéricos como rendimentos, liberdade e qualidade do meio ambiente (Minayo, Hartz, Buss, 2000).

Estudos afirmam existir uma grande dificuldade de se chegar a um consenso quando se trata de definir QV e QVRS por causa das diferentes ciências que trabalham com estes conceitos. Destaca-se ainda que, frequentemente os pesquisadores desta temática, incluem na definição dos termos os sintomas, características do humor, estado funcional e geral de saúde, o que gera confusão na conceituação final da QV e QVRS (Anderson, Burckhardt,1999).

Este estudo contempla a investigação da QVRS dos enfermeiros, no entanto, apresentamos o conceito de QV geral para entendermos melhor as diferenças do conceito de QVRS.

Diferentes definições sobre QVRS relacionam a percepção em relação ao seu estado de saúde, as formas de impacto na vida do indivíduo por mudanças do seu estado de saúde e valores atribuídos à vida e sua relação com o processo doença (Seidl, Zannon, 2004).

A definição de QVRS parte de conceitos inter-relacionados e que centram na avaliação subjetiva do indivíduo e está ligada ao impacto de saúde sobre a capacidade de vida (Bullinger et al,1993). Pode ser descrita como multidimensional, com inclusão de aspectos físicos, fisiológicos e da dimensão social (Saccomann, Cintra e Gallani, 2011). 
A QVRS pode ser vista como um termo que foca os efeitos de saúde, doença, tratamento e qualidade de vida. Por sua vez, exclui aspectos da qualidade de vida que são relacionados à saúde como aspectos culturais, políticos e outros atributos da sociedade (Ferrans, Zerwic, Wilbur e Larson ,2005).

O conceito de QVRS é baseado num modelo teórico com dois pontos principais: características do indivíduo e características do ambiente. Destes pontos, partem cinco módulos que se inter-relacionam: função biológica, sintomas, status funcional, percepção geral de saúde e qualidade de vida global (Wilson, Clearley, 1995).

A função biológica inclui o processo dinâmico de suporte de vida, partindo do pressuposto que alterações biológicas afetam direta e indiretamente todos os componentes de saúde e a QV. Os sintomas são definidos como a percepção do paciente de algo anormal no seu corpo, emocional ou estado cognitivo que pode ser caracterizado como físico, fisiológico e psicofísico (Wilson, Clearley, 1995).

O status funcional é definido de maneira geral como a habilidade de realizar tarefas em diferentes domínios: físico, social, funcional e psicológico. A percepção geral de saúde se dá através de duas características definidoras: primeira, ela integra precocemente todos os componentes que participam do modelo; e segunda, eles são subjetivos na natureza. Ressalta-se então, a QV global caracterizada como um componente final do modelo e de forma subjetiva relaciona bem estar com felicidade e satisfação com a vida (Wilson, Clearley, 1995).

Neste contexto, a saúde é como um item consistentemente importante da QV. Contudo, as medidas de QVRS têm sido desenvolvidas, com o objetivo de acessar aspectos subjetivos, a partir de experiências individuais, que relacionam direta e indiretamente a saúde, a doença, às incapacidades e às deteriorações do estado geral do individuo (Moons, 2004). 
Para Singer, Padilla e Ashing-Giwa (2010), considerando a diversidade cultural da definição da QVRS, quatro dimensões são identificadas para o conceito: física, mental/psicológica, social e percepção global de bem estar. Pode-se ainda incorporar alguns atributos como dor, energia/vitalidade, sono, apetite e sintomas associados a doenças ou tratamentos.

Em razão das características abstratas e subjetivas da QV e da QVRS, a forma de medida destes conceitos se dá de modo indireto, ou seja, medida pela teoria, que segundo Pasquali (1997), a operação empírica de medir o comportamento representa indiretamente a medida do fenômeno e é legitimada pela psicometria.

Atualmente, estes conceitos são mensurados através de instrumentos genéricos ou específicos. Dentre os instrumentos genéricos, destacam-se os não relacionados à saúde, chamados de instrumentos de avaliação da QV geral, e os relacionados à saúde denominados específicos. Os instrumentos genéricos mais utilizados pela literatura são o WHOQOL 100 e versão Bref, SF -36 e o Índice de QVRS de Ferrans e Powers.

Já os instrumentos específicos relacionados à saúde, objetivam mensurar a QVRS em portadores de doenças previamente estabelecidas como câncer, cardiopatias, doenças respiratórias, diabetes e populações específicas como idosos, crianças, neonatos e mulheres. São exemplos de instrumentos genéricos de QVRS o Medical Outcomes Study 36 item Short form Health Survey (MOS SF 36), Sickness Impact Profile - SIP e Medical Outcomes Study Short Form 12 (MOS SF 12) dentre outros.

Destaca-se que a utilização dos instrumentos específicos para QVRS ainda mantêm um contexto multidimensional e geral da QV, muitas vezes enfatizando aspectos específicos das doenças.

Considerando a diversidade dos instrumentos de medida em saúde, a escolha da medida depende dos objetivos e da população a ser 
estudada, sendo essencial que o instrumento reflita o conceito que objetiva mensurar (Bertani, Rezende, Parzewski, Lourenço, 2005).

No Brasil, as pesquisas são mais voltadas para a investigação da QV e QVRS de indivíduos ou grupos portadores de doenças específicas ou submetidos a situações especiais e validação de instrumentos de medida em saúde. Ressalta-se, que a utilização de instrumentos de medida da QV e QVRS junto aos profissionais de saúde, como meio de identificar os principais fatores que podem estar relacionados com a piora da QVRS dos enfermeiros, pode embasar a oferta de soluções e de melhores condições de trabalho.

\subsubsection{Qualidade de vida e saúde dos enfermeiros.}

Posterior a definição dos conceitos de QV e QVRS, enfocamos a contextualização dos estudos voltados ao trabalho do enfermeiro de UTI e sua QVRS.

O trabalho de enfermagem pode se apresentar como penoso, em função das suas características das cargas encontradas neste contexto, como as de natureza física, mental e psíquica do trabalho. Outros fatores como a disposição da planta física do local, excesso de peso dos pacientes, altas demandas para o enfermeiro, relacionamento interpessoal e multiprofissional, turnos de trabalho e a carga horária de trabalho são fatores que podem comprometer a QVRS dos enfermeiros.

O interesse em pesquisas com QVRS vem aumentando porque está relacionado aos processos de melhorias em saúde, a custos e, sobretudo, a uma preocupação propriamente dita, com a QV de algumas populações específicas. 
Estudo realizado com trabalhadores de enfermagem em UTI avaliou sua QV através do instrumento WHOQOL-Bref e conclui-se que a QV dos profissionais é relativamente baixa, destacando-se a baixa correlação dos domínios físicos, psicológico, relação social, meio ambiente e aspectos espirituais/religiosidade/crenças pessoais com a idade e o número de empregos (Paschoa, Zanei, Whitaker, 2007).

Outro estudo utilizando o WHOQOL-100 avaliou a QV de médicos e enfermeiros de UTI pediátrica e neonatal, destacando-se que em relação aos enfermeiros, os maiores escores encontravam-se nos domínios físico, psicológico, relação social, meio ambiente e aspectos espirituais/religiosidade/crenças pessoais. Quando comparados os grupos profissionais, médicos e enfermeiros encontraram-se diferenças no domínio espiritualidade/religiosidade e crenças pessoais, contudo, os achados evidenciam que a QV dos médicos e enfermeiros de UTI é comprometida em todas as suas dimensões (Fogaça, Carvalho, Nogueira-Martins, 2010).

Um estudo realizado no município de São Paulo, com 190 enfermeiros de 19 UTIs, investigou a satisfação profissional e a QV destes profissionais e concluiu que, em relação ao nível de importância atribuída aos domínios da $\mathrm{QV}$, estas enfermeiras consideraram o domínio psicológico e espiritual como os mais importantes, seguidos dos domínios família, saúde e funcionamento, e social e econômico. No entanto, os domínios saúde e funcionamento destacaram-se como os mais comprometidos entre todos. (Lino, 2004).

Investigando a QV de profissionais da saúde: enfermeiros, fisioterapeutas e nutricionistas de um hospital universitário através do WHOQOL-Bref, Spiller, Dyniewicz, Slomp (2008), destacou-se a correlação dos domínios psicológicos e físicos como bastante fortes entre os profissionais, de tal forma que sentimentos, imagem pessoal e auto estima podem se relacionar com outros fatores como dor, desconfortos, capacidade, atividade diária e trabalho. Essa relação é reconhecida como rotineira na prática diária dos profissionais de saúde, segundo as autoras. 
Os profissionais de saúde relatam "indisposição e insatisfação física concomitantemente com a desmotivação, desinteresse e falta de entusiasmo pela vida e o trabalho".

Uma investigação com QVRS de profissionais de enfermagem e erros de medicação em UTI concluiu que os maiores escores de QVRS foram apresentados no domínio capacidade funcional e os menores para vitalidade e dor. De uma maneira geral, o escore sobre o estado de saúde da equipe de enfermagem foi considerado regular. Destaca-se ainda que os escores eram piores para os envolvidos com erros de medicação e entre as classes trabalhadoras, eram piores para os técnicos de enfermagem quando comparados aos enfermeiros. O fato de conhecer os domínios mais negativamente impactados nos profissionais de enfermagem possibilita 0 planejamento de ações de promoção da saúde e prevenção voltada à equipe de enfermagem, de forma a capacitá-los para escolha saudáveis melhorando assim sua QV (Pellicioti, 2009).

Outras formas de comprometimento da QVRS dos enfermeiros podem ser encontradas na literatura como a influência dos turnos de trabalho, condições de trabalho, associação com doenças ocupacionais, erros de medicações e eventos adversos.

Quanto ao turno de trabalho o período noturno pode influenciar na QV do enfermeiro. O estudo ressalta que a multidimensionalidade do conceito de QV para os enfermeiros está relacionada ao atendimento das necessidades básicas como saúde, moradia, convívio familiar e social, lazer, trabalho e remuneração digna (Neves, Branquinho, Paranaguá, Barbosa, Siqueira, 2010).

Em um estudo realizado com 696 enfermeiros, técnicos e auxiliares de enfermagem, foram investigas as condições de trabalho e de vida, hábitos de vida e sintomas de saúde auto-referidos através dos questionários "Resultados de Estudos de Saúde - versão reduzida", "Escala de Estresse no Trabalho" e "Desequilíbrio Esforço-Recompensa". Como 
resultados, observou-se que, aproximadamente $22 \%$ da população foi classificada como trabalhando em condições de alto desgaste e $8 \%$ com mais esforços do que recompensas no trabalho. As dimensões com piores escores do SF-36 foram vitalidade, dor e saúde mental. Um alto desgaste no trabalho, ter mais esforços que recompensas e ser enfermeira associaramse de maneira independente aos baixos escores da dimensão de aspectos emocionais. As dimensões relacionadas à saúde mental foram as que mais sofreram influência dos fatores psicossociais do trabalho. Os resultados indicam que a análise conjunta dos fatores psicossociais de desequilíbrio esforço-recompensa e demanda-controle contribuiu para a discussão sobre os papéis profissionais, condições de trabalho e QVRS de profissionais de enfermagem (Silva, Souza, Borges, Fischer, 2010).

Outro estudo com enfermeiros de hospitais públicos e privados do município de São Paulo investigou o significado e os indicadores de QV no trabalho (QVT) destes profissionais. Para estes enfermeiros o significado da QVT foi associado à percepção de satisfação e de bem estar em relação a diferentes aspectos presentes no seu trabalho como relacionamento interpessoal vertical e horizontal, autonomia, reconhecimento, condições de trabalho e oportunidades de crescimento profissional (Carandina, 2003).

Quanto aos erros de medicação, estes podem afetar os enfermeiros de forma negativa, desencadeando traumas psicológicos pela ocorrência do fato. A deterioração da QVRS dos enfermeiros pode estar associada a sentimentos apontados por Mayo, Ducan (2004), tais como desapontamento, medo, culpa, ansiedade, vergonha, dificuldade de concentração e insônia, podendo despertar nos profissionais falta de confiança em sua habilidade técnica e sentimentos de raiva.

Após a discussão do contexto do trabalho do enfermeiro de UTI, torna-se evidente a necessidade de novos estudos que possam caracterizar as atuais condições de trabalho e dos fatores intervenientes que contribuem para a deterioração da QVRS dos enfermeiros de UTI e que podem refletir nos resultados relacionados ao cuidado. A relevância deste estudo é 
pertinente, a partir das necessidades identificadas na literatura e também pela vivência da autora enquanto enfermeira e parte de um contexto que exibe múltiplas demandas na prática diária em UTI, na agilidade na tomada de decisão, no conhecimento técnico científico específico e atualizado, além da eficiência na prestação do cuidado crítico. 
Metodalogia 


\section{METODOLOGIA}

\section{$5.1 \quad$ NATUREZA DO ESTUDO}

Trata-se de um estudo descritivo, com delineamento transversal e abordagem quantitativa.

\subsection{LOCAIS DO ESTUDO}

A pesquisa foi realizada em 18 instituições de saúde do município de São Paulo, com UTIs para atendimento de pacientes adultos, inscritos no Cadastro Nacional de Estabelecimentos de Saúde da Secretaria de Atenção à Saúde do DATASUS.

Define-se UTI-adulto (UTI-A) como aquela destinada à assistência de pacientes com idade igual ou superior a 18 anos, admitindo-se também 0 atendimento a pacientes de 15 a 17 anos, quando definido nas normas da instituição (ANVISA, 2010).

\subsection{AMOSTRA DE HOSPITAIS COM UTI - CRITÉRIOS DE INCLUSÃO E EXCLUSÃO}

Neste estudo, as unidades elementares a serem amostradas são os enfermeiros que atuam nas UTIs do município de São Paulo. Em vista da dificuldade de obter uma listagem de todos os elementos que compõem a população de enfermeiros, foi utilizada a amostragem por etapas, selecionando inicialmente a amostra de hospitais com UTI para, numa segunda etapa, chegar à amostra de enfermeiros. 
A amostra de hospitais com UTI teve como base o banco de informações do Brasil (2010), no qual foram identificados no município 150 hospitais com leitos de UTI. Desta listagem, foram selecionados os hospitais com capacidade igual ou superior a 100 leitos e com UTI para atendimento de adultos. Excluíram-se os hospitais específicos para pacientes pediátricos e de maternidade e aqueles com número de leitos de UTI inferior a $6 \%$ do total de leitos hospitalares. Os critérios relativos ao tamanho do hospital e à proporção de leitos de UTI foram baseados nas recomendações das Portarias no 3432/GM/MS/1998 e no 1101//GM/MS/2002 (Brasil, 1998, 2002).

Por estes critérios, foram excluídos 31 hospitais, restando o total de 119 hospitais elegíveis para o estudo. De acordo com a entidade mantenedora, 74 eram privados, 38 públicos e sete filantrópicos. Os hospitais foram também classificados por regiões do município: zona sul, norte, centro, oeste e leste.

A Tabela 1 apresenta a distribuição dos 119 hospitais com UTI, segundo tipo de vinculação administrativa e região do município.

Tabela 1 - Distribuição do total de hospitais com UTI do município de São Paulo, por região e tipo de vinculação administrativa. São Paulo, 2010.

\begin{tabular}{lcccc}
\hline Região & $\begin{array}{c}\text { Público } \\
\mathbf{N}(\%)\end{array}$ & $\begin{array}{c}\text { Privado } \\
\mathbf{N}(\%)\end{array}$ & $\begin{array}{c}\text { Filantrópico } \\
\mathbf{N}(\%)\end{array}$ & $\begin{array}{c}\text { Total } \\
\mathbf{N}(\%)\end{array}$ \\
\hline Sul & $12(10,1)$ & $23(19,3)$ & $2(1,7)$ & $37(31,1)$ \\
Norte & $7(5,9)$ & $6(5,0)$ & - & $13(10,9)$ \\
Centro & $5(4,2)$ & $19(16,0)$ & $3(2,5)$ & $27(22,7)$ \\
Oeste & $1(0,8)$ & $10(8,4)$ & $1(0,8)$ & $12(10,1)$ \\
Leste & $13(10,9)$ & $16(13,4)$ & $1(0,8)$ & $30(25,2)$ \\
\hline Total & $38(31,9)$ & $74(62,1)$ & $7(5,8)$ & $119(100)$ \\
\hline
\end{tabular}

\subsubsection{Procedimentos de amostragem dos hospitais com UTI}

O cálculo do tamanho da amostra foi realizado por um especialista em amostragem, sendo estabelecido um intervalo de confiança 
de $95 \%$ e a possibilidade de um erro amostral de, no máximo, 5\%. Dessa forma, a amostra foi estimada em 29 hospitais com UTI do município de São Paulo.

O método utilizado para seleção da amostra foi a amostragem aleatória estratificada. As instituições foram estratificadas segundo a localização geográfica (regiões do município) e o tipo de entidade mantenedora (pública, privada ou filantrópica).

$\mathrm{Na}$ amostragem estratificada, são especificados quantos elementos da amostra serão retirados em cada estrato. Neste estudo, utilizou-se a amostragem estratificada proporcional, na qual o número de elementos sorteados em cada estrato é proporcional ao número de elementos existentes no estrato.

$\mathrm{Na}$ Tabela 2, a seguir, está apresentada a distribuição da amostra de hospitais, de acordo com os estratos.

Tabela 2 - Distribuição da amostra de hospitais com UTI de adultos do município de São Paulo, por região e tipo de vinculação administrativa. São Paulo, 2010.

\begin{tabular}{lcccc}
\hline \multicolumn{1}{c}{ Região } & Público & Privado & Filantrópico & Total \\
\hline Sul & $3(10,3)$ & $6(20,7)$ & $1(3,4)$ & $10(34,5)$ \\
Norte & $2(6,9)$ & $1(3,4)$ & - & $3(10,3)$ \\
Centro & $1(3,4)$ & $5(17,2)$ & $1(3,4)$ & $7(24,1)$ \\
Oeste & - & $2(6,9)$ & - & $2(6,9)$ \\
Leste & $3(10,3)$ & $4(13,8)$ & - & $7(24,1)$ \\
\hline Total & $9(31,3)$ & $18(62,1)$ & $2(6,9)$ & $29(100,0)$ \\
\hline
\end{tabular}




\subsubsection{Dificuldades de composição da amostra}

Os procedimentos de amostragem descritos anteriormente foram adotados no intuito de assegurar que os hospitais com UTI das diferentes regiões do município e de diferentes tipos de vinculação administrativa estivessem adequadamente representados na amostra. No entanto, as dificuldades de acesso aos hospitais e as recusas em participar da pesquisa acabaram comprometendo o planejamento inicial.

Com a recusa inicial, foi realizado um novo sorteio, seguindo os mesmos critérios do primeiro, mesmo assim, houve novas recusas com alegação de reestruturação dos serviços, falta de interesse da instituição para pesquisas e receio de exposição do hospital, mesmo diante da explicação da garantia de sigilo dos dados obtidos com a pesquisa. A amostra final dos hospitais foi composta por 18 instituições.

A Tabela 3 mostra a distribuição dos hospitais com UTI planejados (amostra inicial) e o obtido (amostra final), veja a seguir. 
Tabela 3 - Distribuição dos hospitais com UTI do município de São Paulo planejados $(\mathrm{P})$ e obtidos $(\mathrm{O})$ para a amostra, segundo região do município e tipo de vinculação administrativa. São Paulo, 2012.

\begin{tabular}{ccccccccc}
\hline \multirow{2}{*}{ Região } & \multicolumn{1}{c}{ Público } & \multicolumn{1}{c}{ Privado } & \multicolumn{2}{c}{ Filantrópicos } & \multicolumn{2}{c}{ Total } \\
\cline { 2 - 8 } & $\mathbf{P}$ & $\mathbf{0}$ & $\mathbf{P}$ & $\mathbf{0}$ & $\mathbf{P}$ & $\mathbf{0}$ & $\mathbf{\mathbf { n }}(\%)$ & $\mathbf{0}$ \\
$\mathbf{n}(\%)$
\end{tabular}

P=Planejado; O=Obtido.

$\mathrm{Na}$ Tabela 3 observa-se que os hospitais públicos foram os que ficaram com a menor representação em relação ao total planejado (apenas 3 dos 9 previstos $-33,3 \%$ ), sendo um na região sul e dois na região leste. Entre os hospitais privados, as perdas foram menos significativas, com a inclusão de 13 dos 18 planejados (72,2\%) e com representantes de todas as regiões. Quanto aos filantrópicos, foi possível manter na amostra os dois hospitais planejados, embora um deles seja proveniente de região diferente da prevista.

Em síntese, a amostra de 18 hospitais corresponde a $62 \%$ da proposta inicial, sendo três hospitais públicos (16,7\%), 13 privados $(72,2 \%)$ e dois filantrópicos $(11,1 \%)$, distribuídos nas diferentes regiões do município.

Uma vez obtidas as autorizações dos hospitais, o passo seguinte foi o contato telefônico para o agendamento de um encontro com as responsáveis pela Enfermagem das instituições, a fim de explicar a proposta da pesquisa e os seus procedimentos, obter informações sobre o número de 
UTIs de adultos e definir a melhor forma para a coleta de dados junto aos enfermeiros. Foram identificadas 31 UTIs nos hospitais participantes da pesquisa, sendo $22 \mathrm{com}$ atendimento geral, cinco especializadas em cardiologia e quatro em neurologia.

Os procedimentos para a seleção da amostra dos enfermeiros de UTI estão descritos a seguir.

\subsubsection{Amostra de enfermeiros de UTI - critérios de inclusão e exclusão}

A amostra dos enfermeiros foi composta de acordo com o total de enfermeiros por UTI. Nas 31 UTIs, encontramos 303 enfermeiros distribuídos em todos os turnos de trabalho, sendo 25 no serviço público, 67 nos hospitais filantrópicos e 211 na rede privada. Para compor a amostra dos enfermeiros, adotou-se um intervalo de confiança de 95\% e um erro amostral de $5 \%$.

Foram incluídos na amostra os enfermeiros que estavam diretamente envolvidos com a assistência aos pacientes e que tinham, pelo menos, 6 meses de experiência profissional na área. Excluíram-se os enfermeiros que se encontravam de férias ou afastados do trabalho por licenças (gala, nojo, maternidade, saúde) e os que exerciam exclusivamente funções gerenciais.

Com estes critérios e um percentual de recusas de $10 \%$ a $20 \%$ nos hospitais, a amostra final ficou composta por 180 enfermeiros.

A Tabela 4 apresenta a distribuição dos enfermeiros que compuseram a amostra do estudo. 
Tabela 4 - Distribuição da amostra de enfermeiros de UTI do município de São Paulo, por região e tipo de hospital. São Paulo, 2012.

\begin{tabular}{lcccc}
\hline Região & Público & Privado & Filantrópico & Total \\
\hline Sul & 08 & 54 & - & 62 \\
Norte & - & 17 & - & 18 \\
Centro & - & 29 & 18 & 47 \\
Oeste & - & 14 & - & 14 \\
Leste & 14 & 15 & 11 & 39 \\
\hline Total & 22 & 129 & 29 & 180 \\
\hline
\end{tabular}

Observa-se que o número de enfermeiros é proporcional ao número de hospitais por região, predominando os enfermeiros de hospitais privados $(71,7 \%)$.

\subsection{PRÉ-TESTE}

Foi realizado um pré-teste dos instrumentos do estudo em um hospital do município de São Paulo que não havia sido sorteado para a amostra. A instituição foi escolhida por ter um número expressivo de enfermeiros e diferentes UTls, atendendo também aos critérios de inclusão e exclusão de hospitais estabelecidos previamente.

Para o cumprimento desta fase, encaminhou-se o projeto de pesquisa à Comissão de Ética em Pesquisa da instituição e foi acordado um número de 50 enfermeiros para participar do pré-teste. A coleta de dados seguiu todos os procedimentos descritos, não sendo necessário introduzir alterações nos instrumentos ou nos métodos de coleta.

\subsection{ASPECTOS ÉTICOS DA PESQUISA}

O projeto de pesquisa foi submetido ao Comitê de Ética e Pesquisa (CEP) da Escola de Enfermagem da USP (Anexo 1) e aos CEPs 
de cada instituição participante, quando solicitado. No momento da coleta de dados, foi entregue ao enfermeiro o Termo de Consentimento Livre e Esclarecido (TCLE) (Apêndice I) e uma cópia foi entregue como comprovante de participação e aceitação dos termos da pesquisa.

\subsection{INSTRUMENTOS DE COLETA DE DADOS}

Foram utilizados os seguintes instrumentos para coleta de dados dos enfermeiros e das UTIs:

\subsubsection{Ficha de caracterização sociodemográfica e profissional dos enfermeiros}

Este instrumento visava caracterizar o perfil sociodemográfico e profissional dos enfermeiros de UTI, sendo composto pelos seguintes itens: idade, sexo, tempo de formação profissional, tempo de experiência em UTI, turno de trabalho, número de vínculos empregatícios, renda mensal, religião, maior nível educacional (especialização, mestrado, doutorado e outros), número de eventos científicos frequentados no último ano e carga de trabalho semanal (Apêndice II).

\subsubsection{Instrumento Nursing Work Index - Revised}

Trata-se de um instrumento de medida que avalia a presença de características do ambiente de trabalho do enfermeiro que favorecem a sua prática profissional. $\mathrm{O}$ instrumento foi originalmente desenvolvido por Aiken, Patrician (2000) e foi traduzido e adaptado para a cultura brasileira por Gasparino, Guirardello (2009) (Anexo II). 
A versão original possui 57 itens, sendo que 15 deles estão distribuídos em três subescalas que mensuram os conceitos de autonomia, controle sobre $\mathrm{o}$ ambiente e relações entre médicos e enfermeiros. $O$ reagrupamento de 10 desses 15 itens forma uma quarta subescala, denominada suporte organizacional (Gasparino, Guirardello, 2009).

A subescala autonomia é composta de cinco itens $(4,6,17,24$ e 35) e a subescala controle sobre o ambiente, de sete itens $(1,11,12,13,16$, 46 e 48). Estas duas subescalas buscam representar a liberdade que 0 enfermeiro tem para resolver problemas que afetam a qualidade da assistência de enfermagem. Os itens 2, 27 e 39 integram a subescala relações entre médicos e enfermeiros, que representa o respeito entre os profissionais para a construção de uma comunicação efetiva e o alcance de um objetivo comum em relação ao cuidado do paciente. A subescala suporte organizacional é composta por 10 itens (1, 2, 6, 11, 12, 13, 17, 24, 27 e 48) extraídos das três subescalas anteriores. Estes itens retratam o suporte institucional para que os enfermeiros desenvolvam a sua prática profissional (Gasparino, Guirardello, 2009).

Segundo Kramer, Schmalenberg (2002) a definição de autonomia é a liberdade profissional para assumir responsabilidades quanto à tomada de decisão sobre os cuidados de enfermagem, sem interferência de outros profissionais. $O$ controle sobre o ambiente traduz-se pelo controle das ações clínicas, do trabalho com outros enfermeiros na resolução dos problemas relacionados a eles e aos pacientes, corresponde ao respeito, status e reconhecimento organizacional. O relacionamento médico-enfermeiro é definido como respeito mútuo, boa comunicação e desempenho de papéis que se complementam diante do cuidado. A definição do suporte organizacional não é bem clara porque ele é composto por itens de cada domínio citado anteriormente, complementando-se.

Os itens são respondidos em escala do tipo Likert que varia de 1 (concordo totalmente) a 4 (discordo totalmente). As menores pontuações 
indicam maior presença de atributos favoráveis à prática profissional do enfermeiro (Gasparino, Guirardello, 2009).

\subsubsection{Instrumento de Avaliação de Qualidade de Vida Relacionada à Saúde - Medical Outcomes Study 12 - Item Short Form Health Survey (SF-12)}

Trata-se de um instrumento genérico de QVRS, de fácil administração e compreensão, multidimensional composto por 12 itens, englobado duas escalas ou componente: aspecto físico e mental. Apresenta escores de 1 a 6 que identificam o estado geral de saúde dos respondentes (Anexo III).

O SF-12 é a versão reduzida e sem modificações do SF 36 , suas questões foram retiradas integralmente deste instrumento. Esta redução de itens atendeu criteriosamente o rigor psicométrico, não ocasionando perda significativa de informações.

O SF-12 possui 12 itens com oito dimensões: estado geral de saúde, capacidade funcional, aspectos físicos, dor, aspectos emocionais, vitalidade, saúde mental e aspectos sociais. As quatro primeiras dimensões formam o Componente Físico (CF) e os demais, o Componente Mental (CM) (Ware, Losinski, Leller, 1996). As questões foram escolhidas a partir das dimensões do SF-36 (Ciconelli, 1997; Ciconelli, Ferraz, Santos, Meinão, Quaresma, 1999). No Quadro 1, observa-se a composição do SF-12 e suas respectivas dimensões e componentes dos domínios.

Os itens do instrumento foram estruturados com diversas possibilidades de pontuação (de 1 a 6 ; de 1 a 5 ; 1, 2 e 3 e sim ou não). Os escores são calculados para cada componente, não se admitindo um escore total. Os valores são calculados a partir de uma tabela com os pesos da questão para cada domínio. São 12 notas para cada componente, que ao final são somadas a constantes já estabelecidas. Os valores finais para o CF 
e o CM são interpretados a partir da diferença de pontos e desvios padrão para a população americana. Os escores variam de 0 a 100, com maiores valores representando melhor saúde física e mental (Ware, Losinski, Leller, 1996).

É composto por oito dimensões: capacidade funcional, aspectos físicos, dor, estado geral de saúde, vitalidade, aspectos sociais, aspectos emocionais e saúde mental, possuem um escore final de 0 a 100, no qual zero corresponde à pior estado geral de saúde e 100 a melhor estado de saúde. Seguindo os critérios D'Amorin (2001) escores abaixo de 50 indicam comprometimento da QV.

A utilização do SF 12 foi autorizada pela representante legal do instrumento, especificamente para este estudo. 
Quadro 1 - Distribuição dos itens, dimensões e componentes do instrumento SF 12. São Paulo, 2012.

\begin{tabular}{|c|c|c|}
\hline Itens do SF - 12 & Dimensões & Componentes \\
\hline Auto - avaliação de saúde & Estado geral de saúde & \multirow{6}{*}{$\begin{array}{l}\text { Componente } \\
\text { Físico } \\
\text { QVRS }\end{array}$} \\
\hline $\begin{array}{l}\text { Devido a sua saúde, você teria } \\
\text { dificuldade para atividades moderadas } \\
\text { (mover uma mesa, passar aspirador de } \\
\text { pó, jogar bola, varrer a casa)? }\end{array}$ & Capacidade Funcional & \\
\hline $\begin{array}{l}\text { Devido a sua saúde, você teria } \\
\text { dificuldade para subir vários lances de } \\
\text { escada? }\end{array}$ & & \\
\hline $\begin{array}{l}\text { Realizou menos tarefas do que gostaria } \\
\text { devido a sua saúde física? }\end{array}$ & \multirow{2}{*}{ Aspectos Físicos } & \\
\hline $\begin{array}{l}\text { Esteve limitado no seu tipo de trabalho } \\
\text { ou em outras atividades devido a sua } \\
\text { saúde física? }\end{array}$ & & \\
\hline $\begin{array}{l}\text { Durante as últimas quatro semanas, } \\
\text { quanto a dor interferiu com o seu } \\
\text { trabalho? }\end{array}$ & Dor & \\
\hline $\begin{array}{l}\text { Realizou menos tarefas do que gostaria } \\
\text { devido a problemas emocionais? }\end{array}$ & \multirow{2}{*}{ Aspectos emocionais } & \multirow{6}{*}{$\begin{array}{l}\text { Componente } \\
\text { Mental } \\
\text { QVRS }\end{array}$} \\
\hline $\begin{array}{l}\text { Não trabalhou ou foi cuidadoso devido } \\
\text { problemas emocionais? }\end{array}$ & & \\
\hline $\begin{array}{l}\text { Quanto tempo se sentiu com muita } \\
\text { energia? }\end{array}$ & Vitalidade & \\
\hline $\begin{array}{l}\text { Quanto tempo se sentiu calmo ou } \\
\text { tranquilo? }\end{array}$ & \multirow[t]{2}{*}{ Saúde mental } & \\
\hline Quanto tempo se sentiu desanimado? & & \\
\hline $\begin{array}{l}\text { Quanto tempo do seu tempo a sua } \\
\text { saúde física ou problemas emocionais } \\
\text { interferiram nas suas atividades sociais } \\
\text { (como visitar amigos e parentes)? }\end{array}$ & Aspectos Sociais & \\
\hline
\end{tabular}

\subsubsection{Ficha de caracterização da UTI}

Este instrumento contemplou dados referentes à caracterização da unidade, com itens da planta física, número de leitos, número de pacientes por enfermeiro, intervenções realizadas na unidade como 
procedimentos de alta complexidade a beira leito pelo enfermeiro, cirurgias de grande porte (cirurgias cardíacas e transplantes), taxa de mortalidade e padrão tecnológico (Apêndice III).

\subsection{VARIÁVEIS DO ESTUDO}

- Variáveis dependentes:

- Escore do componente físico do SF12 (CF-SF12);

- Escore do componente mental do SF12 (CM-SF12).

- Variáveis independentes: relacionadas aos enfermeiros e às condições do trabalho (NWI-R).

\subsubsection{Variáveis sociodemográficas e do trabalho dos} enfermeiros

- Idade - variável quantitativa (anos completos);

- Sexo - variável categórica (masculino e feminino);

- Estado civil - variável categórica (solteiro, casado/união consensual, viúvo/separado);

- Tempo de trabalho como enfermeiro de UTI - variável quantitativa;

- Religião (católica, evangélica, budista, espírita)- variável qualitativa;

- Renda mensal - variável quantitativa; 
- Titulação máxima - variável categórica nominal (especialização, mestrado, doutorados, outros);

- Turno de trabalho - variável categórica (manhã, tarde, noite);

- Vínculos empregatícios - variável quantitativa (número de vínculos empregatícios);

- Participação em pesquisas, estudos, eventos - variável categórica (sim ou não);

- Número de eventos frequentados no último ano - variável quantitativa;

- Carga de trabalho semanal - variável quantitativa;

- Número de leitos sob responsabilidade/turno - variável quantitativa;

- Procedimentos de alta complexidade a beira leito - variável quantitativa;

5.7.2 Variáveis relacionadas às condições de trabalho dos enfermeiros

- Escore total e das subescalas do Nursing Working Index-R.

\subsection{PROCEDIMENTOS PARA COLETA DE DADOS}

A coleta de dados foi realizada junto aos hospitais sorteados e suas respectivas UTIs, após a aprovação do Comitê de Ética de cada instituição participante. 
Após o sorteio dos hospitais, a pesquisadora entrou em contato com os respectivos hospitais, explicando a gerência de enfermagem (caso necessário) ou ao coordenador da UTI, os objetivos do trabalho e as estratégias de coleta de dados. Foi solicitada a escala atualizada dos enfermeiros e após exclusão dos profissionais que estavam de férias, licenças (médicas, maternidade, gala, nojo) no período de coleta, os enfermeiros foram convidados a participar do estudo.

Novamente eram explicados os objetivos e a metodologia do estudo, após entendimento entre as partes foi deixado um envelope contendo os instrumentos e agendado um horário para a busca do mesmo. Alguns gerentes ou coordenadores preferiam recolher e entregar todos ao pesquisador. Após o recolhimento dos instrumentos, os mesmos eram conferidos quanto ao preenchimento dos itens e separados em envelopes contendo nome do hospital e região do município.

A coleta de dados foi realizada por meio de contato previamente agendado pela autora ou em alguns casos pela coordenação do serviço ou de acordo com as condições definidas pelas instituições, no período de dezembro de 2011 a fevereiro de 2012.

Os dados referentes à caracterização das UTls foram obtidos mediante observação no próprio local e complementados junto à chefia de enfermagem e aos próprios enfermeiros, caso fosse necessário.

\subsection{OPERACIONALIZAÇÃO DA COLETA DE DADOS}

Em alguns hospitais, para cada turno de trabalho (manhã, tarde e noite), a pesquisadora explicou a proposta do estudo aos enfermeiros participantes, verificando qual era o melhor horário para esta abordagem por solicitação da chefia ou não foi necessário porque se explicava ao coordenador que permanecia em horário integral e os mesmos informavam aos enfermeiros as instruções recebidas. Foi ressaltada ainda, a garantia do 
anonimato da participação na pesquisa. Em outros era explicado apenas á Coordenação da UTI de todos os plantões e estes entregavam os questionários.

Após a aceitação do convite, verbalmente pelo enfermeiro, foi entregue um envelope contendo o Termo de Consentimento Livre e Esclarecido, a ficha de caracterização sociodemográfica e profissional do enfermeiro, o instrumento NWI-R e o SF-12. Uma etiqueta adesiva foi acoplada ao envelope, para lacrar o mesmo com os instrumentos preenchidos, mantendo assim a privacidade do respondente.

Após a entrega dos envelopes com os instrumentos foi combinado com cada enfermeiro que os mesmos seriam recolhidos em até 48 horas para o noturno e o vespertino, e em 24 horas para os turnos manhã e tarde. Caso o enfermeiro respondente comunicasse que, por algum motivo, não tenha dado tempo de responder naquele período, era agendado 0 recolhimento para o próximo dia. Foi destacada em todas as abordagens a importância do preenchimento de todos os itens dos instrumentos corretamente. Os questionários eram conferidos no momento de coleta, evitando assim o preenchimento incorreto dos itens.

A ficha de caracterização da UTI foi preenchida pela pesquisadora no momento do primeiro contato para a coleta de dados com os enfermeiros.

Após o recolhimento dos instrumentos, os mesmos eram armazenados em envelopes contendo nome e região a pertence o hospital, conferidos novamente quanto ao preenchimento.

\subsection{TRATAMENTO E ANÁLISE ESTATÍSTICA DOS DADOS}

Os dados foram inseridos em bancos independentes, digitados por duas pessoas diferentes e conferidos um a um pela pesquisadora. 
Estatísticas descritivas e inferenciais foram realizadas no Programa $R$ versão 2.14.1.

Para todas as variáveis foi realizada uma análise descritiva. As variáveis sexo, estado civil, religião, cursos após a graduação, turno de trabalho, religião, número de vínculos empregatícios, realização de procedimentos de alta complexidade à beira leito pelo enfermeiro e carga horária semanal foram tratadas como categóricas e analisadas em frequências absolutas (n) e relativas (\%). As variáveis quantitativas: idade, tempo de graduação, tempo como enfermeiro de UTI e remuneração mensal foram apresentadas em médias, medianas e desvio padrão, valores mínimos e máximos.

Como teste de comparação de médias para grupos independentes foi utilizado o teste t de Student e como teste de associação, o Qui-Quadrado de Pearson.

Para determinar se dois ou mais grupos de populações de médias iguais, avaliando se há ou não diferença significante entre elas foi utilizada a análise da variância (ANOVA). Esta análise, evita o aumento do erro tipo I ao fazerem múltiplas comparações quando as médias saem da mesma população examinando uma medida dependente. Ao passo que, a análise multivariada de variância compara diferenças de grupos, duas a duas com as variáveis dependentes (Hair, Tatham, Anderson, Black, 2009).

Havendo diferenças estatisticamente significativas entre as médias de mais de um grupo, foi realizado o teste post hoc de Tukey para múltiplas comparações. O teste de Tukey é um complemento à ANOVA e visa identificar quais as médias que, tomadas duas a duas, diferem significativamente entre si (Callegari-Jacques, 2003).

Foi realizada a análise de regressão linear múltipla com todas as variáveis que, nas comparações, apresentaram $p \leq 0,20$. Para a modelagem, utilizou-se o método stepwise forward, em que as variáveis independentes 
foram inicialmente ordenadas por ordem decrescente de valor de $p$, ou seja, da maior significância estatística para a menor. Este método faz a seleção de variáveis para inclusão no modelo de regressão que começa selecionando o melhor preditor da variável dependente a partir do valor de $\mathrm{p}$.

A colinearidade, expressão da relação entre duas (colinearidade) ou mais (multicolinearidade) variáveis independentes, foi examinada para cada variável independente incluída nos modelos, por meio dos fatores de inflação da variância (VIF).

O VIF é um indicador do efeito que as outras variáveis independentes têm sobre o erro padrão de um coeficiente de regressão. Valores altos de VIF indicam um alto grau de colinearidade entre as variáveis independentes. Um valor de VIF próximos de 1 ou $\geq 1$ não indicam presença de colinearidade. A estatística de Durbin-Watson foi utilizada para verificar a presença de correlação serial nos resíduos $(1<x<3)$ (Hair, Tatham, Anderson, Black, 2009).

Para avaliar a homogeneidade das variâncias, foi utilizado o teste de Levene, que mede a igualdade de variâncias para um par de variáveis. Seu uso é recomendado porque é menos afetado por desvios da normalidade, problema comum em regressão (Hair, Tatham, Anderson, Black, 2009).

O coeficiente de correlação tem duas propriedades que caracterizam a natureza de uma relação entre duas variáveis. Uma é o seu sinal (+ ou -) e a outra é sua magnitude. O sinal é o mesmo do coeficiente angular de uma reta imaginária que se "ajustaria" aos dados se fosse traçada num diagrama de dispersão e indica se esta reta é crescente (+), relacionamento positivo ou decrescente (-), relacionamento negativo, e a magnitude de r indica quão próximos da "reta" estão os pontos.

Para os modelos do instrumento SF12 (CF e CM), as médias foram extraídas do quadrado do escore,ou seja, os escores médios nas 
caselas de referência são obtidos pela transformação inversa, por meio da raiz quadrada do escore. Quando se aplica a raiz quadrada em uma dada variável, zeram-se as demais caselas de referência do modelo final para que se obtenha uma média estimada.

Para análise da consistência interna do instrumento NWI-R calculou-se o coeficiente alfa de Cronbach. Este coeficiente é definido como um índice que estima a homogeneidade dos itens por meio das suas variâncias e covariâncias, verificando a congruência de cada item com os outros da mesma medida (Pasqualli, 1997).

O alfa de Cronbach varia de 0 a 1 , indicando respectivamente, ausência total de consistência interna entre os itens e a presença de consistência de 100\% (Pasqualli, 1997). Valores iguais ou acima de 0,70 foram considerados indicativos de consistência interna satisfatória (Lobiondo-Wood, Haber (2001).

Em todos os testes das análises bivariadas foi fixado em $5 \% 0$ nível de significância para a rejeição da hipótese de nulidade $(p<0,05)$. 
Resultados 


\section{RESULTADOS}

\subsection{CARACTERIZAÇÃO DOS HOSPITAIS E UTIS}

Os dados relativos aos hospitais e UTIs serão apresentados em forma de tabelas, com a distribuição das frequências absolutas e relativas, as médias, desvios-padrão, medianas e os intervalos de confiança de 95\%.

A Tabela 5 mostra as variáveis de caracterização dos hospitais participantes do estudo $(n=18)$.

Tabela 5 - Distribuição das variáveis de caracterização dos hospitais. São Paulo, 2012.

\begin{tabular}{|c|c|c|}
\hline Variável & $\mathbf{N}$ & $\%$ \\
\hline \multicolumn{3}{|l|}{ Tipo de instituição } \\
\hline Privada & 13 & 72,2 \\
\hline Pública & 3 & 16,7 \\
\hline Filantrópica & 2 & 11,1 \\
\hline \multicolumn{3}{|l|}{ Zona municipal } \\
\hline Leste & 5 & 27,8 \\
\hline Sul & 5 & 27,8 \\
\hline Centro & 4 & 22,2 \\
\hline Oeste & 2 & 11,1 \\
\hline Norte & 2 & 11,1 \\
\hline \multicolumn{3}{|l|}{ Porte do hospital } \\
\hline Grande & 13 & 72,2 \\
\hline Extra & 4 & 22,2 \\
\hline Médio & 1 & 5,6 \\
\hline \multicolumn{3}{|l|}{ Número de UTIs } \\
\hline 1 & 9 & 50,0 \\
\hline 2 & 7 & 38,9 \\
\hline 3 a 5 & 2 & 11,1 \\
\hline
\end{tabular}


$\mathrm{Na}$ Tabela 5, observa-se um predomínio de hospitais da rede privada $(72,2 \%)$, das zonas sul $(27,8 \%)$ e leste $(27,8 \%)$, de grande porte $(72,2 \%)$ e com apenas uma UTI (50\%).

$\mathrm{Na}$ Tabela 6, são apresentadas as características das 31 UTls dos 18 hospitais da amostra, quanto ao tipo de atendimento, número total de leitos e proporção de leitos por enfermeiro.

Tabela 6 - Distribuição das UTIs segundo o número de leitos, tipo e proporção paciente-enfermeiro. São Paulo, 2012.

\begin{tabular}{|c|c|c|}
\hline Variáveis & $\mathbf{N}$ & $\%$ \\
\hline \multicolumn{3}{|l|}{ Número leitos na UTI } \\
\hline 10 leitos & 11 & 35,4 \\
\hline 11 a 20 & 12 & 38,8 \\
\hline 21 a 40 & 06 & 19,3 \\
\hline$>41$ leitos & 02 & 6,5 \\
\hline \multicolumn{3}{|l|}{ Tipo de UTI } \\
\hline Geral & 22 & 71 \\
\hline Especializada & 09 & 29 \\
\hline Neurológica & 04 & 13 \\
\hline Cardiológica & 05 & 16 \\
\hline \multicolumn{3}{|l|}{ Número de leitos /enfermeiro } \\
\hline $5-8$ leitos & 17 & 54,9 \\
\hline 9 - 15 leitos & 09 & 29,0 \\
\hline $16-25$ leitos & 05 & 16,1 \\
\hline \multicolumn{3}{|c|}{$\begin{array}{l}\text { Realização de procedimentos de alta } \\
\text { complexidade }\end{array}$} \\
\hline $\operatorname{Sim}$ & 25 & 80,7 \\
\hline Não & 06 & 19,3 \\
\hline
\end{tabular}

O total de leitos das 31 unidades participantes, somaram-se 627 leitos. Desses, 42 leitos eram provenientes de hospitais públicos, 252 leitos de hospitais filantrópicos e 333 leitos da rede privada. Destaca-se que, o maior número de leitos foi encontrado num hospital filantrópico com 218 leitos distribuídos em UTI geral, cardiológica e neurológica. Na rede privada, o maior número de leitos encontrado foi de 50, atendendo as mesmas 
especialidades que a do hospital filantrópico. Já para a rede pública, o maior número de leitos foi de 18. A menor quantidade de leitos de UTI disponível foi de dez, para todos os tipos de hospitais.

\subsection{CARACTERIZAÇÃO DOS ENFERMEIROS}

Nas 31 UTls do estudo, foram encontrados 303 enfermeiros distribuídos nos diferentes turnos de trabalho. Deste total, participaram da pesquisa 180 enfermeiros, correspondendo a cerca de $60 \%$ dos profissionais atuantes nas 31 UTIs. Os dados de caracterização sociodemográfica e de trabalho estão apresentados na Tabela 7, a seguir. 
Tabela 7- Caracterização sociodemográfica e de trabalho dos enfermeiros de UTI. São Paulo, 2012.

\begin{tabular}{|c|c|c|}
\hline Variáveis qualitativas & $\mathbf{n}$ & $\%$ \\
\hline \multicolumn{3}{|l|}{ Sexo } \\
\hline Feminino & 124 & 68,9 \\
\hline Masculino & 56 & 31,1 \\
\hline \multicolumn{3}{|l|}{ Estado civil } \\
\hline Solteiro & 85 & 47,2 \\
\hline Casado & 76 & 42,3 \\
\hline Separado/viúvo & 19 & 10,5 \\
\hline \multicolumn{3}{|l|}{ Religião $(n=168)$} \\
\hline Católica & 109 & 64,9 \\
\hline Evangélica & 41 & 24,4 \\
\hline Espírita & 16 & 9,5 \\
\hline Budista & 02 & 1,2 \\
\hline \multicolumn{3}{|l|}{ Turno de trabalho } \\
\hline Manhã (7-3h) & 50 & 27,8 \\
\hline Tarde (13-19h) & 39 & 21,7 \\
\hline Noite (19-07h) & 72 & 40,0 \\
\hline Diurno $(07-19 \mathrm{~h})$ & 19 & 10,5 \\
\hline \multicolumn{3}{|l|}{ Número de vínculos empregatícios } \\
\hline Um vínculo & 134 & 74,4 \\
\hline 2-3 vínculos & 46 & 25,6 \\
\hline \multicolumn{3}{|l|}{ Curso após a graduação } \\
\hline Especialização (sim/não) & $169 / 11$ & $93,9 / 6,1$ \\
\hline Mestrado (sim/não) & 01 & $0,5 / 99,5$ \\
\hline Atualização/ (sim/não) & $143 / 37$ & $79,4 / 20,6$ \\
\hline \multicolumn{3}{|l|}{ Carga horária semanal } \\
\hline$<40$ horas & 122 & 68,0 \\
\hline$\geq 40$ horas & 58 & 32,0 \\
\hline \multicolumn{3}{|l|}{$\begin{array}{l}\text { Execução de procedimentos de alta } \\
\text { complexidade }\end{array}$} \\
\hline $\operatorname{Sim}$ & 130 & 72,2 \\
\hline Não & 50 & 27,8 \\
\hline
\end{tabular}


Continuação Tabela 7.

Tabela 7- Caracterização sociodemográfica e de trabalho dos enfermeiros de UTI. São Paulo, 2012.

\begin{tabular}{lccc}
\hline Variáveis quantitativas & $\begin{array}{c}\text { Média/Desvio } \\
\text { Padrão }\end{array}$ & Mediana & $\begin{array}{c}\text { IC 95\% } \\
\text { I - S }\end{array}$ \\
\hline Idade & $35,6(7,0)$ & 34,0 & $34,6-36,6$ \\
Tempo de Graduação (anos) & $8,9(5,5)$ & 8,0 & $8,0-9,7$ \\
$\begin{array}{l}\text { Tempo como enfermeiro na } \\
\text { UTI (anos) }\end{array}$ & $6,6(5,2)$ & 5,0 & $5,8-7,4$ \\
$\begin{array}{l}\text { Número de eventos } \\
\text { científicos no último ano }\end{array}$ & $2,4(3,9)$ & 2,0 & $1,86-3,02$ \\
Remuneração mensal (reais) & $4.171,00(1.485,74)$ & $3.600,00$ & $3.952,50-4.389,60$ \\
\hline
\end{tabular}

$\mathrm{Na}$ Tabela 7, observa-se que os enfermeiros deste estudo eram predominantemente do sexo feminino (68,9\%), jovens (média de idade de 35,6 anos), católicos $(64,9 \%)$ e solteiros (47,2\%). Estavam formados, em média, há 9 anos e trabalhavam em UTI há cerca de 6,6 anos. A maioria trabalhava durante o dia (60\%), cumprindo uma escala diária de seis horas nos turnos da manhã ou da tarde, ou uma escala diurna de 12 horas diárias. Predominaram os enfermeiros com apenas um vínculo empregatício (74,4\%) e os que trabalhavam menos de 40 horas semanais (68\%), com pelo menos uma folga por semana. Os enfermeiros do turno diurno (7-19h) também tinham uma folga por semana e os dos plantões noturnos, uma folga a cada 15 dias. Quase a totalidade dos enfermeiros (93,9\%) havia frequentado algum curso de especialização e cerca de $80 \%$, cursos de atualização. Em relação à participação em eventos científicos no último ano, a média observada foi de 2,4 eventos. A maioria (72,2\%) executava procedimentos de alta complexidade à beira leito na unidade de trabalho. 


\subsection{QUALIDADE DE VIDA RELACIONADA À SAÚDE E CONDIÇÕES DE TRABALHO DOS ENFERMEIROS}

6.3.1 Análise descritiva dos itens do SF-12

A seguir, na Tabela 8, observa-se a distribuição das respostas dos enfermeiros às questões do instrumento SF-12. 
Tabela 8 - Distribuição dos enfermeiros de UTI segundo respostas aos itens do SF-12. São Paulo, 2012.

Durante as últimas quatro semanas, você teve algum dos seguintes problemas com o seu trabalho ou com alguma atividade diária regular, como consequência de sua saúde física?

Questão

Não Sim

4. Realizou menos tarefas do que gostaria?

5. Esteve ilimitado no seu tipo de trabalho ou

$\begin{array}{cc}123 & 57 \\ 68,3 & 31,7\end{array}$

em outras atividades

$135 \quad 45$

Durante as últimas quatro semanas, você teve algum dos seguintes problemas com o seu trabalho ou com alguma atividade diária regular, como consequência de algum problema emocional (como sentir-se deprimido ou ansioso)?

\begin{tabular}{lccc}
\hline \multicolumn{1}{c}{ Questão } & & Não & Sim \\
\hline 6. Realizou menos tarefa do que gostaria? & $\mathrm{N}$ & 116 & 64 \\
\hline 7. Não trabalhou ou não fez qualquer das & $\mathrm{N}$ & 64,4 & 35,6 \\
atividades com tanto cuidado como geralmente & $\%$ & 756 & 44 \\
faz? & $\%$ & 24,4 \\
\hline
\end{tabular}




\section{Continuação Tabela 8}

Tabela 8 - Distribuição dos enfermeiros de UTI segundo respostas aos itens do SF-12. São Paulo, 2012.

Os seguintes itens são sobre atividades que você poderia fazer atualmente durante um dia comum. Devido a sua saúde, você teria dificuldade para fazer essas atividades? Neste caso, quanto?

\begin{tabular}{|c|c|c|c|c|c|c|}
\hline Questão & & 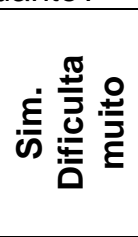 & 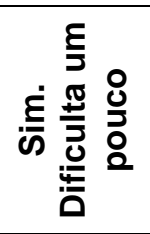 & 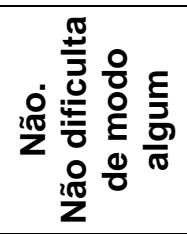 & & \\
\hline $\begin{array}{l}\text { 2. Atividades moderadas, tais como mover } \\
\text { uma mesa, passar aspirador de pó, jogar bola, } \\
\text { varrer a casa }\end{array}$ & $\mathrm{N}$ & 4,5 & 17,2 & 141 & & \\
\hline \multirow[t]{2}{*}{ 3. Subir vários lances de escada. } & $\begin{array}{l}\mathrm{N} \\
\% \\
\end{array}$ & $\begin{array}{l}12 \\
6,7 \\
\end{array}$ & $\begin{array}{c}62 \\
34,4 \\
\end{array}$ & $\begin{array}{r}106 \\
58,9 \\
\end{array}$ & & \\
\hline & & 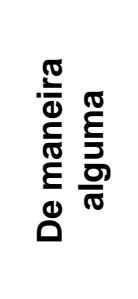 & 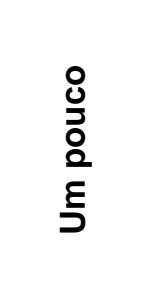 & 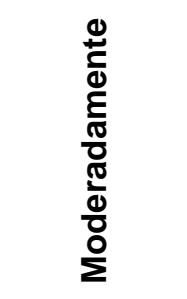 & 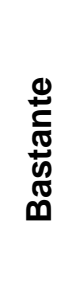 & 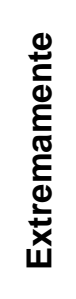 \\
\hline \multirow{2}{*}{$\begin{array}{l}\text { 8. Durante as últimas quatro semanas, quanto } \\
\text { a dor interferiu com o seu trabalho normal } \\
\text { (incluindo tanto o trabalho, fora de casa e } \\
\text { dentro de casa)? }\end{array}$} & $\mathrm{N}$ & 84 & 48 & 35 & 12 & 1 \\
\hline & $\%$ & 46,6 & 26,7 & 19,4 & 6,7 & 0,6 \\
\hline
\end{tabular}




\section{Continuação Tabela 8}

Tabela 8 - Distribuição dos enfermeiros de UTI segundo respostas aos itens do SF-12. São Paulo, 2012.

\begin{tabular}{|c|c|c|c|c|c|c|}
\hline Questão & & 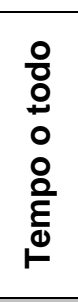 & 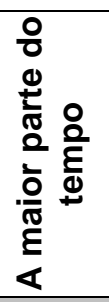 & 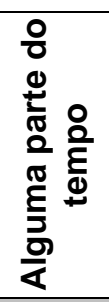 & 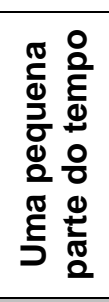 & 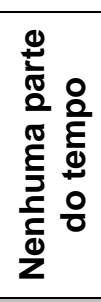 \\
\hline $\begin{array}{l}\text { 12. Durante as últimas quatro semanas, quanto } \\
\text { do seu tempo a sua saúde física ou problemas } \\
\text { emocionais interferiram nas suas atividades } \\
\text { sociais (como visitar amigos, parentes, etc)? }\end{array}$ & $\mathrm{N}$ & 3,9 & 11,7 & 28,3 & 28,3 & 27,8 \\
\hline
\end{tabular}

Estas questões são sobre como você se sente e como tudo tem acontecido com você durante as últimas quatro semanas. Para cada questão, por favor, dê uma resposta que mais se aproxime da maneira como você se sente. Em relação as últimas quatro semanas.

\begin{tabular}{|c|c|c|c|c|c|c|c|}
\hline Questão & & $\begin{array}{l}\circ \\
\stackrel{\circ}{E} \\
\Phi \\
\stackrel{0}{0} \\
\circ \\
\stackrel{0}{0} \\
\circ\end{array}$ & 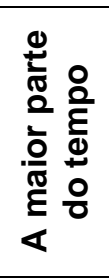 & 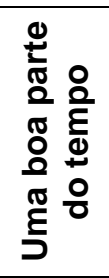 & 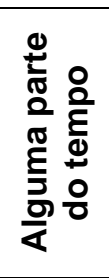 & 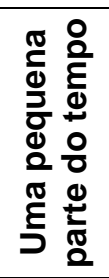 & 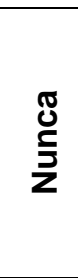 \\
\hline \multirow{2}{*}{$\begin{array}{l}\text { 9. Quanto tempo você tem se sentido calmo ou } \\
\text { tranquilo? }\end{array}$} & $\mathrm{N}$ & 6 & 67 & 60 & 31 & 14 & 2 \\
\hline & $\%$ & 3,3 & 37,2 & 33,3 & 17,2 & 7,9 & 1,1 \\
\hline \multirow{2}{*}{$\begin{array}{l}\text { 10. Quanto tempo você tem se sentido com } \\
\text { muita energia? }\end{array}$} & $\mathrm{N}$ & 12 & 39 & 52 & 48 & 23 & 6 \\
\hline & $\%$ & 6,7 & 21,7 & 28,9 & 26,6 & 12,8 & 3,3 \\
\hline \multirow{2}{*}{$\begin{array}{l}\text { 11. Quanto tempo você tem se sentido } \\
\text { desanimado e abatido? }\end{array}$} & $\mathrm{N}$ & 1 & 16 & 24 & 39 & 76 & 24 \\
\hline & $\%$ & 0,6 & 8,9 & 13,3 & 21,7 & 42,2 & 13,3 \\
\hline
\end{tabular}


$\mathrm{Na}$ Tabela 8, observa-se que nos itens 4 e 5, que avaliam as consequências da saúde física no trabalho ou em outras atividades regulares, $68,3 \%$ dos enfermeiros responderam que não realizaram menos tarefas do que gostariam. Assim, como $75 \%$ não se sentiram limitados no trabalho ou em outras atividades devidos a problemas físicos. As questões 6 e 7, referentes ao impacto de problemas emocionais no trabalho ou em alguma atividade diária regular, 64,4\% responderam que não deixaram de realizar as tarefas que gostariam e $75,6 \%$, que não deixaram de trabalhar ou de fazer quaisquer atividades com o mesmo cuidado habitual.

Para a questão 2, 78,3\% responderam que não há dificuldade de modo algum para realizar atividades moderadas; na questão 3, 58,9\% responderam que subir vários lances de escada não é uma dificuldade de modo algum para eles.

Em relação à questão $1,56,7 \%$ classificaram a sua saúde como boa, $29,4 \%$ como muito boa e 7,8\% como excelente. Na questão $8,46,6 \%$ referiram que a dor não interferiu de maneira alguma no trabalho ou em outras atividades.

$\mathrm{Na}$ questão 12 "quanto do seu tempo a sua saúde física ou problemas emocionais interferiram nas suas atividades sociais", os enfermeiros responderam "alguma parte do tempo" (28,3\%), "uma pequena parte do tempo" $(28,3 \%)$ e "nenhuma parte do tempo" $(27,8 \%)$.

Para a questão 9 "quanto tempo você tem se sentido calmo ou tranquilo" $37,2 \%$ dos enfermeiros responderam "a maior parte do tempo". Os enfermeiros responderam "uma boa parte do tempo" na questão 10 , perfazendo $28,9 \%$ dos respondentes em relação ao tempo que eles se sentiam com muita energia. Já para a questão $11,42,2 \%$ referiram que se sentiram desanimados e abatidos apenas "uma pequena parte do tempo".

$\mathrm{Na}$ análise das respostas do instrumento SF-12 por componente e dimensões. No componente físico, com as dimensões estado 
geral de saúde, capacidade funcional, aspectos físicos e dor. Para o componente mental e suas dimensões aspectos emocionais, vitalidade, saúde mental e aspectos sociais, calcularam-se a média e desvio padrão para cada item conforme apresentação a seguir.

$\mathrm{Na}$ Tabela 9, observam-se as médias e desvios-padrão para escores das dimensões dos componentes físico e mental do SF-12.

Tabela 9 - Média e desvio-padrão das dimensões dos Componentes Físico e Mental do SF-12. São Paulo, 2012.

\begin{tabular}{lccc}
\hline \multicolumn{1}{c}{ Dimensão } & Média & $\begin{array}{l}\text { Desvio } \\
\text { padrão }\end{array}$ & Componente \\
\hline Estado geral de Saúde & 68,0 & 18,1 & \\
Capacidade Funcional & 81,5 & 25,1 & QVRS \\
Aspectos Físicos & 28,3 & 39,9 & Físico \\
Dor & 77,9 & 24,6 & \\
\hline Aspectos emocionais & 30,0 & 37,6 & QVRS \\
Vitalidade & 35,4 & 23,2 & Mental \\
Saúde Mental & 64,8 & 16,9 & \\
Aspectos Sociais & 66,1 & 28,0 & \\
\hline
\end{tabular}

Os dados da Tabela 9 mostram que a média das dimensões do CF são maiores que as do $\mathrm{CM}$. No $\mathrm{CF}$, a menor média foi encontrada no domínio "aspectos físicos" $(28,3 ; \mathrm{dp}=39,9)$. No $\mathrm{CM}$, as dimensões com menores média foram aspectos emocionais $(30,0 ; d p=37,6)$ e vitalidade $(35,4 ; \mathrm{dp}=23,2)$.

No Gráfico 1, apresentamos os dados do SF-12 distribuídos por dimensões e componentes. 
Gráfico 1 - Distribuição das respostas do SF-12 por componentes e dimensões. São Paulo, 2012.

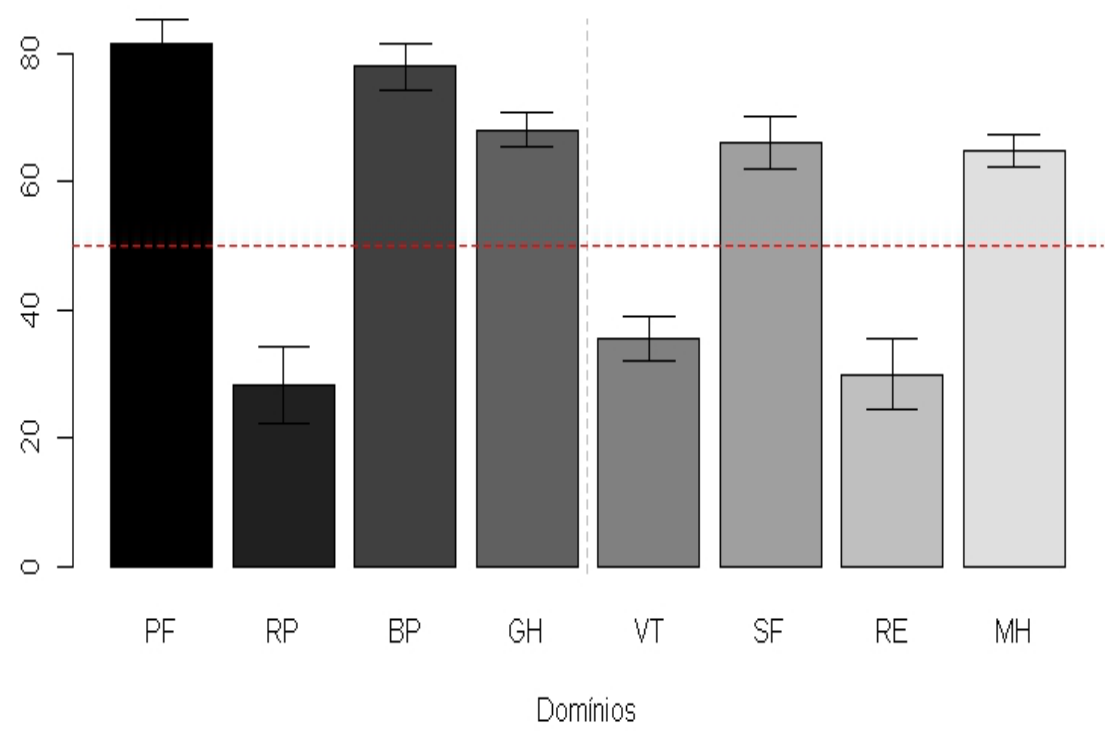

Os dados do Gráfico 1, com as siglas PF equivalem a Capacidade Funcional, RP (Aspectos Físicos), BP (Dor) e GH (estado geral de saúde) dimensões pertencentes ao domínio Físico. Já as siglas VT (Vitalidade), SF (Aspectos Sociais), RE (Aspectos Emocionais e MH (Saúde Mental) são dimensões pertencentes ao componente mental do SF-12. Destaca-se a linha tracejada que é a média de corte do escore, escores abaixo de 50 indicam comprometimento da QVRS.

No Gráfico 1, observa-se que a distribuição das respostas por dimensões são maiores no CF do que no CM. No CF, a menor distribuição foi no domínio aspectos físicos (RP). No CM, os domínios com menores distribuições foram aspectos emocionais (RE) e vitalidade (VT). 
Para avaliarmos a percepção dos enfermeiros em relação ao seu ambiente de trabalho utilizou-se o instrumento NWI-R. No Gráfico 2, apresentamos os dados em relação à frequência das respostas dos enfermeiros para o instrumento NWI - R.

Gráfico 2 - Distribuição das respostas dos enfermeiros para o NWI-R. São Paulo, 2012.

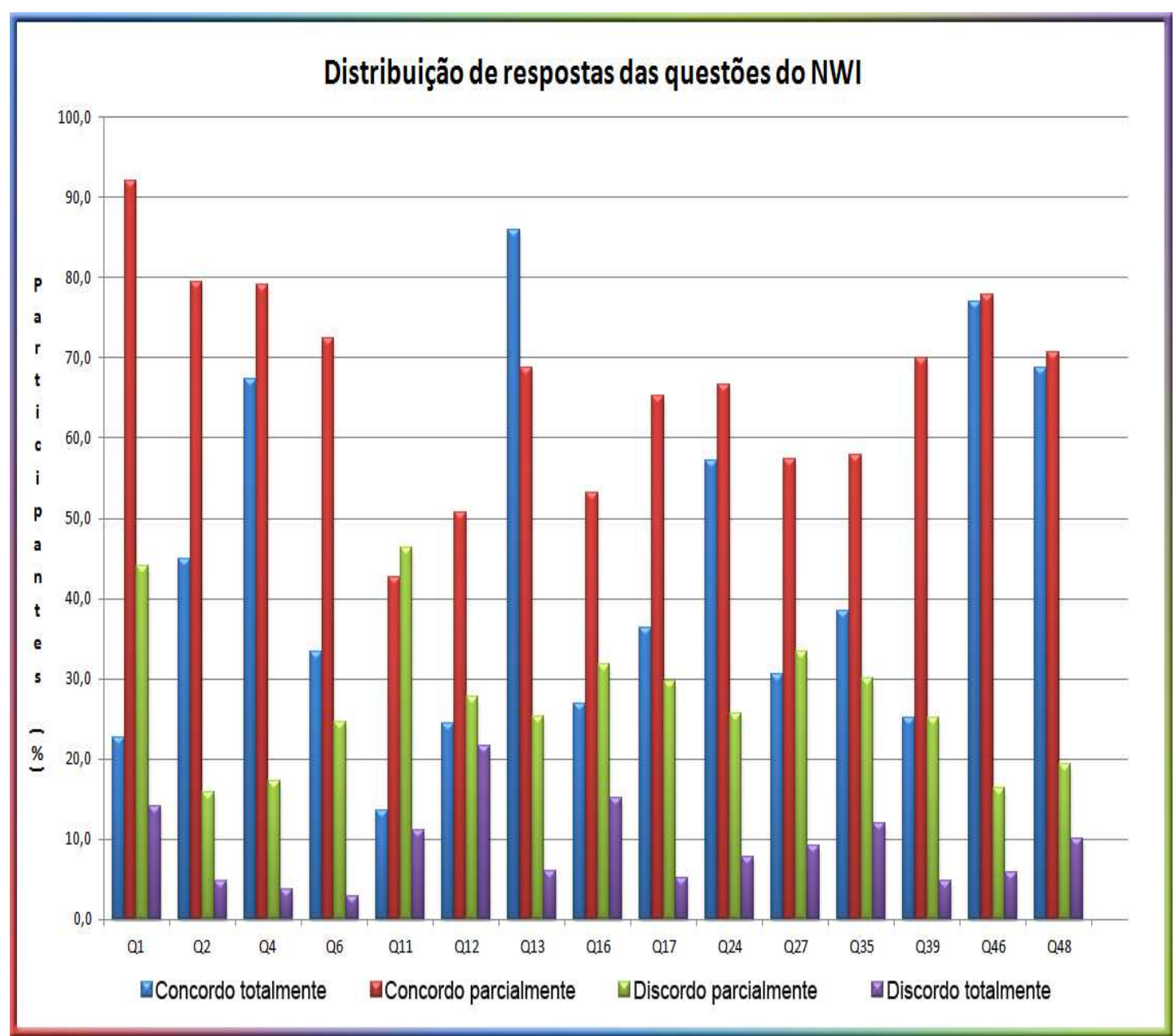

$\mathrm{Na}$ maioria dos itens, observa-se que mais de $60 \%$ dos enfermeiros concordaram total ou parcialmente com as afirmações contidas nos itens do NWI, o que parece ratificar a existência de condições adequadas de trabalho nas UTIs onde atuavam. 
Cinco itens tiveram mais de $80 \%$ de concordância: "Uma equipe de supervisores que dá suporte aos enfermeiros", "Oportunidade de trabalhar em uma unidade altamente especializada", ambos com $87,5 \%$ de concordância e "Os médicos e os enfermeiros possuem boas relações de trabalho" (85,9\%)," O gerente de enfermagem é um bom administrador e líder" (83,2\%) e "A designação de pacientes promove a continuidade do cuidado" $(82,6 \%)$.

Destaca-se que quanto menor o escore do NWI-R e das suas subescalas, melhores são as percepções das condições de trabalho. Os resultados sugerem que, em geral, as percepções das condições de trabalho dos enfermeiros de UTI eram favoráveis.

\subsection{AVALIAÇÃO DA CONFIABILIDADE DO NWI-R}

A confiabilidade do instrumento Nursing Work Index-R (NWI-R) foi avaliada pela consistência interna dos itens, utilizando-se o coeficiente alfa de Cronbach. Os quatro domínios do NWI-R foram analisados segundo o agrupamento dos itens proposto por Aiken e Patrician (2000). Os resultados estão apresentados na Tabela 10.

Tabela 10 - Consistência interna do instrumento NWI - R. São Paulo, 2012.

\begin{tabular}{lcc}
\hline \multicolumn{1}{c}{ Domínio } & $\mathbf{N}^{\circ}$ de Itens & $\alpha$ Cronbach \\
\hline Total & 15 & 0,90 \\
Autonomia & 05 & 0,80 \\
Controle sobre o ambiente & 07 & 0,80 \\
Relação médico/enfermeiro & 03 & 0,81 \\
Suporte organizacional & 10 & 0,84 \\
\hline
\end{tabular}

Os dados da Tabela 10 mostram a consistência interna do NWI-R para o total dos itens e para as subescalas, com valores entre 0,80 e 0,90. 


\subsection{ASSOCIAÇÕES ENTRE QUALIDADE DE VIDA RELACIONADA À SAÚDE E VARIAVEIS SELECIONADAS}

A Tabela 11 mostra os dados descritivos dos escores dos componentes físico e mental do SF-12 e do NWI-R.

Tabela 11 - Estatística descritiva dos escores dos instrumentos SF-12 e NWI-R. São Paulo, 2012. $(n=180)$

\begin{tabular}{llllc}
\hline $\begin{array}{l}\text { Instrumento / } \\
\text { Domínios }\end{array}$ & Média & DP & Mediana & IC 95\% \\
& & & & Inf. - Sup. \\
\hline SF12-CF & 49,0 & 7,6 & 50,5 & $47,8-50,0$ \\
SF12-CM & 46,0 & 10 & 47,3 & $44,3-47,2$ \\
NWI-R total & 2,0 & 0,5 & 2,0 & $2,0-2,1$ \\
NWI_R autonomia & 2,0 & 0,6 & 2,00 & $1,9-2,0$ \\
NWI_R controle & 2,1 & 0,6 & 2,00 & $2,0-2,2$ \\
NWI_R relação & 2,0 & 0,7 & 2,00 & $1,9-2,1$ \\
NWI_R suporte & 2,1 & 0,5 & 2,00 & $2,0-2,1$ \\
\hline
\end{tabular}

A média dos escores dos CF e CM do SF-12 foram respectivamente de 49,0 (dp=7,6) e 46,0 ( $d p=10)$, valores que apontam para um maior comprometimento do componente mental em relação ao físico.

Já para o escore total NWI-R, a média observada foi de 2,0 com $\mathrm{dp}=0,5$, indicando a presença de elementos favoráveis para 0 trabalho desses enfermeiros nas UTIs. Quando analisadas as médias por domínios do NWI-R, mantiveram-se entre 2,0 e 2,1.

6.5.1 Associações entre os Componentes Físico e Mental do SF-12 e variáveis. 
$\mathrm{Na}$ Tabela 12 estão apresentadas as associações entre os escores do SF-CF e as variáveis selecionadas, com $\mathrm{p}<0,05$.

Tabela 12 - Associações entre o escore do SF-CF e variáveis sociodemográficas e de trabalho dos enfermeiros e dos hospitais. São Paulo, 2012.

\begin{tabular}{|c|c|c|c|c|c|c|c|}
\hline Variável & Grupo & $\mathrm{n}$ & Média & DP & Mediana & $\begin{array}{c}\text { IC95\% } \\
\text { Inf. - Sup. }\end{array}$ & $\begin{array}{c}\text { Valor } \\
\mathbf{p}\end{array}$ \\
\hline \multirow{2}{*}{ Sexo } & Feminino & 124 & 48.0 & 7,8 & 48,7 & $46,6-49,4$ & \multirow{2}{*}{0,015} \\
\hline & Masculino & 56 & 51 & 6,8 & 52 & $49,2-52,7$ & \\
\hline \multirow{4}{*}{ Idade } & $(20,30]$ & 46 & 48,8 & 7,4 & 49,3 & $46,6-50,9$ & \multirow{4}{*}{0,664} \\
\hline & $(30,40]$ & 91 & 48,6 & 8,2 & 50,5 & $47,0-50,3$ & \\
\hline & $(40,50]$ & 36 & 50,2 & 6,1 & 51,2 & $48,2-52,2$ & \\
\hline & $(50,60]$ & 7 & 47 & 8,8 & 50,8 & $40,5-53,5$ & \\
\hline \multirow{4}{*}{ Religião } & Budista & 2 & 51,4 & 3,8 & 51,4 & $46,1-56,7$ & \multirow{4}{*}{0,708} \\
\hline & Católica & 109 & 49,2 & 7,3 & 50,5 & $47,9-50,6$ & \\
\hline & Espírita & 16 & 50,1 & 8,9 & 51,5 & $45,7-54,4$ & \\
\hline & Evangélica & 41 & 47,9 & 8,1 & 50,5 & $45,5-50,4$ & \\
\hline \multirow{4}{*}{$\begin{array}{l}\text { Turno de } \\
\text { trabalho }\end{array}$} & Manhã & 50 & 49,7 & 7,3 & 51,4 & $47,7-51,8$ & \multirow{4}{*}{0,648} \\
\hline & Noite & 72 & 48,1 & 8,1 & 49,9 & $46,2-50,0$ & \\
\hline & Tarde & 39 & 49,5 & 6,8 & 48,9 & $47,4-51,6$ & \\
\hline & Vespertino & 19 & 48,7 & 8 & 49,7 & $45,1-52,3$ & \\
\hline \multirow{4}{*}{$\begin{array}{l}\text { Tempo de } \\
\text { graduação }\end{array}$} & $(1980,1990]$ & 8 & 45,5 & 7,6 & 45,2 & $40,2-50,8$ & \multirow{4}{*}{0,057} \\
\hline & $(1990,2000]$ & 33 & 46,2 & 8,3 & 47,1 & $43,4-49,1$ & \\
\hline & $(2000,2005]$ & 68 & 49,8 & 7 & 50,7 & $48,1-51,5$ & \\
\hline & $(2005,2012]$ & 71 & 49,7 & 7,6 & 51,6 & $47,9-51,5$ & \\
\hline \multirow{2}{*}{ Especialização } & Não & 11 & 47,1 & 8,6 & 48,2 & $42,0-52,2$ & \multirow{2}{*}{0,415} \\
\hline & Sim & 169 & 49 & 7,5 & 50,5 & $47,9-50,2$ & \\
\hline \multirow{2}{*}{$\begin{array}{l}\text { Número de } \\
\text { vínculos } \\
\text { empregatícios }\end{array}$} & 1 & 134 & 48,9 & 7,6 & 50,5 & $47,6-50,1$ & \multirow{2}{*}{0,842} \\
\hline & 2 ou 3 & 46 & 49,1 & 7,8 & 50,5 & $46,9-51,4$ & \\
\hline
\end{tabular}


Continuação Tabela 12

Tabela 12 - Associações entre o escore do SF-CF e variáveis sociodemográficas e de trabalho dos enfermeiros e dos hospitais. São Paulo, 2012.

\begin{tabular}{|c|c|c|c|c|c|c|c|}
\hline Variável & Grupo & $\mathbf{n}$ & Média & DP & Mediana & $\begin{array}{c}\text { IC95\% } \\
\text { Inf. - Sup. }\end{array}$ & $\begin{array}{c}\text { Valor } \\
\mathbf{p}\end{array}$ \\
\hline \multirow{3}{*}{$\begin{array}{l}\text { Tempo de UTI } \\
\text { (anos) }\end{array}$} & $(0,5]$ & 92 & 49,4 & 7,4 & 51 & $47,9-50,9$ & \multirow{3}{*}{0,636} \\
\hline & $(5,10]$ & 57 & 48,7 & 8,6 & 50,5 & $46,5-50,9$ & \\
\hline & $(10,50]$ & 31 & 47,9 & 6,3 & 48,6 & $45,7-50,2$ & \\
\hline \multirow{3}{*}{$\begin{array}{l}\text { Remuneração } \\
\text { (faixa) }\end{array}$} & Até $3 \mathrm{mil}$ & 34 & 49,9 & 7,2 & 51,1 & $47,5-52,3$ & \multirow{3}{*}{0,317} \\
\hline & & 117 & 48,3 & 7,8 & 49,8 & $46,9-49,7$ & \\
\hline & Mais de 5,001 & 29 & 50,3 & 7,2 & 51,2 & $47,7-52,9$ & \\
\hline $\begin{array}{l}\text { Leitos por } \\
\text { enfermeiro }\end{array}$ & $\begin{array}{l}\text { Até } 8 \\
\text { Mais } 8\end{array}$ & $\begin{array}{c}112 \\
68\end{array}$ & $\begin{array}{l}50,1 \\
46,9\end{array}$ & $\begin{array}{c}7 \\
8,2\end{array}$ & $\begin{array}{c}51 \\
47,4\end{array}$ & $\begin{array}{l}48,9-51,4 \\
44,9-48,8\end{array}$ & 0,004 \\
\hline \multirow{2}{*}{$\begin{array}{c}\text { Procedimentos } \\
\text { de alta } \\
\text { complexidade }\end{array}$} & Não & 32 & 50,4 & 7 & 52,3 & $48,0-52,9$ & \multirow{2}{*}{0,213} \\
\hline & Sim & 148 & 48,6 & 7,7 & 49,9 & $47,4-49,8$ & \\
\hline \multirow{2}{*}{$\begin{array}{l}\text { Carga de } \\
\text { trabalho }\end{array}$} & $<40 \mathrm{~h}$ & 122 & 49,3 & 7,3 & 50,7 & $48,0-50,6$ & \multirow{2}{*}{0,319} \\
\hline & $\geq 40 \mathrm{~h}$ & 58 & 48,1 & 8,1 & 49,1 & $46,0-50,2$ & \\
\hline \multirow{3}{*}{$\begin{array}{l}\text { Eventos } \\
\text { científicos }\end{array}$} & 0 & 36 & 48 & 7,9 & 50,7 & $45,5-50,6$ & \multirow{3}{*}{0,737} \\
\hline & 1 a 4 & 131 & 49,1 & 7,7 & 50,1 & $47,8-50,4$ & \\
\hline & 5 ou mais & 13 & 49,5 & 6,6 & 50,8 & $45,9-53,0$ & \\
\hline \multirow{5}{*}{$\begin{array}{c}\text { Zona } \\
\text { Municipal }\end{array}$} & Centro & 47 & 48,2 & 7 & 48,6 & $46,2-50,2$ & \multirow{5}{*}{0,391} \\
\hline & Leste & 39 & 48,5 & 8,1 & 49,7 & $46,0-51,1$ & \\
\hline & Norte & 18 & 51,4 & 4,4 & 51,1 & $49,4-53,5$ & \\
\hline & Oeste & 14 & 51,3 & 7,3 & 54,7 & $47,5-55,1$ & \\
\hline & Sul & 62 & 48,4 & 8,4 & 50,8 & $46,3-50,5$ & \\
\hline \multirow{3}{*}{$\begin{array}{l}\text { Tipo de } \\
\text { Hospital }\end{array}$} & Filantrópico & 28 & 46,4 & 7,6 & 46,8 & $43,6-49,2$ & \multirow{3}{*}{0,08} \\
\hline & Privado & 130 & 49,7 & 7,3 & 50,8 & $48,4-50,9$ & \\
\hline & Público & 22 & 47,6 & 8,8 & 50,5 & $43,9-51,2$ & \\
\hline
\end{tabular}

$\mathrm{Na}$ Tabela 12, observa-se que existem diferenças estatisticamente significativas entre o SF-12 - CF e as variáveis sexo $(p=$ $0,015)$, tempo de graduação $(p=0,057)$ e leitos por enfermeiro $(p=0,004)$.

A seguir, na Tabela 13 observam-se as associações entre o SF $\mathrm{CM}$ e as variáveis sociodemográficas, de trabalho e dos hospitais. 
Tabela 13 - Associação entre o escore do SF-CM e variáveis sociodemográficas e de trabalho dos enfermeiros e dos hospitais. São Paulo, 2012.

\begin{tabular}{|c|c|c|c|c|c|c|c|}
\hline Variável & Grupo & $\mathbf{n}$ & Média & DP & Mediana & $\begin{array}{c}\text { IC } \\
\text { I - S }\end{array}$ & $\begin{array}{l}\text { Valor } \\
\text { de p }\end{array}$ \\
\hline \multirow{2}{*}{ Sexo } & Masculino & 56 & 46,7 & 10,2 & 49,7 & $44,1-49,4$ & \multirow{2}{*}{0,371} \\
\hline & Feminino & 124 & 45,3 & 9,9 & 46,9 & $43,6-47,0$ & \\
\hline \multirow{4}{*}{ Idade } & $(20,30]$ & 46 & 43,7 & 9,8 & 45 & $40,8-46,5$ & \multirow{4}{*}{0,007} \\
\hline & $(30,40]$ & 91 & 44,8 & 10,3 & 46,4 & $42,7-46,9$ & \\
\hline & $(40,50]$ & 36 & 49,4 & 8,9 & 51,7 & $46,5-52,3$ & \\
\hline & $(50,60]$ & 7 & 53,5 & 5,2 & 53,7 & $49,6-57,4$ & \\
\hline \multirow{4}{*}{ Religião } & Budista & 2 & 40,1 & 10,2 & 40,1 & $26,1-54,2$ & \multirow{4}{*}{0,603} \\
\hline & Católica & 109 & 46,3 & 10 & 47,4 & $44,5-48,2$ & \\
\hline & Espírita & 16 & 43,4 & 9,5 & 45,4 & $38,8-48,1$ & \\
\hline & Evangélicos & 41 & 45,7 & 10,2 & 47,4 & $42,6-48,8$ & \\
\hline \multirow{4}{*}{ Turno } & Manhã & 50 & 44,6 & 10,1 & 45 & $41,8-47,4$ & \multirow{4}{*}{0,649} \\
\hline & Noite & 72 & 46,1 & 10 & 47,9 & $43,8-48,4$ & \\
\hline & Tarde & 39 & 45,5 & 9,5 & 48,2 & $42,5-48,5$ & \\
\hline & Vespertino & 19 & 47,9 & 11,5 & 50,3 & $42,7-53,1$ & \\
\hline \multirow{4}{*}{$\begin{array}{l}\text { Tempo de } \\
\text { graduação }\end{array}$} & $(1980,1990]$ & 8 & 50,1 & 3,2 & 50,2 & $47,8-52,3$ & \multirow{4}{*}{0,231} \\
\hline & $(1990,2000]$ & 33 & 47,8 & 10,7 & 50,1 & $44,1-51,4$ & \\
\hline & $(2000,2005]$ & 68 & 44,3 & 10,3 & 45,2 & $41,8-46,7$ & \\
\hline & $(2005,2012]$ & 71 & 45,7 & 9,8 & 47,4 & $43,5-48,0$ & \\
\hline \multirow{2}{*}{ Especialização } & Não & 11 & 41,5 & 11,4 & 43,5 & $34,8-48,2$ & \multirow{2}{*}{0,145} \\
\hline & Sim & 169 & 46 & 9,9 & 47,8 & $44,5-47,5$ & \\
\hline \multirow{2}{*}{$\begin{array}{l}\text { Número de } \\
\text { Vínculos }\end{array}$} & 1 & 134 & 45,9 & 9,9 & 47,6 & $44,2-47,6$ & \multirow{2}{*}{0,718} \\
\hline & 2 ou mais & 46 & 45,3 & 10,3 & 47,1 & $42,3-48,3$ & \\
\hline \multirow{3}{*}{$\begin{array}{c}\text { Tempo como } \\
\text { enfermeiro UTI }\end{array}$} & $(0,5]$ & 92 & 46 & 9,7 & 48,3 & $44,0-48,0$ & \multirow{3}{*}{0,014} \\
\hline & $(5,10]$ & 57 & 43,2 & 10,8 & 43,1 & $40,4-46,0$ & \\
\hline & $(10,50]$ & 31 & 49,7 & 8,2 & 51,3 & $46,8-52,6$ & \\
\hline \multirow{3}{*}{$\begin{array}{l}\text { Remuneração } \\
\text { mensal (faixa) }\end{array}$} & Até 3 mil & 34 & 43,3 & 9,8 & 44,5 & $40,0-46,6$ & \multirow{3}{*}{0,052} \\
\hline & De 3,001 a 5 mil & 117 & 47,1 & 9,7 & 49,2 & $45,3-48,8$ & \\
\hline & Mais de 5001 & 29 & 43,3 & 11 & 46,1 & $39,3-47,3$ & \\
\hline \multirow{2}{*}{$\begin{array}{c}\text { Leitos por } \\
\text { enfermeiro }\end{array}$} & Até 8 & 112 & 45,9 & 10 & 47,3 & $44,1-47,8$ & \multirow{2}{*}{0,7538} \\
\hline & Mais 8 & 68 & 45,4 & 10,2 & 47,1 & $43,0-47,9$ & \\
\hline \multirow{2}{*}{$\begin{array}{l}\text { Procedimentos de } \\
\text { alta complexidade }\end{array}$} & Não & 32 & 45,8 & 10,2 & 48,9 & $42,3-49,3$ & \multirow{2}{*}{0,9798} \\
\hline & Sim & 148 & 45,7 & 10 & 47,2 & $44,1-47,4$ & \\
\hline \multirow{2}{*}{ Carga de trabalho } & $<40 \mathrm{~h}$ & 122 & 45,9 & 10,1 & 47,6 & $44,1-47,7$ & \multirow{2}{*}{0,793} \\
\hline & $>40 \mathrm{~h}$ & 58 & 45,5 & 10 & 47,1 & $42,9-48,0$ & \\
\hline
\end{tabular}


Continuação Tabela 13

Tabela 13 - Associação entre o escore do SF-CM e variáveis sociodemográficas e de trabalho dos enfermeiros e dos hospitais. São Paulo, 2012.

\begin{tabular}{clccccccc}
\hline \multicolumn{1}{c}{ Variável } & \multicolumn{1}{c}{ Grupo } & n & Média & DP & Mediana & IC & Valor de \\
& & & & & & I - S & p \\
\hline \multirow{3}{*}{ Eventos científicos } & 0 & 36 & 45 & 10 & 45,5 & $41,7-48,2$ & \\
& 1 a 4 & 131 & 46,4 & 9,3 & 47,8 & $44,8-48,0$ & 0,235 \\
& 5 ou mais & 13 & 41,7 & 15,7 & 46,9 & $33,1-50,2$ & \\
& Centro & 47 & 45,4 & 9 & 46,9 & $42,8-48,0$ & \\
& Leste & 39 & 43,3 & 11,1 & 44 & $39,8-46,8$ & \\
Zona municipal & Norte & 18 & 50,7 & 6,5 & 51,4 & $47,7-53,7$ & 0,138 \\
& Oeste & 14 & 46 & 10,4 & 49,5 & $40,6-51,5$ & \\
& Sul & 62 & 46,1 & 10,5 & 49,1 & $43,4-48,7$ & \\
\hline \multirow{2}{*}{ Tipo de Hospital } & Filantrópico & 28 & 42,5 & 9,7 & 42 & $38,9-46,1$ & \\
& Privado & 130 & 46,2 & 10 & 47,9 & $44,5-47,9$ & 0,156 \\
& Público & 22 & 47,4 & 10,3 & 49,6 & $43,0-51,7$ & \\
\hline
\end{tabular}

$\mathrm{Na}$ Tabela 13, observamos que no $\mathrm{SF} 12-\mathrm{CM}$, as variáveis estatisticamente significativas foram idade (p 0,007), tempo de atuação como enfermeiro na UTI $(p 0,01)$ e remuneração salarial $(p=0,052)$.

A seguir apresentamos os dados obtidos com a correlação entre QVRS e condições de trabalho, ou seja, as correlações dos instrumentos SF-12 e NWI-R. Os dados da Tabela 14, a seguir, referem-se dados de correlação entre o NWI-R e os componentes físico e mental do SF-12.

Tabela 14 - Coeficientes de correlação entre o NWI-R e os componentes do SF-12. São Paulo, 2012.

\begin{tabular}{lcccc}
\hline \multicolumn{1}{c}{ Escore } & \multicolumn{2}{c}{ SF12-CF } & \multicolumn{2}{c}{ SF12-CM } \\
& $\mathbf{r}^{2}$ & valor de $\mathbf{p}$ & $\mathbf{r}^{\mathbf{2}}$ & valor de $\mathbf{p}$ \\
\hline NWI-R & $-0,249$ & 0,001 & $-0,344$ & $<0,001$ \\
NWI_R autonomia & $-0,221$ & 0,003 & $-0,287$ & $<0,001$ \\
NWI_R controle & $-0,235$ & 0,001 & $-0,339$ & $<0,001$ \\
NWI_R relação & $-0,183$ & 0,014 & $-0,252$ & 0,001 \\
NWI_R suporte & $-0,256$ & 0,001 & $-0,314$ & $<0,001$ \\
\hline
\end{tabular}


$\mathrm{Na}$ Tabela 14, percebe-se que para todos os itens e domínios do NWI-R o valor de $p$ é significativo estatisticamente, o que demonstra correlação com os domínios físico e mental do SF-12, porém, as variáveis do NWI-R são fracamente correlacionadas com o SF-CF e um pouco melhor com o SF-CM, indicando associação, contudo, fraca ou relativamente fraca.

Neste estudo adotou-se como classificação para a intensidade da correlação linear, ou seja, qual é a qualidade do ajuste dos dados à reta de regressão os seguintes valores:

- $0<|r|<0,3$, correlação muito fraca, provavelmente a relação matemática se afasta dos dados

- $0,3 \leq|r|<0,6$ correlação relativamente fraca

- $0,6 \leq|r|<1$ dados estão fortemente correlacionado. 


\subsection{ANÁLISE DE REGRESSÃO LINEAR MÚLTIPLA}

Inicialmente, foi feita uma modelagem múltipla incluindo todas as variáveis que apresentaram valor do $p \leq 0,20$. A lista das variáveis selecionadas para a regressão linear com os respectivos valores de p está apresentada na Tabela 15, para os SF-CF, SF-CM e NWI-R, respectivamente.

Tabela 15 - Lista de variáveis candidatas aos modelos de regressão linear múltipla para os componentes físico e mental do SF-12 e NWI-R por ordem decrescente de significância. São Paulo, 2012.

\begin{tabular}{l|c}
\hline \multicolumn{1}{c}{ Variáveis por componente } & Valor de p \\
\hline Componente Físico & 0,08 \\
Tipo de hospital & 0,05 \\
Ano de graduação & 0,01 \\
Sexo & 0,014 \\
NWI_R Relação & 0,004 \\
Leitos por enfermeiro & 0,003 \\
NWI_R Autonomia & 0,001 \\
NWI_R (todos os itens) & 0,001 \\
NWI_R Controle & 0,001 \\
NWI_R Suporte & \\
\hline Componente Mental & 0,15 \\
Tipo de hospital & 0,14 \\
Especialização & 0,13 \\
Zona do município & 0,05 \\
Remuneração salarial & 0,01 \\
Tempo de enfermeiro na UTI & 0,001 \\
Idade & 0,001 \\
NWI_R Relação & $<0,001$ \\
NWI_R Autonomia & $<0,001$ \\
NWI_R (todos os itens) & $<0,001$ \\
NWI_R Controle & $<0,001$ \\
NWI_R Suporte & 0 \\
\hline
\end{tabular}

Observa-se na Tabela 15 a entrada das variáveis no modelo de regressão por ordem decrescente para o SF-CF, SF-CM e NWI-R para o 
total dos itens e para os domínios, todas atendendo o critério de possuírem um $\mathrm{p}<0,20$.

A seguir, apresentamos as Tabelas 16 e 17 com os resultados da análise de regressão linear múltipla para o SF-CF e SF-CM.

Tabela 16 - Regressão linear múltipla para o componente físico do SF - $12^{*}$. São Paulo, 2012.

\begin{tabular}{|c|c|c|c|c|c|}
\hline Variável & $\begin{array}{c}\text { Coeficiente } \\
\beta\end{array}$ & P - valor & VIF & $\mathbf{R}^{2}$ & $R^{2} a j / D W$ \\
\hline Intercept & 3077,8 & $P<0,01$ & & & \\
\hline Sexo masculino & 241,0 & 0,03 & 1,0 & & \\
\hline Idade & 4,5 & 0,65 & 1,4 & & \\
\hline $\begin{array}{l}\text { Hospital privado } \\
\text { Hospital público }\end{array}$ & $\begin{array}{l}-68,2 \\
-154,9\end{array}$ & $\begin{array}{l}0,71 \\
0,47\end{array}$ & 1,1 & & \\
\hline $\begin{array}{l}\text { Tempo de graduação } \\
\text { (anos) }\end{array}$ & $-17,5$ & 0,16 & 1,4 & & \\
\hline $\begin{array}{l}\text { Leitos por enfermeiro } \\
(>8)\end{array}$ & $-251,6$ & 0,07 & 1,3 & & \\
\hline NWI - autonomia & $-18,0$ & 0,94 & 2,8 & & \\
\hline NWI - controle & 15,0 & 0,96 & 3,2 & & \\
\hline NWI - relação & $-54,8$ & 0,72 & 2,0 & & \\
\hline NWI - Suporte & $-207,8$ & 0,72 & 6,0 & & \\
\hline $\begin{array}{l}\text { Estabilidade do } \\
\text { modelo }\end{array}$ & & & & 0,128 & $0,076 / 1,868$ \\
\hline Intercept & 3040,8 & $<0,01$ & & & \\
\hline Sexo masculino & 257,2 & 0,02 & 1 & & \\
\hline $\begin{array}{l}\text { Leitos por enfermeiro } \\
\text { (> } 8 \text { leitos) }\end{array}$ & $-193,2$ & 0,07 & 1,1 & & \\
\hline NWI_suporte & $-290,6$ & $<0,01$ & 1,1 & & \\
\hline
\end{tabular}

A Tabela 16 nos mostra que, quando a regressão estabilizou o modelo para o SF - CF, permaneceram no modelo final da regressão linear múltipla como variáveis preditoras a variável sexo, leitos por enfermeiro e o domínio suporte - NWI - R.

Os dados da Tabela 16 nos mostram que ser do sexo masculino acrescenta 257,2 pontos na melhoria da sua QVRS (componente físico), 
cuidar de mais que oito leitos por enfermeiros, diminui 193,2 pontos no componente mental da sua QVRS, entretanto, ao analisarmos a percepção das condições de trabalho dos enfermeiros de UTI nota-se que o escore do NWI-R suporte diminui 290,6, indicando melhores condições em relação ao suporte organizacional no trabalho em UTI.

Entretanto, cabe ressaltar que a diminuição do escore da SF-12 independente do domínio, indica piora da condição da QVRS. Contudo, menores escores do NWI-R para o total dos itens ou para os domínios, indicam que existem atributos que favorecem uma boa prática de enfermagem. Neste caso, a QVRS no domínio CF é diminuída pelo aumento do número de leitos por enfermeiro mesmo diante de condições de suporte organizacional adequadas na UTI.

Os valores de VIF indicam que não houve colinearidade entre a variável dependente e a independente neste modelo, por serem próximos de 1. Já o valor do $R^{2}$ ajustado, explica $8 \%$ da variabilidade através das variáveis que permaneceram no modelo final por causa da correlação fraca, porém, estatisticamente significativa.

No Gráfico 3, abaixo se observa o modelo final da regressão linear do CF e suas variáveis preditoras. A média do CF- SF12 estimada pelo modelo, fixando as referências (sexo feminino e até 8 leitos por enfermeiro) e variando o escore do domínio Suporte - NWI. 
Gráfico 3. Distribuição do modelo final de regressão para o CF fixando as referências sexo feminino e leitos por enfermeiro até oito, com intervalo de confiança de 95\%. São Paulo, 2012.

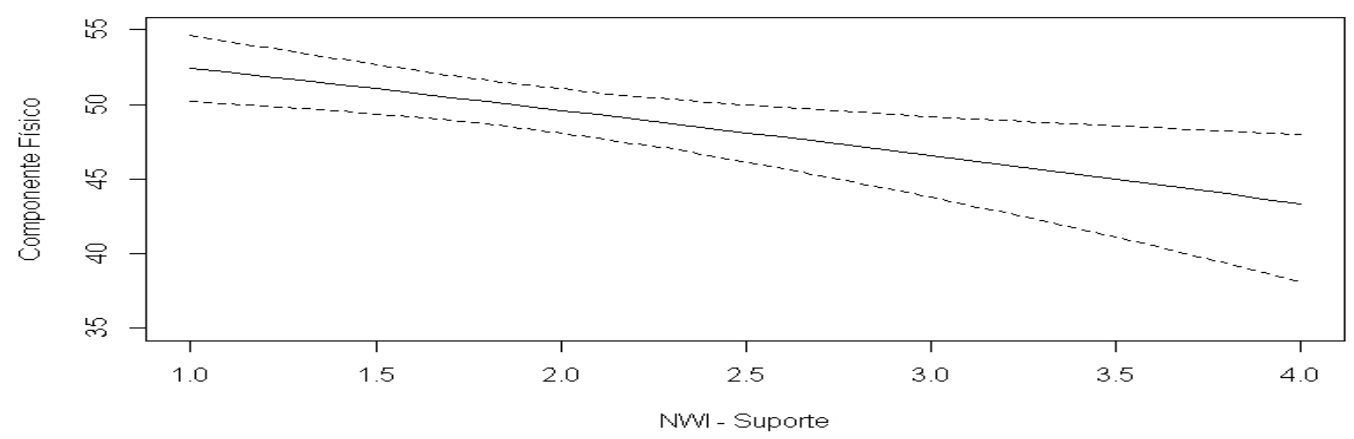

No Gráfico 3, observa-se que quanto maior o escore do NWI-R suporte organizacional, pior o componente físico da QVRS para enfermeiros do sexo masculino e que cuidam de mais que oito leitos.

$\mathrm{Na}$ Tabela 17, observamos que a estabilidade da regressão para o modelo com SF - CM, entrando com todas as variáveis com $p \leq 0,20$, as variáveis preditoras no modelo final foram a idade e o domínio controle sobre o ambiente do NWI - R. 
No Gráfico 4, abaixo, se observa o modelo final da regressão linear do CM e suas variáveis preditoras. A média do CM SF12 estimada pelo modelo fixando a idade média dos enfermeiros (35,6 anos) e variando o escore do domínio NWI-R Controle.

Gráfico 4. Distribuição do modelo final de regressão para o $\mathrm{CM}$ fixando a idade média dos enfermeiros e variando o escore NWI-R- Controle, com intervalo de confiança de 95\%. São Paulo, 2012.

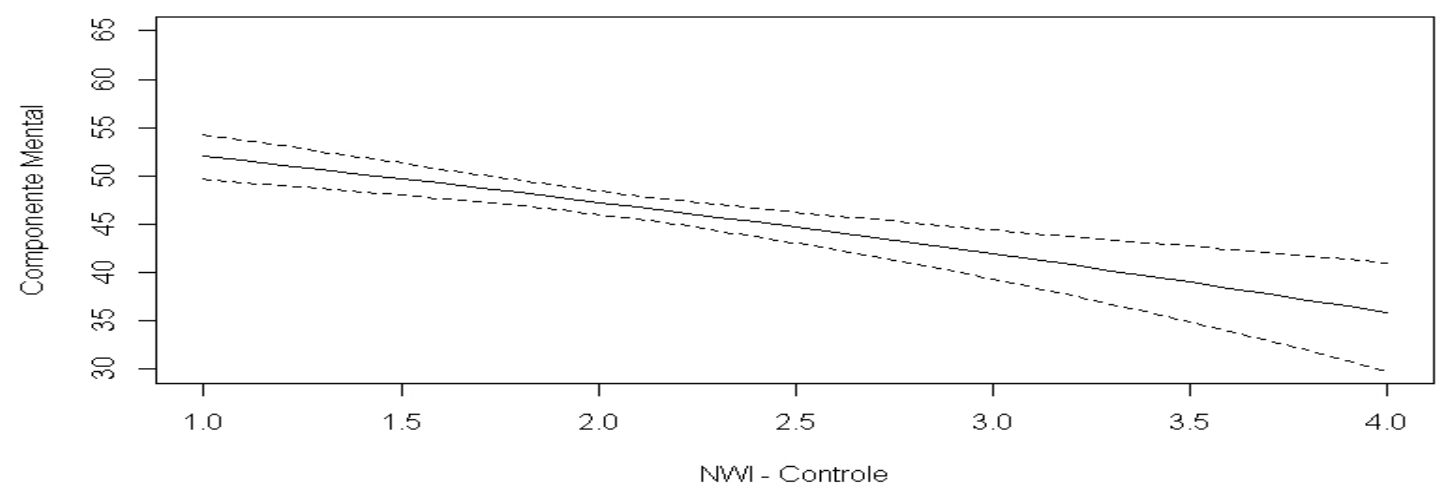

No Gráfico 4, observamos que conforme se aumenta o escore do NWI-R-controle, piora o escore da QVRS para o componente mental de enfermeiros com idade média de 35, 6 anos.

Já no Gráfico 5, observa-se a média do CM SF-12 estimada pelo modelo fixando o escore médio do domínio NWI-R- Controle e variando a idade dos enfermeiros. Vejamos a seguir. 
Gráfico 5. Distribuição do modelo final de regressão para o $\mathrm{CM}$ fixando o escore médio do NWI-R-Controle e variando a idade dos enfermeiros, com intervalo de confiança de 95\%. São Paulo, 2012.

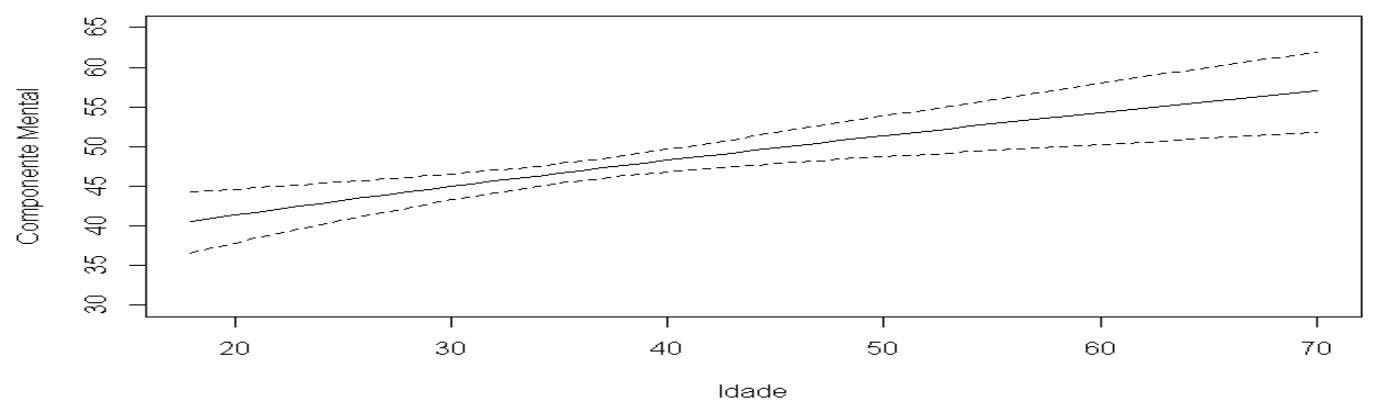

No Gráfico 5, observamos que com o aumento da idade dos enfermeiros da UTI aumenta-se o escore do CM da QVRS.

Para avaliar a homogeneidade da variância do modelo de regressão para o SF - CF foi aplicado o teste de Levene. O teste confirma que a variância entre os grupos formados para as variáveis "Sexo" e "Leitos por enfermeiro" são semelhantes (valor de F 1,6429 e PR (>F) 0,1812). $O$ teste não permite sua aplicação em variáveis contínuas apenas categóricas por isso não foi aplicado ao $\mathrm{CM}$.

No Anexo IV, está apresentada a análise dos resíduos dos modelos finais de regressão. Os resíduos nada mais são que o cálculo para o erro na previsão de nossos dados da amostra. Considerando que o erro aleatório ocorrerá, assumimos que esse erro é uma estimativa do verdadeiro erro aleatório na população, não apenas o erro na previsão de nossa amostra. $O$ erro na população que estamos estimando é distribuído com uma média de 0 e uma variância constante. Os Gráficos 6 e 7 (anexo IV) apresentam a análise dos resíduos segundo o modelo final para o SF 12 (CF e CM). Os erros apresentam aderência à curva normal, com a sequência esperada, indicando homocedasticidade, ou seja, o modelo apresentado para o SF 12 e NWI-R não apresenta vieses. 
Discussãa 


\section{DISCUSSÃO}

Este estudo teve como objetivo principal avaliar a QVRS e as condições de trabalho dos enfermeiros de UTI do município de São Paulo. Para tanto, foram avaliadas as características sociodemográficas, profissionais e trabalho dos enfermeiros, as condições de trabalho dos enfermeiros através do Nursing Work Index- R e QVRS com o instrumento SF 12 e seus componente. Atendendo a sequência dos objetivos do estudo, apresentamos a discussão dos resultados a seguir.

Em relação à caracterização dos hospitais (Tabela 5), observa-se a predominância $(72,2 \%)$ dos hospitais privados, o que vai de encontro com a realidade brasileira quando se trata de tratamento intensivo, ou seja, maior quantidade de leitos disponíveis no setor privado de saúde. Já para a disposição dos hospitais, em termos de localização geográfica, a maioria deles encontrava se nas zonas sul e leste, com percentual de $27,8 \%$ cada. $O$ que já era esperado por conta da facilidade de acesso e maior concentração de hospitais, principalmente na zona sul.

Quanto ao porte dos hospitais, atendendo aos critérios de inclusão do estudo, observa-se que a maioria era de grande porte, $72,2 \%$, ou seja, com mais de 150 leitos. Algumas instituições participantes contam com mais de 500 leitos de internação, como é o caso das instituições filantrópicas.

Os hospitais que possuíam duas ou mais UTIs também possuíam atendimento intensivo geral e especializado em cardiologia ou neurologia. Entretanto, a metade dos hospitais possuía apenas uma unidade (50\%) com atendimento geral. Uma instituição possuía seis UTIs sendo, 02 cardiológicas, duas neurológicas e duas gerais, totalizando 218 leitos de UTI, sendo considerada uma das maiores instituições da América do Sul. 
$\mathrm{Na}$ análise das características das UTIs (Tabela 6), observa-se que o percentual das UTIs com até 10 leitos corresponde a $35,4 \%$ e UTls com 11 a 20 leitos, perfazendo $38,8 \%$. As menores UTIs possuíam 10 leitos e a maior 86 leitos, contudo observa-se que a média de leitos entre as 31 UTIs do estudo foi de 20 leitos.

Quanto ao tipo de atendimento intensivo, predominantemente o atendimento era geral $(71 \%)$ e em relação à proporção dos leitos por enfermeiro, nota-se que a maioria das UTIs atendia a RDC $n^{\circ} 7$ de 2010 (vigente no momento) quanto à proporção ou fração de leitos na UTI, 54,9\% das unidades apresentava uma relação de 5 a 8 leitos por enfermeiro (Brasil, 2010).

Os resultados corroboram com os dados identificados pelo censo de UTIs brasileiras 2010, realizado pela AMIB, onde identificaram um total de 25.367 leitos em 2342 UTIs. Observaram predominância de UTI adulto $68,4 \%$, na rede privada $39,5 \%$ e na região sudeste $52,7 \%$. Quanto ao perfil de distribuição de UTIs, 58,3\% dos hospitais possuíam apenas uma unidade e $26,6 \%$ duas. Já para o número de leitos, 35\% possuíam de 6 a 10, 27,8\% de 11 a 20, 15,1\% de 21 a 30 e 22,1\% com mais de 30 leitos (AMIB, 2010).

Em relação à realização de procedimentos de alta complexidade na unidade como atendimento a pós-operatório de grandes cirurgias, intervenções a beira leito como monitorização hemodinâmica, realização de traqueostomia, procedimentos hemodialiticos, passagem de cateter de PIC entre outros procedimentos, $80,7 \%$ das UTIs executavam tais procedimentos. Os hospitais que não realizavam estas intervenções transferiam o paciente para um hospital especializado que permitisse tal monitorização ou terapêutica. Ressalta-se a importância da participação do enfermeiro diante destes eventos, como detentor de conhecimento especializado, embasamento científico e formação diferenciada dos demais membros da equipe de enfermagem. 
A necessidade de capacitação profissional dos enfermeiros em UTI é essencial, principalmente por causa dos inúmeros procedimentos especializados realizados no setor e pela gravidade dos pacientes. A competência técnica científica deve ser atualizada e baseada em conceitos teóricos sólidos. While (1994) destaca a importância de o enfermeiro ser competente na sua prática assistencial. Para o autor, o conceito de competência inclui conhecimento, habilidade, atitude, performance e nível de suficiência no trabalho.

A amostra foi composta por 180 enfermeiros $(59,4 \%)$ dos 303 enfermeiros que trabalham nas 31 UTIs dos 18 hospitais participantes do estudo. Na caracterização dos enfermeiros (Tabela 7), percebe-se que historicamente existe uma predominância do sexo feminino $(68,9 \%)$ na profissão (Espírito Santo, Oguisso, Fonseca, 2011). Apresentavam-se com uma diferença pequena em relação ao estado civil, onde $47,2 \%$ dos enfermeiros eram solteiros e 43,3\% casados. Eram católicos (64,9\%), trabalhavam a noite $(40 \%)$, possuíam apenas um vínculo empregatício $(74,4 \%)$, especialistas $(93,9 \%)$, cumpriam uma carga de trabalho menor que 40 horas semanais e executava procedimentos de alta complexidade à beira leito em sua prática diária $(72,2 \%)$.

A média de idade era de 35,6 anos, com tempo de graduação médio de 8,9 anos e 6,6 anos de experiência em UTI. Participaram de cursos de extensão profissional numa média de 2,4 eventos no último ano e possuíam renda média de $R \$ 4.171,00$.

Os resultados vão de encontro aos achados de outros estudos que caracterizam os enfermeiros. Destaca-se apenas a participação em cursos de extensão, em que $20 \%$ não participaram de nenhum evento, porém, dois enfermeiros participaram de 36 cursos de extensão no último ano. Outros cursos destacados foram o de passagem de PICC e ACLS. A maioria das instituições participantes oferece cursos de extensão como meio de atualização profissional para seus colaboradores alguns em caráter obrigatório outros não. 
A questão da idade dos profissionais pode repercutir na sua dinâmica de trabalho e muitas vezes interferir nos resultados. O'Kane (2011) em seu estudo, investigando enfermeiros recém formados em UTI, baseado nos relatos de enfermeiros com mais experiência, identificou que entre as enfermeiras com pouca experiência em UTI percebeu-se um estado de ansiedade em relação a administração do tempo, das responsabilidades e na socialização no ambiente de trabalho. Destaca-se ainda que a competência baseada na prática, ou seja, o tempo de experiência evidenciado em profissionais com mais idade, seja altamente importante para registros efetivos e prevenção de implicações legais futuras.

Santos (2004) destaca em seu estudo realizado com 158 enfermeiros de UTI que, ao avaliar as demandas de atenção dos enfermeiros observou-se que os enfermeiros com idade até 29 anos referiram maior demanda para as situações burocráticas e os enfermeiros com idade de 30 a 39 anos apontaram as situações como falta de oportunidade de falar francamente sobre problemas da unidade com outras pessoas que nela trabalham com a situação de maior demanda de atenção.

Com isso, ressalta-se que a percepção de trabalho de enfermeiros mais jovens pode ser diferente dos enfermeiros com mais idade e tempo de experiência profissional. O conceito de trabalho na UTI envolve um trabalho assistencial e burocrático ao mesmo tempo, envolve uma equipe multiprofissional, o paciente e seus familiares, exigindo muito da capacidade do enfermeiro em atender múltiplas e diferentes demandas na sua prática diária.

O tempo de experiência profissional encontrado foi de nove anos em média, de graduação em enfermagem e de 6,6 anos de experiência em UTI pode indicar que enfermeiros menos experientes podem estar mais expostos ao comprometimento de sua QVRS. Clarke (2007) conclui em seu estudo em 11.516 enfermeiros de 188 hospitais da Pensilvânia que enfermeiros com menos de cinco anos de formação são mais susceptíveis a 
ferimentos cortantes, principalmente relacionando às condições do ambiente de trabalho.

Bogaert, Clark, Vermeyen, Meulemans, Heyning (2010) também contemplam em seu estudo que a experiência de trabalho em unidades cirúrgicas, clínicas e UTI é um fator que influencia as condições de trabalho.

Quanto à especialização dos enfermeiros, a maioria possuía o título na área de UTI, entretanto, observou-se que muitos cursavam docência em enfermagem. Já a remuneração, a média salarial apresenta-se consideravelmente boa por causa das variações que encontramos. $O$ menor salário encontrado foi de $R \$ 2.150,00$ e o maior $R \$ 8.500,00$ (com duplo vínculo). Atualmente, os profissionais que atuam na UTI necessitam ter experiência profissional prévia e de preferência com titulo de especialista na área de UTI, cardiologia ou emergência. O mercado de trabalho hoje busca este tipo de perfil para o enfermeiro de UTI, devido aos inúmeros procedimentos e complexidade do cuidado prestado, o que otimiza tempo de treinamento e diminuição de custos.

A especialização dos enfermeiros é percebida como um complemento da formação acadêmica e pode acrescentar conhecimento, o que favorece uma boa prática de enfermagem. Santos (2004) identificou diferenças na percepção das demandas de trabalho de enfermeiros de UTI para profissionais enfermeiros com e sem titulo de especialização nas situações que envolviam um conhecimento especializado (atendimento a parada cardíaca) e no relacionamento com paciente (falta de oportunidade de expressar sentimentos em relação aos pacientes). Fica claro que a percepção das necessidades na UTI é diferenciada em relação à capacitação profissional dos enfermeiros.

Destacamos a predominância do sexo feminino na amostra, a carga de trabalho cumprida na semana e a dinâmica de trabalho na UTI. Podemos inferir que mesmo cumprindo uma carga de trabalho menor que 40 horas semanais, a mulher não encerra suas atividades ao término do 
plantão. Muitas vezes esta jornada de trabalho é substituída por afazeres domésticos e cuidado aos familiares.

Um estudo exploratório realizado por Portela, Rotenberg, Waissmann (2005) avaliou a associação de carga de trabalho profissional e doméstico com doenças e queixas sobre o sono e falta de tempo em enfermeiras assistenciais de um hospital público no Rio de Janeiro. Os resultados identificaram que longas jornadas profissionais se associaram a relatos de tensão, ansiedade e insônia, à falta de tempo para o lazer ou descanso. No entanto, longas jornadas domésticas se associaram a menor tempo para os filhos, falta de tempo para si e comprometimento da saúde.

Spindola (2000) também corrobora com a sobrecarga de trabalho para a mulher, destacando ainda, a condução desta situação ao estresse emocional.

O perfil dos enfermeiros encontrados nas UTls do estudo mostra uma tendência assistencial no Brasil. Estar diretamente relacionado ao cuidado, porém, na forma de gestor assistencial, diferente do gestor administrativo (supervisão ou gerencia), o que permite uma visão das necessidades biopsicosociobiológica do paciente crítico sem interferir na qualidade do cuidado.

Martins, Robazzi, Marziale, Garanhani, Haddad (2009) em uma pesquisa realizada no Paraná em um hospital universitário destaca que na ótica dos enfermeiros gerenciamento em UTI significa prestar cuidados ao paciente, administrar a assistência de enfermagem e administrar a equipe de saúde.

Neste contexto da dinâmica de trabalho, o enfermeiro, passa a ser um articulador assistencial no cuidado intensivo. É envolvido com o cuidado direto, com a equipe multiprofissional e ao mesmo tempo mantém um controle sobre o ambiente de trabalho, fundamental para que os processos do cuidado se desenvolvam da melhor maneira possível. 
Quantos aos demais profissionais encontrados nas UTIs do estudo e sua relação com números de pacientes, observa-se que, para o técnico de enfermagem (TE) a proporção de pacientes em 100\% das UTIs era de dois para cada TE. Quanto ao número de médicos intensivistas, observou-se que a menor proporção foi de um médico para quatro pacientes e a maior, um para 14 pacientes. Destaca-se que, nos hospitais filantrópicos além do chefe de plantão (intensivista) encontravam-se também residentes na unidade.

Analisarmos o perfil sociodemográfico e de trabalho dos enfermeiros de UTI nos subsidia a entendermos o contexto da QVRS destes profissionais.

Na Tabela 8, os enfermeiros classificaram seu estado de saúde geral como boa e não apresentavam limitações físicas no trabalho ou em outras atividades regulares e não realizaram menos tarefas do que gostariam. Em relação ao impacto emocional no trabalho ou em alguma atividade diária regular, a maioria também não deixou de realizar as tarefas que gostariam, deixaram de trabalhar ou de fazer quaisquer atividades com o mesmo cuidado habitual. Destaca-se que 46,6\% dos enfermeiros referiram que a dor não interferiu de maneira alguma no trabalho ou em outras atividades. Na avaliação de quanto do seu tempo a sua saúde física ou problemas emocionais interferiram nas suas atividades sociais as respostas eram pouco divergentes apresentando-se para os enfermeiros como "alguma parte do tempo" (28,3\%), "uma pequena parte do tempo" (28,3\%) e "nenhuma parte do tempo" $(27,8 \%)$.

Em relação ao sentir-se calmo ou tranquilo, $37,2 \%$ dos enfermeiros que a maior parte do tempo e 28,9\% com muita energia. Quanto ao sentirem-se desanimados e abatidos, os enfermeiros referiram apenas uma pequena parte do tempo (42,2\%). 
Diante destes resultados, observa-se que a QVRS dos enfermeiros de uma maneira geral é tida como boa. Entretanto, analisou-se a QVRS por dimensões do SF-12.

No contexto da UTI, o resultado relacionado à QVRS nos causa interesse principalmente, quando os associamos à segurança do trabalho do enfermeiro. A literatura identifica o aumento dos riscos de erros e iatrogenias, diante do comprometimento da QVRS dos profissionais, de inadequadas situações do ambiente ou do próprio trabalho.

$\mathrm{Na}$ análise dos domínios físico e mental da QVRS (Tabela 9), considerou-se que médias abaixo de 50 , baseados na população americana, indicam um comprometimento da QVRS (D'Amorim, 2011) e a melhor QV deveria apresentar escores próximos de 100 pontos e os piores próximos a zero, observa-se que o comprometimento da QVRS desses enfermeiros, ocorreu mais no CM para as dimensões saúde mental e aspectos sociais quando analisadas as frequências de respostas.

A dimensão aspecto social por sua vez, mede o impacto da saúde física e dos problemas emocionais nas atividades sociais. Desta forma, percebe-se que as múltiplas demandas da prática diária do enfermeiro na UTI, podem desencadear um comprometimento mental da sua QVRS impedindo o enfermeiro de interagir com o meio, com seus familiares e amigos, em função da carga de trabalho e da continuidade da jornada com trabalhos domésticos.

$\mathrm{Na}$ avaliação da distribuição das medidas descritivas agrupadas no CF e CM - SF-12 percebe-se que no CF, a dimensão aspectos físicos obteve uma média de $28,3 \mathrm{com}$ dp de 39,9 . No componente mental, as médias foram abaixo de 50 para os aspectos emocionais $(30,0 ; \mathrm{dp}=37,6)$ e para a dimensão vitalidade $(35,4 ; \mathrm{dp}=23,2)$. Apresentados também na forma gráfica (Gráfico 1). 
Os dados encontrados para a dimensão Vitalidade corroboram com os resultados encontrados no estudo que avaliou QVRS de profissionais de enfermagem e erros de medicação em UTI com média de 53,83 e dp=21,79 (Peliciotti, 2009).

Tanto os escores médios da dimensão aspectos físicos, vitalidade e aspectos emocionais são semelhantes aos resultados encontrados na investigação da QV de pacientes cardiopatas (Saccomann, Cintra , Gallani, 2010), reumatológicos (D’Amorin, 2001) e pneumopatas (Camelier, 2004). Podemos inferir que apesar dos enfermeiros, responderem que seu estado de saúde é bom (frequencia de respostas), quando analisados por dimensões, nos revelam uma condição bastante preocupante, a de possuírem condições semelhantes à de pacientes com diferentes patologias.

Estudos no Brasil, utilizando o instrumento SF-12 para avaliação da QVRS em enfermeiros são escassos na literatura em relação aos enfermeiros. Este fato limita a comparação dos escores médios encontrados nessa população. Entretanto outros estudos utilizando outros instrumentos avaliando a QV e a QVRS de profissionais da saúde podem ser encontrados.

As pesquisas no Brasil utilizando o instrumento SF-12 como instrumento estão relacionadas às investigações junto a paciente de diferentes patologias, como os estudos realizados por Andrade, Camelier, Rosa, Santos, Jezler, Silva (2007) com pacientes portadores de esclerose sistêmica progressiva, Camelier (2004) com pacientes portadores de DPOC, D’Amorin (2001) com pacientes reumatológicos, Aquino, Sun, Oliveira, Martins, Silva, Mattar (2009) com gestantes e violência sexual, Ribeiro (2011) avaliando a QVRS de idosos e Fleck et al (2002) com pacientes depressivos.

Estudo com trabalhadores de enfermagem em UTI utilizando o WHOQOL-bref demonstraram que a QV destes profissionais é baixa em todos os domínios considerando os valores de 0-100, com médias de 66,3 
para Relações Sociais, 60,8 para o domínio Psicológico, 53,1 para o Físico e 49,4 para o Meio Ambiente (Paschoa, Zanei, Whitaker, 2007). Outro estudo investigou a QV e a capacidade de trabalho dos enfermeiros em Taiwan em diferentes unidades de oito hospitais, utilizando também o WHOQOL-bref, onde os achados indicaram correlação estatisticamente significante entre a capacidade de trabalho e os domínios Ambiente, Físico, Psicológico e Social na avaliação da QV (Chiu et al, 2007).

Investigando a QV dos profissionais da saúde (enfermeiros, fisioterapeutas e nutricionistas) de um hospital universitário utilizando o WHOQOL-Bref, os resultados mostraram uma pior média para os enfermeiros no domínio Ambiente, de 58,29 $(11,44)$ quando comparados as demais profissões (Spiller, Dyniewicz, Slomp, 2008).

Outra pesquisa utilizando o SF-36 com 696 profissionais de enfermagem investigou a QVRS e as condições de trabalho, demonstrando que $22 \%$ destes profissionais trabalhavam em condições de alto desgaste, com diminuição dos escores médios do SF-36 para os domínios vitalidade, dor e saúde mental, o que condiz com os achados deste estudo, exceto a dor (Silva, Souza, Borges, Fisher, 2010).

Associando a QVRS dos enfermeiros às condições do ambiente de trabalho na UTI neste estudo, focamos condições relacionadas a turnos, horas semanais de trabalho, número de leitos por enfermeiros e as dimensões do NWI-R: autonomia, controle sobre o ambiente de trabalho, relação médico-enfermeiro e suporte organizacional.

Os dados apresentados no Gráfico 2, demonstram a distribuição das frequências de respostas para o NWI-R. Nota-se que o item "Tempo e oportunidade suficientes para discutir, com outros enfermeiros, os problemas relacionados aos cuidados do paciente" foi o único em que as respostas concordantes $(49,4 \%)$ e discordantes $(50,1 \%)$ foram aproximadamente equivalentes. Em todos os outros itens, mais de $60 \%$ dos enfermeiros concordaram total ou parcialmente com as afirmações contidas nos itens do 
NWI-R, o que parece identificar a existência de condições adequadas de trabalho nas UTIs onde atuavam. Alguns itens como "uma equipe de supervisores que dá suporte aos enfermeiros", "oportunidade de trabalhar em uma unidade altamente especializada", "os médicos e os enfermeiros possuem boas relações de trabalho" obtiveram mais de $85 \%$ de concordância de respostas entre os enfermeiros e os itens "o gerente de enfermagem é um bom administrador e líder" e "a designação de pacientes promove a continuidade do cuidado" obtiveram índices de mais de $80 \%$.

Estudos com o NWI-R, no Brasil, se restringem ao processo de tradução do instrumento para o português (Gasparino e Guirardello, 2009). Entretanto, o uso do instrumento pelo mundo vem aumentando progressivamente sendo aplicados nos Estados Unidos, na Europa e países asiáticos.

Gasparino, Guirardello e Aiken (2011) descreveram a validação da versão brasileira do NWI-R com 278 enfermeiros de três hospitais universitários do estado de São Paulo concluindo que o instrumento apresentou medida satisfatória para o total dos itens e para suas subescalas tornando-o valido e adaptado à cultura brasileira.

Um estudo realizado com 546 enfermeiros, de 42 unidades (clínica, cirúrgica e UTI) belgas utilizando o NWI-R revelou associação entre o tipo de unidade, o nível de satisfação e o burnout destes enfermeiros no domínio controle sobre o ambiente, destacando que unidades com alta complexidade de cuidado podem interferir na satisfação e risco de burnout destes enfermeiros. As médias encontradas para os escores do NWI-R demonstravam boas condições de trabalho em todas as unidades estudadas, indicavam ainda que a alteração no ambiente de trabalho possa repercutir diretamente sobre a dinâmica do serviço como um todo, não somente para os resultados relacionados ao paciente (Bogaert, Clark, Vermeyen, Meulemans, Heyning, 2010). 
Outro estudo com 462 enfermeiros de UTI gerais e especializadas avaliou a qualidade do relacionamento médico-enfermeiro e concluiu que é importante conhecer como esse fator pode afetar o ambiente de trabalho e os resultados assistenciais. A deterioração do relacionamento médicoenfermeiro pode aumentar a chance de erros com medicação por conta da falta efetiva de comunicação entre os profissionais. O autor reforça que um bom relacionamento interprofissional pode representar melhorias nos resultados de maneira bastante ampla, agregando qualidade aos mesmos (Manojlovich, 2007).

Os resultados deste estudo não indicaram nenhum achado importante do ponto de vista estatístico para o domínio relação médicoenfermeiro, mas sabemos que o relacionamento multiprofissional, com opiniões divergentes, necessidades diversas podem resultar em grandes conflitos, porém, se não houver uma sintonia entre a equipe de trabalho na UTI, a dinâmica de atendimento ao paciente crítico será fortemente afetada.

Entretanto, a literatura a importancia da manutenção de um bom relacionamento entre enfermeiros e médicos independente da unidade de trabalho como fator determinante da diminuição de conflitos, estresse e satisfação com o trabalho (Tabak, Koprak, 2007).

Os resultados apresentados corroboram com a maioria dos estudos, que reforçam que as condições do ambiente de trabalho podem afetar os profissionais envolvidos na prática assistencial na UTI, principalmente a sua QVRS e no desempenho profissional (Flyin, Aiken (2002), d'Errico et al (2006), ferreira, Griep, Fonseca, Rotenberg (2012), Rogers, Hwang, Scott, Aiken, Donges (2004), Santos (2004) e Aiken et al (2012) .

A literatura retrata consistentemente a relação do ambiente e as condições de trabalho, refletindo na qualidade do cuidado. Os aspectos relacionados ao risco de doenças, horas de trabalho, características dos hospitais, controle e segurança dos equipamentos envolvidos na assistência, 
complexidade de procedimentos realizados taxas de infecção podem afetar as condições de trabalho e consequentemente a QV desses trabalhadores (Clarke, 2007; Cummings, Hayduk, Estabrooks (2006); Hall, Doran (2007); Marziale, 2001).

Para manter a qualidade das pesquisas em saúde destacamos a importância de se utilizar instrumentos de medida, genéricos ou específicos, válidos e confiáveis.

Analisando a confiabilidade do instrumento NWI-R, realizou-se a análise da consistência interna do total dos itens e dos quatro domínios do NWI-R propostos por Aiken, Patrician (2000): autonomia, controle sobre o ambiente, relação médico/enfermeiro e suporte organizacional. Os resultados apresentados na Tabela 11 indicam um $\alpha=0,90$ para todos os itens e quando avaliado por domínio, o domínio autonomia apresentou um $\alpha=0,80$, controle sobre 0 ambiente $\alpha=0,80$, relação médico/enfermeiro $\alpha=$ 0,81 e o domínio suporte organizacional, um $\alpha=0,84$. O que permite avaliar o instrumento NWI-R como confiável haja vista os escores apresentados após análise do total dos itens e por domínios.

Os valores da consistência interna do NWI-R para o total dos itens e para seus domínios corroboram com os encontrados por Gasparino e Guirardello (2009) em seu estudo com $\alpha=0,95$ para o total dos itens, controle sobre 0 ambiente $\alpha=0,75$, relação médico/enfermeiro $\alpha=0,75$, domínio suporte organizacional $\alpha=0,75$ e um $\alpha=0,63$ para autonomia. Já no estudo desenvolvido por Aiken e Patrician (2000) obtiveram um $\alpha=0,96$ para o total dos itens, controle sobre o ambiente $\alpha=0,91$, autonomia $\alpha=0,85$, relação médico/enfermeiro $\alpha=0,84$ e o domínio suporte organizacional, um $\alpha=0,84$.

Diante dos escores obtidos na análise da confiabilidade do NWI$\mathrm{R}$, considera-se o instrumento confiável. Comparando com os resultados obtidos no estudo de tradução e adaptação cultural do instrumento realizado por Gasparino, Guirardello (2009), os resultados confirmam um coeficiente 
alfa satisfatórios para o total dos itens e para os domínios autonomia, controle sobre o ambiente e relações entre médico e enfermeiro e suporte organizacional. Hair, Tatham, Anderson, Black (2008), Pasqualli (1997) recomenda que o limite inferior aceitável seja de 0,70.

$\mathrm{Na}$ Tabela 11, apresenta-se a estatística descritiva dos escores dos instrumentos SF 12 e NWI-R. Para o instrumento SF 12, no CF o mesmo obteve-se média de 49,0, com dp=7,6 e intervalo de confiança (IC) de $95 \%$ de 47,8 a 50,0. Para o CM foi observada uma média dos escores de $46,0, d p=10$, mediana de 47,3 e IC $95 \%$ de 44,3 a 47,2 . Diante destes resultados podemos concluir que a QVRS dos enfermeiros de UTI deste estudo, possui quase todas as dimensões do SF 12 comprometidas, principalmente no $\mathrm{CM}$.

Para o instrumento NWI-R, a média observada para o total dos itens e para os domínios não variou muito, para o total dos escores uma média de 2,0 ( $\mathrm{dp}=0,5)$, domínio Autonomia 2,0 $(\mathrm{dp}=0,6)$, Controle sobre o ambiente 2,1 ( $d p=2,1)$, relação médico-enfermeiro 2,0 $(\mathrm{dp}=0,7)$ e suporte organizacional 2,1 ( $\mathrm{dp}=0,5)$, demonstrando que as percepções do ambiente de trabalho dos enfermeiros de UTI são adequadas a uma boa prática assistencial nas unidades estudadas.

Já na análise das associações entre os escore do SF 12 - CF (Tabela 12) revela-se a correlação do $C F$ com as variáveis sexo $(p=0,015)$, tempo de graduação $(p=0,057)$ e leitos por enfermeiro $(p=0,004)$. Esta correlação descreve que ser do sexo feminino, ter menor tempo de graduação, trabalhar em hospitais em que tenham menos leitos por enfermeiro contribui para uma pior QVRS no domínio CF. Pode-se inferir sobre estes achados, que o tempo de graduação agrega conhecimento profissional e uma melhor estrutura pessoal e profissional para lidar com situações da prática diária, o que não acontece com um enfermeiro com poucos anos de formado mesmo diante de menos leitos sob sua gestão, como este caso. Estes resultados corroboram com estudo realizado com 148 enfermeiros de sete UTI brasileiras sobre conduta e sentimentos diante de 
erros de medicação e um dos principais fatores destacados foi a falta de experiência profissional e a alta demanda de trabalho na unidade (Padilha, 2002)

Para a análise das associações descritiva do SF-12 - CM (Tabela 13) houve correlação para as variáveis: idade $(p=0,007)$, tempo como enfermeiro de UTI $(0,014)$, remuneração salarial $(p=0,052)$. Estes resultados consideram que enfermeiros mais jovens, com tempo menor de experiência em UTI, com menor remuneração salarial e dependendo da zona do município podem ter um comprometimento da sua QVRS no componente mental quando comparados aos demais enfermeiros.

Estes achados vão de encontro ao real cenário vivido na saúde, onde enfermeiros recém formados, mais jovens, encontram inúmeras dificuldades para se inserir no mercado de trabalho e por falta de experiência profissional acabam se submetendo a receber salários mais baixos, atuando na gestão de inúmeros leitos de pacientes gravemente doentes em busca de agregar conhecimento na sua carreira profissional.

Os resultados do estudo corroboram também com o estudo realizado com 478 enfermeiros utilizando o NWI-R, que concluiu que a variável idade influencia na percepção dos aspectos organizacionais, porém, não descarta a possibilidade de que enfermeiros mais jovens não tenham conhecimento da prática dos enfermeiros, quando comparados aos profissionais com mais experiência profissional, destacam-se os achados para baixos escores do NWI-R para enfermeiros mais experientes encontrados no domínio autonomia, controle sobre o ambiente e suporte organizacional, talvez esteja associado às inúmeras atividades que lhes são conferidos e pelo fato de terem maior conhecimento profissional (Hinno et al, 2009).

$\mathrm{Na}$ análise dos coeficientes de correlação entre os componentes do SF-12 (físico e mental) e o instrumento NWI-R (total dos itens e domínios) percebe-se que a correlação é relativamente fraca para o SF-CM e fraca 
para o SF-CF. Contudo, apresenta-se estatisticamente significativa (Tabela 14). Destacando-se uma melhor correlação do NWI-R com o CM quando comparado ao CF do SF-12.

Para identificarmos as possíveis associações foi realizada a análise de regressão linear com todas as variáveis com $p<0,20$ para o CF, CM e NWI-R.

$\mathrm{Na}$ regressão linear foi analisada a relação entre a variável dependente, QVRS - CF e CM (critério) e as várias variáveis independentes (preditoras). O objetivo desta análise é usar as variáveis independentes cujos valores são conhecidos para prever os valores da variável dependente (Hair et al, 2009). Neste caso, estimar o valor da variável dependente QVRS. Os pesos denotam a contribuição relativa das variáveis independentes para a previsão geral e facilitam interpretar suas relações com a variável dependente, neste estudo os pesos determinados para as variáveis independentes foram a determinação do valor de $p$ em $<0,20$.

Neste método de análise, inicialmente são colocadas todas as variáveis sociodemograficas, de trabalho e dos hospitais no modelo de regressão. Na Tabela 15, é apresentada a lista das variáveis que foram candidatas ao modelo de regressão linear para o instrumento SF-12 (CF e $\mathrm{CM}$ ) e para o NWI-R com seus respectivos valores de $\mathrm{p}$. Observa-se que todas as variáveis apresentadas na tabela apresentam diferenças significativas, ou seja, são menores que $p<0,20$.

A modelagem estatística foi realizada pela soma das diferenças quadradas entre a média e valores previstos da variável dependente para todas as observações, representando assim a quantia de melhoramento na explicação da variável dependente QVRS atribuível às variáveis independentes (Hair et al, 2009). 
Foi realizada a análise de regressão linear para o SF-12 CF e CM, com entrada de todas as variáveis com $p<0,20$ e estabilizando, com as variáveis preditoras (modelo final).

$\mathrm{Na}$ Tabela 16, são apresentados os dados da regressão linear multipla para CF-SF 12 e NWI-R. As variáveis preditoras para o modelo final foram sexo, proporção de leitos por enfermeiro e o domínio Suporte Organizacional do NWI - R.

$\mathrm{Na}$ análise das correlações das variáveis preditoras observa-se que para o sexo masculino acrescenta-se 257,2 pontos na melhoria do componente físico da sua QVRS, cuidar de mais que oito pacientes na UTI diminui 193,2 pontos no CM da sua QVRS. Para avaliação da percepção do enfermeiro em relação às condições do ambiente de trabalho na UTI, o escore diminui 290,6 pontos.

O acréscimo de pontos no escore do SF 12, CF ou CM, implica em melhoria da QVRS, entretanto, a diminuição nos escores do NWI-R indicam que os atributos no ambiente de trabalho permitem executar uma assistência com melhores condições.

Diante destes resultados, pode-se observar que a QVRS das mulheres para o CF é pior do que a observada nos homens, talvez pela jornada de trabalho que é estendida após a saída do hospital, dando continuidade aos afazeres domésticos e cuidado aos filhos. Esta extensão da jornada de trabalho pode refletir em alterações da saúde mental dos profissionais inseridos neste contexto. Embora, não foi o objetivo deste estudo a literatura nos revela que as alterações da QV dos profissionais de saúde pode resultar em quadros depressivos, rotatividade profissional (Rios, Barbosa, Belasco, 2010; Gomes, Lunardi-Filho, Erdmann, 2006).

Destaca-se ainda, a relação número de leitos por enfermeiro pioram a QVRS dos enfermeiros e o domínio suporte organizacional, diminuído melhoram os escores da QVRS. Entretanto, uma QVRS 
prejudicada, diante de um número de leitos aumentado, mesmo diante de um suporte organizacional adequado não significa que o enfermeiro desempenhe suas funções com qualidade, em função da complexidade do cuidado intensivo e da necessidade de redimensionamento de recursos materiais e humanos voltados à uma boa prática de enfermagem.

Os valores de VIF indicam que não houve colinearidade, ou seja, existe relação entre a variável dependente e as variáveis independentes. $O$ valor de $\mathrm{R}^{2}$ ajustado indica que cerca de $8 \%$ da variabilidade é explicada por essas variáveis, devido a uma fraca correlação.

No Gráfico 3, a média do CF- SF12 estimada pelo modelo final da regressão, fixou as caselas de referência (sexo feminino e até 8 leitos por enfermeiro) e variou o escore do domínio Suporte - NWI com isto observase que quanto maior o escore do NWI-R suporte piores as condições do ambiente de trabalho e piores as condições de QVRS para enfermeiros.

A ausência de um suporte organizacional para o enfermeiro de UTI pode comprometer sua QVRS e os resultados relacionados à sua assistência. Neste modelo o gênero em relação à enfermagem, o número de pacientes por enfermeiro podem interferir nas condições de trabalho, na percepção das necessidades e prioridades relacionadas ao cuidado crítico e sobretudo, nos resultados assistenciais.

Condições de trabalho comprometidas podem estar associadas à problemas de saúde e ao ambiente laboral devido a extensas jornadas de trabalho, a exposição de agentes de riscos, aumentando-se o índice de absenteísmo para os trabalhadores, além de interferir na qualidade da assistência prestada (Silva, Marziale, 2006).

Na Tabela 17, a análise de regressão linear para o CM-SF12 nos mostra que o modelo final as variáveis preditoras foram idade e o domínio controle sobre o ambiente do NWI-R. Observa-se que para cada ano de idade do enfermeiro acrescenta-se 31 pontos no escore mental da QVRS e 
melhorando o controle sobre o ambiente de trabalho na UTI, em 474 pontos, já que quanto menor o escore do NWI-R melhores são as percepções dos atributos para uma boa prática de enfermagem.

Ao interpretarmos esses achados, percebe-se que as condições de trabalho são favorecidas à prática na UTI, entretanto os enfermeiros que se beneficiam destas melhores condições são os enfermeiros mais velhos, que possuem um CM melhor quando comparados aos mais jovens.

No Gráfico 4, observamos que conforme se aumenta o escore do NWI-R-controle, piora-se o escore da QVRS para o componente mental de enfermeiros com idade média de 35,6 anos. Diante deste resultado podemos inferir que, o conhecimento adquirido ao longo dos anos pela prática e pela atualização profissional resulta em segurança na tomada de decisão e implica em melhor controle sobre o ambiente de trabalho, em melhores condições de relacionamento multiprofissional e principalmente em melhores resultados para o paciente.

Já no Gráfico 5, observa-se a média do CM SF12 estimada pelo modelo fixando o escore médio do domínio NWI-R-Controle e variando a idade dos enfermeiros, nota-se que o aumento da idade melhora os escores do componente mental da QVRS dos enfermeiros. A literatura confirma esta relação. $O$ enfermeiro com mais experiência profissional e mais idade detém um melhor controle sobre seu ambiente de trabalho.

Chiu, Wang, Lu, Pan, Kumashiro, IImarien (2007) destacam em seu estudo com 1534 enfermeiros de oito hospitais chineses, em que avaliaram a evolução da habilidade profissional e QV de enfermeiros de unidades clínicas, que os enfermeiros mais jovens necessitam de um esforço mental maior na sua prática de trabalho quando relacionados aos enfermeiros mais velhos.

A maturidade pessoal e profissional agrega melhores condições de reflexão na prática diária de enfermagem, subsidia uma tomada de 
decisão mais coesa e precisa, além de interferir diretamente sobre os resultados.

Melhorar as condições de trabalho na enfermagem tem sido foco de estudos pelo mundo em busca de uma melhoria profissional. Um estudo realizado em hospitais públicos da Austrália, em unidades cirúrgicas e clinicas, utilizando o NWI-R, destacou a importância da liderança em enfermagem na inter relação com a sua equipe de trabalho, de maneira que os problemas da prática sejam discutidos e por meio de um feedback resultem em soluções rápidas e otimizadas, o que permitiu uma melhoria na satisfação no trabalho e com a enfermagem (Duffield, Roche e Stasa, 2010).

O perfil de trabalho do enfermeiro na UTI como gestor assistencial do cuidado não limita a sua capacidade no processo de tomada de decisão em relação ao paciente crítico. Muito pelo contrário, ele necessita de aprimoramento educacional e profissional para lidar com situações onde seu colaborador não detém capacitação técnica científica suficiente, como os TE, profissional predominantemente encontrado nas UTIs do estudo. O perfil das UTIs visitadas atende essas características, um enfermeiro assistencial e TE, entretanto, a falta de bases científicas sólidas pode acarretar em aumento de custos, dias de internação, horas de trabalho e no comprometimento da QVRS do gestor do cuidado, no caso o enfermeiro, pela sobrecarga de trabalho ou acúmulo de funções.

Os resultados deste estudo corroboram com a literatura, em relação ao número de pacientes por enfermeiro e o ambiente de trabalho influenciando nos resultados relacionados ao cuidado do enfermeiro, aumentando as chances de complicações e óbitos diante de uma demanda aumentada decorrente da deterioração da sua QVRS. Esses resultados também são influenciados pelo nível educacional dos enfermeiros já considerado em outros estudos realizados como fator determinante da qualidade do cuidado dos enfermeiros e relacionado com a taxa de mortalidade, um indicador de qualidade assistencial (Aiken et al, 2011; Aiken et al 2008; Aiken, Clarke, Sloane, Lake ,2009). 
A mudança de pensamento dos gestores de saúde não é influenciada apenas pela promoção de QV para seus colaboradores, a questão de suporte é essencial para uma prática mínima de erros e custos. Com isto destacam-se os programas de melhorias profissionais nos serviços de saúde.

A análise dos resíduos mostra que no modelo final do SF-12 (CF e CM) realizada com a média dos quadrados e NWI-R, os dados apresentam aderência à curva normal, com a sequência esperada, indicando homocedasticidade, ou seja, a variância dos termos de erro aparece constante no intervalo de valores de uma variável independente, concluindo que o modelo não apresenta vieses (Anexo 4).

Os resultados do presente estudo evidenciaram uma preocupação da necessidade de investigar em qual contexto o cuidado intensivo esta sendo praticado. Estudos internacionais buscam entender o porquê da escassez dos enfermeiros de UTI, no Brasil dispomos de muitos enfermeiros, contudo observamos que o nível de formação acadêmica pode prejudicar ou limitar seu aperfeiçoamento ao longo da sua trajetória profissional. Isto se dá pela necessidade de cumprir a graduação associada ao trabalho, muitas vezes sem nenhuma relação com a área de enfermagem.

Estudo realizado com médicos e enfermeiros de UTI destacou a alta deterioração da saúde mental dos enfermeiros e um grande desequilíbrio entre esforço e recompensa para a equipe médica, além de evidenciar um aumento de doenças psiquiátricas nesses profissionais (Jasper, Stephan, Al-Khalafa, Rennekampff, Vogt, Mirastschihski, 2011). Outros estudos, destacaram a interação profissional dos enfermeiros com o ambiente de trabalho como fator influenciador do comportamento das pessoas, dos custos, da estrutura organizacional e principalmente dos resultados (Aiken, Clarke, Sloane et al (2008), Friese, Lake, Silber, Sochalski (2008), Stone, Larson, Mooney-Kane, Smolowitz, Lin, Dickl (2006) e Gershon, Stone, Zeltser, Faucett, Macdavitt, Chou (2007). 
A repercussão do trabalho na saúde mental dos enfermeiros, como os resultados destacaram influencia negativamente também nas atividades diárias fora do trabalho deste profissional e no seu convívio familiar limitando-o em termos de lazer e diversão.

Fatores como trabalhar com enfermeiros competentes, manter um bom relacionamento enfermeiro-médico, deter o poder de decisão, possuir autonomia profissional, manter o controle da prática de enfermagem, suporte educacional, percepção adequada das necessidades da equipe e desenvolvimento da real importância do paciente para o nosso trabalho são definidos como fontes essenciais para uma melhor satisfação e estimulo para ambiente de trabalho produtivo. Isto se repercute ainda na forma de magnetismo profissional, ou seja, uma forma de apreensão profissional na prática assistencial da enfermagem (Kramer e Schmalenberg, 2008).

Considerando os resultados do estudo, destacamos que a QVRS dos enfermeiros de UTI é fortemente influenciada pelas condições do ambiente de trabalho como o número de pacientes por enfermeiro, fatores do ambiente, tipo e localização dos hospitais, características sociodemográficas como idade, tempo de formação e de atuação na UTI e a complexidade dos procedimentos que conforme a legislação profissional determina, aumenta-se a cada dia, impossibilitando o enfermeiro de interagir melhor com sua equipe de trabalho e com o próprio paciente crítico. 
Conclusães 


\section{CONCLUSÕES}

Este estudo analisou a relação entre condições de trabalho e QVRS de enfermeiros de UTI no município de São Paulo e os resultados obtidos permitiram chegar às seguintes conclusões, apresentadas a seguir.

- Em relação à caracterização sociodemográfica e de trabalho dos enfermeiros: predominantemente do sexo feminino, solteiros, com média de 35,6 anos, católicos, trabalhavam no período noturno, possuíam apenas um vínculo empregatício, tinham em média de 8,9 anos de tempo de graduação, eram especialistas em enfermagem, em média, 6,6 anos de atuação como enfermeiros na UTI, trabalhavam menos que 40 horas semanais e realizava procedimentos a beira leito de alta complexidade. Quanto à renda mensal, em média, apresentam o valor de $R \$ 4.171,00$ e sua participação cursos de extensão profissional foi de 2,4 eventos no último ano.

- Na avaliação da QVRS em relação aos CF e CM, conclui-se que a dimensão aspectos físicos (CF) e as dimensões aspectos emocionais e vitalidade ( $\mathrm{CM}$ ) obtiveram médias abaixo de 50, indicando um comprometimento da QVRS dos enfermeiros para estes aspectos, entretanto, destaca-se um comprometimento maior no $\mathrm{CM}$. As melhores médias foram encontradas nas dimensões capacidade funcional e dor (CF) e saúde mental e aspectos sociais (CM).

- Em relação às associações entre as condições de trabalho e os componentes da QVRS, a análise de regressão constatou que as variáveis preditoras sexo, proporção de leitos por enfermeiro e o domínio suporte organizacional - NWI 
mostraram associação com o CF. Já no CM, a regressão linear constatou associação significativa com as variáveis preditoras idade e domínio controle sobre o ambiente - NWI-R.

- Em relação às hipóteses do estudo, constata-se que as condições de trabalho (autonomia, controle sobre o ambiente, relacionamento médico-enfermeiro e suporte organizacional) estão parcialmente associadas ao CF e CM da QVRS dos enfermeiros, destacando um comprometimento maior, para o domínio controle sobre o ambiente e suporte organizacional. 


\section{Consideraçäes finais}




\section{CONSIDERAÇÕES FINAIS}

O ambiente do cuidado intensivo é por natureza, repleto de fatores, que podem afetar a QVRS dos enfermeiros. Neste estudo, identificamos alguns dos fatores que podem desencadear a deterioração da qualidade de vida desses profissionais. O lidar com situações conflitantes, o cuidado crítico numa linha bastante limítrofe, entre a vida e a morte, o fato de nos adaptarmos às situações de dor e sofrimento vivenciadas pelos pacientes e seus familiares, são fatores, a partir dos quais se constata, a longo prazo, que podem repercutir na $\mathrm{QV}$ e no estado de saúde dos enfermeiros, responsável pela gestão do cuidado.

Este estudo não nos trouxe soluções para estes problemas, mas subsidiou novas perspectivas de investigações que merecem ser realizadas, a fim de melhorar não somente a QVRS e as condições de trabalho dos enfermeiros, mas de toda a equipe de saúde que se inter-relacionam na UTI. O uso de instrumentos confiáveis para mensurar conceitos subjetivos como a QVRS devem fazer parte do contexto dos pesquisadores.

Destaca-se a necessidade de um repensar sobre como podemos melhorar este ponto de vista, tão discutido e pouco melhorado na atualidade. A legislação atual nos insere num contexto bastante complexo na ótica das condições de trabalho, ou seja, com o aumento do número de pacientes por enfermeiro, o cuidado crítico efetivamente passará a ser prejudicado no dia a dia, em função das inúmeras atividades que o enfermeiro de UTI realiza. A literatura retrata, em diversos estudos, que o número de pacientes influencia na qualidade do cuidado e nos resultados, inclusive na sua mortalidade. 
Limitaçaes da estuda 


\section{LIMITAÇÕES DO ESTUDO}

Este estudo contou com inúmeras limitações para sua realização, a começar pelo número de recusas dos hospitais para fazerem parte da amostra. As razões pelas quais, a maioria recusava, estavam relacionadas com a estruturação e quadro de pessoal insuficiente o que na opinião deles iria denegrir a imagem institucional.

A burocracia dos tramites para aprovação dos CEP das instituições também colaborou para que algumas delas emitissem seus pareceres após o término da coleta estabelecido pela autora, entretanto, a solicitação de coleta foi acatada visto o interesse destas instituições em conhecer melhor o perfil dos enfermeiros e as suas condições de trabalho.

Quanto ao número de enfermeiros, observou-se que em algumas instituições o índice de recusa foi de até 30\% em alguns locais, alegando não se interessar em participar de pesquisas, pelo fato de não agregar nada a eles. Ressalta-se assim, a necessidade de mudança de paradigmas para os enfermeiros no geral em relação à importância da pesquisa no processo de melhoria da profissão. Devido às características do estudo não dispomos de dados que possibilitem a comparação dos resultados, entretanto, ressalta-se a importância da continuidade do mesmo para que possamos consolidar o real contexto do enfermeiro de UTI e suas condições de trabalho.

Quanto aos achados, observou-se que os enfermeiros possuem pouco tempo de experiência em UTI, talvez o estudo não tenha sido capaz de captar as razões deste resultado, destacando a necessidade de se utilizar outros instrumentos que permitam identificar as condições de saúde dos enfermeiros, a incidência das doenças que acometem estes profissionais, 0 nível de rotatividade nas UTIs e caracterizar de uma maneira mais ampla 
todos os aspectos em relação às condições de saúde dos enfermeiros de UTI não se prendendo apenas à QVRS.

$\mathrm{Na}$ estratégia de regressão múltipla, um número menor de variáveis poderia ter aumentado a precisão das análises realizadas explicando assim, melhor a variabilidade das variáveis.

Mesmo diante das limitações do estudo, os resultados trazem informações relevantes sobre aspectos pouco explorados, como a QVRS dos enfermeiros de UTI, indicando caminhos para o desenvolvimento de novos estudos sobre condições de trabalho e de saúde destes profissionais. 
Referências 


\section{REFERÊNCIAS}

1. Abdolmohsin SAH, Thomas THW. Modeling organizational determinants of hospital mortality. Health Serv Res 1991; 26 (3): 303-323.

2. Aiken LH, Cimiotti JP, Sloane DM, Smith HL, Flynn L, Neff D. Effects of nurse staffing and nurse education on patient deaths in hospitals with different nurse work environments. Med Care 2011. 49 (12): 1047-1053.

3. Aiken LH et al. Patient safety, satisfaction, and quality of hospital care: cross sectional surveys of nurses and patients in 12 countries in Europe and the United States. BMJ 2012; 344: e 1711, 1-14.

4. Aiken LH, Clarke SP, Cheung RB, Sloane DM, Silber JH. Educational levels of hospital nurses and surgical patient mortality. JAMA 2003; 290 (12): 1617-1623.

5. Aiken LH, Clarke SP, Sloane DM et al. Effects of hospital care environment on patient mortality and nurse outcomes. J Nurs Adm 2008; 38: $220-226$.

6. Aiken LH, Clarke SP, Sloane DM, Lake ET. Effects of hospital care environment on patient mortality and nurse outcomes. JONA 2009; 39 (7/8): supplement, S $45-51$.

7. Aiken LH, Clarke SP, Sloane DM, Sochalski J, Silber JH. Hospital nurse staffing and patient mortality, nurse burnout, and job dissatisfaction. JAMA 2002; 288 (16): 1987-93.

8. Aiken LH, Patrician PA. Measuring organizational traits of hospitals: the Revised Nursing Work Index. Nurs Res 2000; 49(3):146-53. 
9. Allan HT, Cowie $H$, Smith $P$. Overseas nurses' experiences of discrimination: a case of racist bullying? J Nurs Manag 2009; 17(7): 898906.

10. AMIB - Associação de Medicina Intensiva Brasileira. Regulamento Técnico para Funcionamento de Unidades de Terapia Intensiva, 2009. Acesso http://www.amib.org.br/fileadmin/RecomendacoesAMIB.pdf.

11. AMIB - Associação de Medicina Intensiva Brasileira, Censo Brasileiro de UTIs - AMIB 2010, http://www.amib.com.br/censo default2.asp

12. Anderson KL, Burckardt CS. Conceptualization and measurement of quality of life as an outcome variable for health care intervention and research. J Adv Nurs 1999 ; 29 (2) : 298-306.

13. Andrade TL, Camelier AA, Rosa FW, Santos MP, Jezler S, Silva JLP. Aplicabilidade do questionário de qualidade de vida relacionada à saúde - The 12 - Item Short-Form Health Survey - em pacientes portadores de esclerose sistêmica progressiva. J Bras Pneumologia 2007; 33 (4): 41422.

14. Aquino NMR, Sun SY, Oliveira EM, Martins MG, Silva JF, Mattar R. Violência sexual e associação com a percepção individual de saúde entre mulheres gestantes. Rev Saúde Pública 2009; 43 (6): 954-960.

15. Bakker AB, Blanc PM le, Schaufeli WB. Burnout contagion among intensive care nurses. J Adv Nurs 2005; 51 (3): 276-287.

16. Barbieri C, Carson SS, Amaral AC. Year in review 2007: critical care intensive care unit management. Critical Care 2008; 12 229-235.

17. Batista KM, Bianchi ERF. Estresse do enfermeiro em unidade de emergência. Rev Lat Enferm 2006; 14 (4): 534-9. 
18. Beccaria RLM, Pereira RAM, Contrin LM, Lobo SMA, Trajano DHL. Eventos adversos na assistência de enfermagem em uma unidade de terapia intensiva. Rev Bras Ter Intensiva 2009; 21(3): 276-282.

19. Bertani IF, Rezende RM, Parzewski CCF, Loureço EAS. Instrumentos e métodos para medir qualidade de vida. Rev Soc Cardiol estado São Paulo 2005; 15 (5): 8-16.

20. Bianchi ERF. Enfermeiro hospitalar e o stress. Rev Esc Enferm USP 2000; 34 (4): 390-4.

21. Bogaert PV, Clarke S, Vermeyen K, Meulemans H, Heyning PV. Practice environments and their associations with nurse-reported outcomes in Belgian hospitals: Development and preliminary validation of a Dutch adaptation of the Revised Nursing Work Index. Int J Nurs Stud 2009; 46: 55-65.

22. Bogaert PV, Meuleemans H, Vlarke S, Vermeyen K, Heyning PV. Hospital nurse practice environment, burnout, job outcomes and quality of care: test off a structural equation model. J Adv Nurs 2009; 65 (10): 2175-2185.

23. Brasil. Agência Nacional de Vigilância Sanitária - ANVISA, www.anvisa.gov.br, acesso em abril de 2012, RDC 26.

24. Brasil. Agência Nacional de Vigilância Sanitária - ANVISA, www.anvisa.gov.br, acesso em junho de $2010, \operatorname{RDC}^{\circ} 7$.

25. Brasil. Ministério da Saúde. DATASUS. Acesso http//cnes.datasus.gov.br / mod_ind tipo_leito_uti. Acessado em 01.06.2010.

26. Brasil. Ministério da Saúde. Departamento Nacional de Auditoria do SUS. Portaria $n^{\circ} 3432$, de 12 de agosto de 1998, DO 154, 13/8/98. 
27. Brasil. Ministério da Saúde. Portaria n 1101, de 12 de junho de 2002. Acesso: $\quad$ http://dtr2001.saude.gov.br/sas/PORTARIAS/Port2002/Gm/GM1101.htm

28. Bucchi SM, Mira VL, Santos LSC. O ambiente de terapia intensiva. In Enfermagem em Terapia Intensiva: do ambiente da unidade à assistência ao paciente. São Paulo: Martinari, 2010: 37-50.

29. Buerhaus PR, Staiger FO, Auerbach DI. Implications of an aging registered nurse workforce. JAMA 2000; 283 (22): 2948-54.

30. Bulhões I. Riscos do trabalho de Enfermagem. Rios de Janeiro: Folha Carioca, 1994.

31. Bullinger $\mathrm{N}$ et al. Developing e evaluating cross cultural instruments from minimum requirements to optimal models. Qual Lif Res 1993; 2 (6): 4519.

32. Callegari-Jacques, SM. Bioestatística - princípios e aplicações. 2003, São Paulo: Artmed.

33. Camilier AA. Avaliação da qualidade de vida relacionada à saúde em pacientes com DPOC: estudo de base populacional com o SF-12 na cidade de São Paulo - SP [tese]. São Paulo: Escola Paulista de Medicina, Universidade federal de São Paulo; 2004.

34. Campos JF, David HSL. Avaliação do contexto de trabalho em terapia intensiva sob o olhar da psicodinâmica do trabalho. Rev Esc Enfermagem USP. 2011; 45 (2): 363-8.

35. Carandina DM. Qualidade de vida no trabalho: construção e validação de um instrumento de medida para enfermeiras [tese]. São Paulo: Escola de Enfermagem, Universidade de São Paulo, 2003. 
36. Cavalheiro AM, Moura Junior DF, Lopes AC. Estresse de enfermeiros com atuação em unidades de terapia intensiva. Rev Lat Enferm [internet] 2008,[acesso em dezembro, 2011]; 16 (1).

37. Chavaglia SRR, Borges CM, Amaral SEM, Iwamoto HH, Ohl RIB. Ambiente do centro de terapia intensiva e o trabalho da equipe de enfermagem. Rev Gaúcha Enf 2011; 32(4): 654-61.

38. Chiu MC, Wang MJJ, Lu, CW, Pan SMP, Kumashiro M, Illmarinen J. Evaluating work ability and quality of life for clinical nurses in Taiwan. Nurs Outlook. 2007; 55: 318-326.

39. Cho SH, Mark VA, Yun SC, June KJ. Differences in intensive care unit work environments among within hospitals using subscales and a composite measure of the Revise Nursing Work Index. J Adv Nurs. 2011; 67 (12): 2637-48.

40. Cho SH, Kefian S, Barkauskas VH, Smith DG. The effects of nurse staffing on adverse events, morbidity, mortality, and medical costs. Nurs Res 2003; 52 (2): 71-79.

41. Ciconelli RM. Tradução para o português e validação do questionário genérico de qualidade de vida "Medical Outcomes Study 36-Item shortform Health Survey (SF-36"[tese]. São Paulo: Escola Paulista de Medicina, Universidade federal de São Paulo; 1997.

42. Ciconelli RM, Ferraz MB, Santos W, Meinão I, Quaresma MR. Tradução para a língua portuguesa e validação do questionário genérico de avaliação de qualidade de vida SF-36 (Brasil SF-36). Rev Bras Reumatol 1999; 39 (3): 143-150.

43. Clarke SP. Hospital work environments, nurse characteristics, and sharps injuries. Am J Inf Control 2007; 35 (5): 302-309.

44. Coli RCP, Anjos MF, Pereira LL. Postura dos enfermeiros de uma unidade de terapia intensiva frente ao erro: uma abordagem à luz dos 
referenciais bioéticos. Rev Lat AM Enfermagem [internet]. 2010 [ acesso em dezembro, 2010]; 18 (3).

45. Cronin-Stubbs D, Rooks CA. The stress, social support, and burnout of critical care nurses: the results of research. Heart Lung 1985; 14 (1): 31 39.

46. Cummings GG, Haydik L, Estabrooks CA. Is the Nursing Work Index Measuring UP? Nurs Research. 2006; 55(2): 82-93.

47. D'Amorin, AB. Avaliação das formas auto - administradas dos questionários MHAQ e SF 12 em pacientes com doenças reumatológicas. [dissertação], Universidade Federal de São Paulo, 2001.

48. Donabedian A. Evaluating physician competence. Bull WHO 2000; 78 (6): 857-60.

49. Donabedian A. The seven pillars of quality. Arch Pathol Lab Med 1990; 114 (11): 1115-8.

50. Duffield $\mathrm{C}$, Roche MA, Stasa $\mathrm{H}$. Nursing staffing, nursing wokload, the work environment and patient outcomes. Appl Nurs Res 2010; 20 (1-2); 23-33.

51. Duffield CM; Roche MA; Blay N; Stasa H. Nursing unit managers, staff retention and the work environment. J Clin Nurs 2010; 20: 23-33.

52. Elias MA; Navarro VL. A relação entre o trabalho, a saúde e as condições de vida: negatividade e positividade no trabalho das profissionais de enfermagem de um hospital escola. Rev Lat Am Enfermagem 2006; 14 (4): 517-25.

53. Errico A d' et al. Hospital injury rates in relation to socioeconomic status and working conditions. Occup Environ Med 2007; 64: 325-333. 
54. Espirito Santo TB, Oguisso T, Fonseca RMGS. A profissionalização da enfermagem brasileira na mídia escrita no final do século XIX: uma análise de gênero. Rev Lat Am Enfermagem [Internet]. 2011 [acesso em 12.12.11]; 19 (5): [07 telas]. Disponível em: www.eerp.usp.br/rlae.

55. Ewart GW, Marcus L, Gaba MM, Bradner RH, Medina JL, Chandler EB. The critical care medicine crisis: a call for federal action. Chest. 2004; 125 (4): 1518-1521.

56. Ferrans CE, Zerwic JJ, Wilbur JE, Larson JL. Conceptual model of health related quality of life. J Nurs Scholarship 2005; 37 (4): 336-342.

57. Ferreira RC, Griep RH, Fonseca MJM, Rotenberg L. Abordagem multifatorial do absenteísmo por doença em trabalhadores de enfermagem. Rev Saúde Publica 2012; 46 (2): 259-68.

58. Fleck MPA et al. Desenvolvimento da versão em português do instrumento de avaliação de qualidade de vida da OMS (WHOQOL-100). Rev Bras Psiquiatr 1999; 21 (1):19-28.

59. Fleck MPA et al. Associação entre sintomas depressivos e funcionamento social em cuidados primários à saúde. Rev Saúde Pública 2002; 36 (4): 431-438.

60. Flynn L, Aiken LH. Does international nurse recruitment influence practice values in U.S. Hospitals? J Nurs Scholar 2002; 34 (1): 67-73.

61. Fogaça MC, Carvalho WB, Martins LAN. Estudo preliminar sobre a qualidade de vida dos médicos e enfermeiros intensivistas pediátricos e neonatais. Rev Esc Enferm USP 2010; 44 (3): 708-12.

62. Friese CR, Lake ET, Silber JH, Sochalski J. Hospital nurse practice environments and outcomes for surgical oncology patients. Health Serv Res 2008; 43:1145-63. 
63. Gasparino RC, Guirardello EB. Adaptação cultural e validação do Instrumento Nursing Work Índex - revised para a cultura brasileira [dissertação]. Campinas: Universidade Estadual de Campinas, 2007.

64. Gasparino RC, Guirardello EB. Tradução e adaptação para a cultura brasileira do "Nursing Work Index - Revised". Acta Paul Enferm 2009; 22 (3): 281-7.

65. Gasparino RC, Guirardello EB, Aiken LH. Validation of the Brazilian version of the Nursing Work Index- Revised (B-NWI-R). J Clin Nurs 2011; 20 (23-24): 3494-3501.

66. Gershon RRM, Stone PW, Zeltser M, Faucett J, Macdavitt K, Chou SS. Organizational climate and nurse health outcomes in tehe Unite States: a systematic review. Ind Health 2007; 45: 622-36.

67. Gomes GC, Lunardi Filho WD, Erdmann AL. O sofrimento psíquico em trabalhadores de UTI interferindo no seu modo de viver a enfermagem. Rev Enf UERJ. 2006; 14 (1): 7 pg.

68. Guerrer FJL, Bianchi ERF. Caracterização do estresse nos enfermeiros de UTI. Rev Esc Enferm USP 2008; 42 (2): 355-62.

69. Hair JF, Tatham RL, Anderson RE, Black W. Análise Multivariada de dados. São Paulo: Bookman, $5^{\mathrm{a}}$ edição.

70. Hall LMG, Doran D. Nurses' perceptions of hospital work environments. J Nurs Management. 2007; 15: 264-273.

72. Hall LMG, Doran D, Pink GH. Nurse staffing models, nursing hours, and patient safety outcome. JONA 2004; 34 (1): 41-45.

73. Hinno $S$ et al. Nurses' perceptions of the organizational attributes of their practice environment in acute care hospitals. J Nurs Management 2009; 17, 965-974. 
74. Jasper S, Stephan M, Al-Khalafa H, Rennekampff HO, Vogt PM, Mirastschihski U. Too little appreciation for great expenditure? Workload and resources in ICUs. Int Arch Occup Environ Health 2011.

75. Jolivet A et al. Linking hospital workers' organizational work environment to depressive symptoms: a mediating effect of effort -reward imbalance? The ORSOSA study. Social Science Med 2010; 71: 534-540.

76. Kanai-Pak M, Aiken LH, Sloane DM, Poghosyan L. Poor Work environments and nurse inexperience are associated with burnout, job dissatisfaction, and quality deficits in Japanese hospitals. J Clin Nurs 2008; 17 (24): 3324-29.

77. Kelley MA, Chalfin DB, Ingbar D, Sessler CN. The crisis care crisis in the United States. Chest 2004; 125 (4): 1514-1517.

78. Kramer GA, Hafner LP. Shared values: impact staff nurse job satisfaction and perceived productivity. Nurs Res 1989; 38 (3):172-7.

79. Kramer M, Schmalenberg C. Confirmation of a healthy work environment. Crit Care Nurs 2008; 28 (2): 56-64.

80. Kurcgant $P$, Tronchin DMR, Melleiro MM. A construção de indicadores de qualidade para a avaliação de recursos humanos nos serviços de enfermagem: pressupostos teóricos. Acta Paul Enferm 2006; 19 (1): 8891.

81. Leplat J, Cuny X. Introdução à psicologia do trabalho. Tradução Helena Domingos Lisboa: Fund Calouste Gulbenkian, 1977.

82. Lino MM. Qualidade de vida e satisfação de enfermeiras de Unidades de Terapia Intensiva [tese]. São Paulo: Escola de Enfermagem, Universidade de São Paulo; 2004.

83. Liou SR, Cheng CY. Using the practice environment scale of the nursing work index on Asian Nurse. Nurs Res 2009. 58 (3); 218-225. 
84. LoBiondo-Wood G, Haber J. Pesquisa em enfermagem - métodos, avaliação crítica e utilização. Rio de Janeiro: Ed. Guanabara Koogan; 2001.

85. Manojlovich M. Environments, nurse-physian communication, and patient's outcome. AJCC 2007; 16 (6): 536-543.

86. Martins JT, Robazzi MLCC, Marziale MHP, Garanhani ML, Haddad MCL. Significados do gerenciamento de unidade de terapia intensiva para o enfermeiro. Rev Gaúcha Enf 2009; 30 (1): 113-9.

87. Marziale MHP. Enfermeiros apontam as inadequadas condições de trabalho como responsáveis pela deterioração da qualidade da assistência de enfermagem. Rev Lat Am Enfermagem. 2001; 9 (3):1.

88. Mark VA, Hagenmueller AC. Technological and environmental characteristic of intensive care units. JONA 1994; 24 (4S): 65-71.

89. Martins JT, Robazzi MLCC. O trabalho do enfermeiro em UTI: sentimentos de sofrimento. Rev Lat Am Enfermagem 2009 [ acesso em dezembro, 2010]; 18 (3), 17 (1).

90. Mayo AM, Ducan D. Nurse perceptions of medication errors - what we need to know for patient safety.J Nurs Care Qual 2004; 19 (3): 209-17.

91. Miller S. The clinical nurse specialist: a way forward? J Adv Nurs 1995; 22: 494-501.

92. Minayo MCS, Hartz ZMA, Buss PM. Qualidade de vida e saúde: um debate necessário. Ciências e Saúde Colet 2000; 5 (1): 7-18.

93. Mininel VA, Baptista PCP, Felli VEA. Cargas psíquicas e processos de desgaste em trabalhadores de enfermagem de hospitais universitários brasileiros. Rev Lat- Am Enfermagem [Internet], mar-abr 2011 [acesso em: 19.05.2012]; 19 (2): [ 09 telas]. Disponível em: www.eerp.usp.br/rlae 
94. Moons P. Why call it health-related quality of life when you mean perceived health status? Eur J Cardiov Nurs 2004; 3: 275-277.

95. Nachreiner NM, Gerberich SG, Ryan AD, McGovern PM. Minnesota nurses' Study: perceptions of violence and the work environment. Ind Health 2007; 45: 672-678.

96. Neves MJAO, Branquinho NCSS, Paranaguá TTB, Barbosa MA, Siqueira KM. Influência do trabalho noturno na qualidade de vida do enfermeiro. Rev Enferm UERJ 2010; 18 (1): 42-47.

97. O'Kane CE. Newly qualified nurses experiences in the intensive care unit. Nurs Crit Care 2011; 17 (1): 44-50.

98. Oleson M. Subjectively perceived quality of life. J Nurs Scholarship 1990; 22: 197-90.

99. Oliveira EB, Lisboa MTL. Análise da produção científica da vertente saúde do trabalhador de enfermagem: subjetividade e trabalho. Rev Enf UERJ 2004; 12: 24-29.

100. Padilha KG. Ocorrências iatrogênicas com medicações em unidade de terapia intensiva: condutas adotadas e sentimentos expressos pelos enfermeiros. Rev Esc Enferm USP 2002; 36 (1): 50-7.

101. Padilha, KG. Ocorrências iatrogênicas na UTI e o enfoque da qualidade. Rev Lat Am Enfermagem 2001; 9 (1): 91-6.

102. Paschoa S, Zanei SSV, Whitaker IY. Qualidade de vida dos trabalhadores de enfermagem de UTI. Acta Paul Enferm 2007; 20 (3): 305-10.

103. Paschoal T, Tamayo A. Validação da escala de estresse no trabalho. Estud Psicol 2004; 9(11): 45-52.

104. Pasqualli L. Psicometria: teoria e aplicações. Brasília: Ed. UnB; 1997. 
105. Pelliciotti JSS. Qualidade de vida relacionada á saúde de profissionais de enfermagem e erros de medicação em unidades de terapia Intensiva [dissertação]. São Paulo: Escola de Enfermagem, Universidade de São Paulo; 2009.

106. Portela LF, Rotenberg L, Waissmann W. Health, sleep and lack of time: relations to domestic and paid work in nurses. Rev Saúde Pública 2005; 39 95): 802-8.

107. Ribeiro KT. Fatores associados à qualidade de vida relacionados à saúde de idosos residentes no município de São Paulo - Estudo SABE: Saúde, Bem estar e envelhecimento [tese]. São Paulo. Universidade de São Paulo, 2011.

108. Rios KA, Barbosa DA, Belasco AGS. Avaliação de qualidade de vida e depressão de técnicos e auxiliares de enfermagem. Rev Lat Am Enfermagem 2010; [acesso em 20.03.2012]; 18 (3):[09 telas]. Disponível em: www.eerp.usp.br/rlae.

109. Rocha MCP, De Martino MMF. O estresse e qualidade do sono do enfermeiro nos diferentes turnos hospitalares. Rev Esc Enferm USP 2010; 44 (2): 280-6.

110. Rocha SSL; Felli VEA. Qualidade de vida no trabalho docente em enfermagem. Rev Lat Am Enfermagem 2004; 12 (1): 28-35.

111. Rogers AE, Hwang WT, Scott LD, Aiken LH, Dinges DF. The working hours of hospital staff nurses and patient safety. Health Affairs 2004; 23 (4): 202-212.

112. Saccoman ICRS; Cintra FA, Gallani MCBJ. Health related quality of life among the elderly with heart failure: a generic measurement. São Paulo Med J 2010; 128(4):192-6.

113. Santos LSC. Demandas de atenção no ambiente de trabalho do enfermeiro: análise da confiabilidade e validade de um instrumento 
[dissertação]. Campinas: Faculdade de Ciências Médicas, Universidade de Campinas, 2004.

114. Singer MK, Padilla GV, Giwa KA. Health-related quality of life and culture. Sem Oncol Nurs 2010; 26 (1): 59-67.

115. Seid EMF, Zannon CMLC. Qualidade de vida e saúde: aspectos conceituais e metodológicos. CAD Saúde Public 2004; 20 (2): 580-588.

116. Sengin, KK. Work related attributes of RN job satisfaction in acute care hospitals. J Nurs Adm 2003; 33 (6): 317-320.

117. Silva AA, Souza JMP, Borges FNS, Fischer FM. Health related quality of life and working conditions among nursing providers. Rev Saúde Publica 2010; 44 (4): 718-25.

118. Silva AA, Rotenberg L, Fischer FM. Jornada de trabalho na enfermagem: entre necessidades individuais e condições de trabalho. Rev Saúde Publica 2011; 45 (6): 1117-26.

119. Silva DMPP, Marziale MHP. Condições de trabalho versus absenteísmo-doença no trabalho de enfermagem. Ciência, Cuidado e Saúde 2006; 5, supl: 166-172

120. Spiller AP, Dyniewicz AM, Slomp MGFS. Qualidade de vida de profissionais da saúde em hospital universitário. Cogitare Enferm 2008; 13 (1): 88-95.

121. Stone PW. Nurse' working conditions: implications for infectious disease. Emerg Infec Disease 2004;10:1984-89.

122. Stone PW, Larson EL, Mooney-Kane C, Smolowitz J, Lin SX, Dick AW. Organizational climate and intensive care unit nurse's intention to leave. Critical Care Med 2006; 34, 1907-12. 
123. Stone PW, Gershon RRM. Nurse work environments and occupational safety in intensive care units. JONA 2009; 39 (7/8): s 27-s34.

124. Tabak N, Koprak O. Relationship between how nurses resolve their conflicts with doctors, their stress and job satisfaction. J Nurs Management. 2007; 15: 321-331.

125. Thomas MB. Registered nurses select multiple factors associated with their erros. Crit Care Nurs Clin N Am. 2010; 22: 279-282.

126. Trinkoff A, Geiger-Brown JG, Brady B, Lipscomb J, Muntaner C. How long and how much are nurses now working? AJN 2006; 106 (4): 60-71.

128. Ware JE. SF 36 Health Survey Update. Spine 2000; 25 (24): 31303139.

129. Ware JJ, Kosinski M, Keller SD. A 12-Item Short - Form Health Survey: construction of scales and preliminary tests of reliability and validity. Med Care 1996; 34 (3); 220-33.

130. Warshawsky NE, Havens DS. Global use of the Practice Environment Scale of the Nursing Work Index. Nurs Res 2011; 60 (1): 17-31.

131. While AE. Competence versus performance: which is more important? J Adv Nurs 1994; 20: 525-531.

132. WHOQOL GROUP. The development of the World Health Organization quality of life assessment instrument (the WHOQOL). In: Orley J, Kuyken W. Quality of life assessment: international perspectives. Heigelberg: Springer Verlag; 1994, p 41-60.

133. Wilson IB, Clearly PD. Linking clinical variables with health related quality of life. J Am Med Assoc 1995; 273: 59-65. 
134. World Health Organization. The Word Health Organization Quality of life assessment (WHOQOL): position paper from the word health organization. Soc Sci Med 1995; 41 (10): 1403-9.

135. Zapka JM, Lemon SC, Magner RP, Hale J. Lifestyle behaviours and weight among hospital based nurses. J Nurs Manag 2009; 17(7): 853860. 
Anexas 


\section{ANEXOS}

\section{Anexo I}

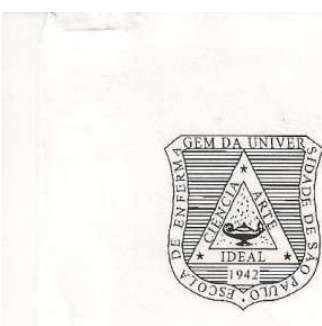

\section{UNIVERSIDADE DE SÃO PAULO
ESCOLA DE ENFERMAGEM}

Av. Dr. Enéas de Carvalho Aguiar, 419 - CEP 05403-000

Tel.: (011) 3061-7548/8858 - Fax: (011) 3061-7548 -

Săo Paulo - SP - Brasil

São Paulo, 28 de junho de 2011.

Ilm. ${ }^{a} \mathrm{Sr} .{ }^{\mathrm{a}}$

Luciana Soares Costa Santos

Ref.: Processo nº 1052/2011/CEP-EEUSP - SISNEP CAAE: 0057.0.196.000-11

Prezada Senhora,

Em atenção à solicitação referente à análise do projeto "Qualidade de vida relacionada à saúde e condições de trabalho dos enfermeiros de Unidade de Terapia Intensiva do município de São Paulo", informamos que o mesmo foi considerado aprovado pelo Comitê de Ética em Pesquisa da Escola de Enfermagem da Universidade de São Paulo (CEP/EEUSP).

Analisado sob o aspecto ético-legal, atende às exigências da Resolução $\mathrm{n}^{\circ}$ 196/96 do Conselho Nacional de Saúde.

Esclarecemos que após o término da pesquisa, os resultados obtidos deverão ser encaminhados ao CEP/EEUSP, para serem anexados ao processo.

Atenciosamente,

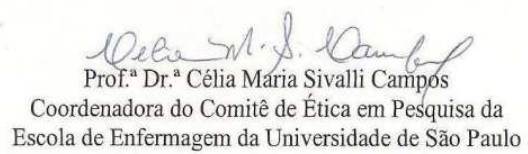




\section{Anexo II}

\section{Instrumento Nursing Work Index - Revised - Versão Brasileira}

Por favor, indique para cada item, nesta seção, até que ponto você concorda que ele está presente em seu trabalho atual. Indique o quanto você concorda, fazendo um círculo em volta do número apropriado.

\begin{tabular}{|c|c|c|c|c|c|}
\hline & Presente no trabalho atual & $\begin{array}{l}\text { Concordo } \\
\text { Totalmente }\end{array}$ & $\begin{array}{c}\text { Concordo } \\
\text { Parcialmente }\end{array}$ & $\begin{array}{c}\text { Discordo } \\
\text { Parcialmente }\end{array}$ & $\begin{array}{l}\text { Discordo } \\
\text { Totalmente }\end{array}$ \\
\hline 1 & $\begin{array}{l}\text { Serviços de apoio adequados } \\
\text { que me permitem dedicar tempo } \\
\text { aos pacientes }\end{array}$ & 1 & 2 & 3 & 4 \\
\hline 2 & $\begin{array}{l}\text { Os médicos e os enfermeiros } \\
\text { possuem boas relações de } \\
\text { trabalho }\end{array}$ & 1 & 2 & 3 & 4 \\
\hline 4 & $\begin{array}{l}\text { Uma equipe de supervisores que } \\
\text { dá suporte aos enfermeiros }\end{array}$ & 1 & 2 & 3 & 4 \\
\hline 6 & $\begin{array}{l}\text { A enfermagem tem controle } \\
\text { sobre sua prática }\end{array}$ & 1 & 2 & 3 & 4 \\
\hline 11 & $\begin{array}{l}\text { Tempo e oportunidade suficientes } \\
\text { para discutir, com outros } \\
\text { enfermeiros, os problemas } \\
\text { relacionados aos cuidados do } \\
\text { paciente }\end{array}$ & 1 & 2 & 3 & 4 \\
\hline 12 & $\begin{array}{l}\text { Equipe com número suficiente de } \\
\text { enfermeiros para proporcionar } \\
\text { aos pacientes um cuidado com } \\
\text { qualidade }\end{array}$ & 1 & 2 & 3 & 4 \\
\hline 13 & $\begin{array}{l}\text { O gerente de enfermagem é um } \\
\text { bom administrador e líder }\end{array}$ & 1 & 2 & 3 & 4 \\
\hline 16 & $\begin{array}{l}\text { Equipe suficiente para realizar o } \\
\text { trabalho }\end{array}$ & 1 & 2 & 3 & 4 \\
\hline 17 & $\begin{array}{l}\text { Liberdade para tomar decisões } \\
\text { importantes no cuidado ao } \\
\text { paciente e no trabalho }\end{array}$ & 1 & 2 & 3 & 4 \\
\hline 24 & $\begin{array}{l}\text { Não ser colocado em uma } \\
\text { posição de ter que realizar } \\
\text { atribuições que são contra meus } \\
\text { princípios }\end{array}$ & 1 & 2 & 3 & 4 \\
\hline 27 & $\begin{array}{l}\text { Enfermeiros e médicos trabalham } \\
\text { muito em equipe }\end{array}$ & 1 & 2 & 3 & 4 \\
\hline 35 & $\begin{array}{l}\text { O gerente de enfermagem da } \\
\text { suporte à sua equipe, em suas } \\
\text { decisões, mesmo que conflitem } \\
\text { com as do médico }\end{array}$ & 1 & 2 & 3 & 4 \\
\hline 39 & $\begin{array}{l}\text { Colaboração (prática conjunta) } \\
\text { entre enfermeiros e médicos }\end{array}$ & 1 & 2 & 3 & 4 \\
\hline 46 & $\begin{array}{l}\text { Oportunidade de trabalhar em } \\
\text { uma unidade altamente } \\
\text { especializada }\end{array}$ & 1 & 2 & 3 & 4 \\
\hline 48 & $\begin{array}{l}\text { A designação de pacientes } \\
\text { promove a continuidade do } \\
\text { cuidado (isto é: um mesmo } \\
\text { enfermeiro cuida dos mesmos } \\
\text { pacientes em dias consecutivos) }\end{array}$ & 1 & 2 & 3 & 4 \\
\hline
\end{tabular}




\section{Anexo III \\ Instrumento de Avaliação de Qualidade de Vida relacionado à saúde - MOS SF 12.}

Instruções: Este questionário faz algumas perguntas sobre as atividades que você realiza durante o seu dia. Responda cada questão marcando a resposta como indicado. Se estiver em dúvida de como responder, por favor, tente responder o melhor que puder.

1. Em geral você diria que sua saúde é: (circule uma)

\begin{tabular}{|c|c|c|c|c|}
\hline EXCELENTE & MUITO BOA & BOA & RUIM & MUITO RUIM \\
\hline $\mathbf{1}$ & $\mathbf{2}$ & $\mathbf{3}$ & $\mathbf{4}$ & $\mathbf{5}$ \\
\hline
\end{tabular}

Os seguintes itens são sobre atividades que você poderia fazer atualmente durante um dia comum. Devido a sua saúde, você teria dificuldade para fazer essas atividades? Neste caso, quanto?

(circule um número para cada linha)

\begin{tabular}{|l|c|c|c|}
\hline Atividades & $\begin{array}{c}\text { Sim. } \\
\text { Dificulta muito }\end{array}$ & $\begin{array}{c}\text { Sim } \\
\text { Dificulta um pouco }\end{array}$ & $\begin{array}{c}\text { Não dificulta de } \\
\text { modo algum }\end{array}$ \\
\hline 2. $\begin{array}{l}\text { Atividades } \\
\text { moderadas, tais } \\
\text { como mover uma } \\
\text { mesa, passar } \\
\text { aspirador de pó, } \\
\text { jogar bola, varrer a } \\
\text { casa }\end{array}$ & 1 & 2 & 3 \\
\hline 3. Subir vários lances \\
de escada
\end{tabular}

Durante as últimas quatro semanas, você teve algum dos seguintes problemas com o seu trabalho ou com alguma atividade diária regular, como consequência de sua saúde física? (circule uma em cada linha)

\begin{tabular}{|l|c|c|}
\hline $\begin{array}{l}\text { 4. Realizou menos tarefas } \\
\text { do que gostaria? }\end{array}$ & Sim & Não \\
\hline $\begin{array}{l}\text { 5. Esteve limitado no seu } \\
\text { tipo de trabalho ou em } \\
\text { outras atividades }\end{array}$ & Sim & Não \\
\hline
\end{tabular}

Durante as últimas quatro semanas, você teve algum dos seguintes problemas com o seu trabalho ou com alguma atividade diária regular, como consequência de algum problema emocional (como sentir-se deprimido ou ansioso)?

(circule uma em cada linha)

\begin{tabular}{|c|c|c|}
\hline $\begin{array}{l}\text { 6. Realizou menos tarefas } \\
\text { do que gostaria? }\end{array}$ & Sim & Não \\
\hline $\begin{array}{l}\text { 7. Não trabalhou ou não fez } \\
\text { qualquer das atividades } \\
\text { com tanto cuidado como } \\
\text { geralmente faz? }\end{array}$ & Sim & Não \\
\hline
\end{tabular}

8. Durante as últimas quatro semanas, quanto a dor interferiu com o seu trabalho normal (incluindo tanto o trabalho, fora de casa e dentro de casa)? (circule uma)

\begin{tabular}{|c|c|c|c|c|}
\hline $\begin{array}{c}\text { De maneira } \\
\text { alguma }\end{array}$ & $\begin{array}{c}\text { Um } \\
\text { pouco }\end{array}$ & Moderadamente & Bastante & Extremamente \\
\hline
\end{tabular}


Estas questões são sobre como você se sente e como tudo tem acontecido com você durante as últimas quatro semanas. Para cada questão, por favor, dê uma resposta que mais se aproxime da maneira como você se sente. Em relação as últimas quatro semanas. (circule um número para cada linha)

\begin{tabular}{|l|c|c|c|c|c|c|}
\hline & $\begin{array}{c}\text { Todo } \\
\text { tempo }\end{array}$ & $\begin{array}{c}\text { A maior } \\
\text { parte do } \\
\text { tempo }\end{array}$ & $\begin{array}{c}\text { Uma } \\
\text { boa } \\
\text { parte do } \\
\text { tempo }\end{array}$ & $\begin{array}{c}\text { Alguma } \\
\text { parte do } \\
\text { tempo }\end{array}$ & $\begin{array}{c}\text { Uma } \\
\text { pequena } \\
\text { parte do } \\
\text { tempo }\end{array}$ & Nunca \\
\hline $\begin{array}{l}\text { 9. Quanto tempo você } \\
\text { tem se sentido calmo } \\
\text { ou tranquilo? }\end{array}$ & 1 & 2 & 3 & 4 & 5 & 6 \\
\hline $\begin{array}{l}\text { 10. Quanto tempo você } \\
\text { tem se sentido com } \\
\text { muita energia? }\end{array}$ & 1 & 2 & 3 & 4 & 5 & 6 \\
\hline $\begin{array}{l}\text { 11.Quanto tempo você } \\
\text { tem se } \\
\text { sentido desanimado e } \\
\text { abatido? }\end{array}$ & 1 & 2 & 3 & 4 & 5 & 6 \\
\hline
\end{tabular}

12. Durante as últimas quatro semanas, quanto do seu tempo a sua saúde física ou problemas emocionais interferiram nas suas atividades sociais (como visitar amigos, parentes, etc)? (circule uma)

\begin{tabular}{|c|c|c|c|c|}
\hline Todo o tempo & $\begin{array}{c}\text { A maior parte do } \\
\text { tempo }\end{array}$ & $\begin{array}{c}\text { Alguma parte do } \\
\text { tempo }\end{array}$ & $\begin{array}{c}\text { Uma pequena } \\
\text { parte do tempo }\end{array}$ & $\begin{array}{c}\text { Nenhuma parte } \\
\text { do tempo }\end{array}$ \\
\hline 1 & 2 & 3 & 4 & 5 \\
\hline
\end{tabular}




\section{Anexo IV}

Resíduos do modelo estatístico final e da distribuição normal do CF- SF 12. São Paulo, 2012.
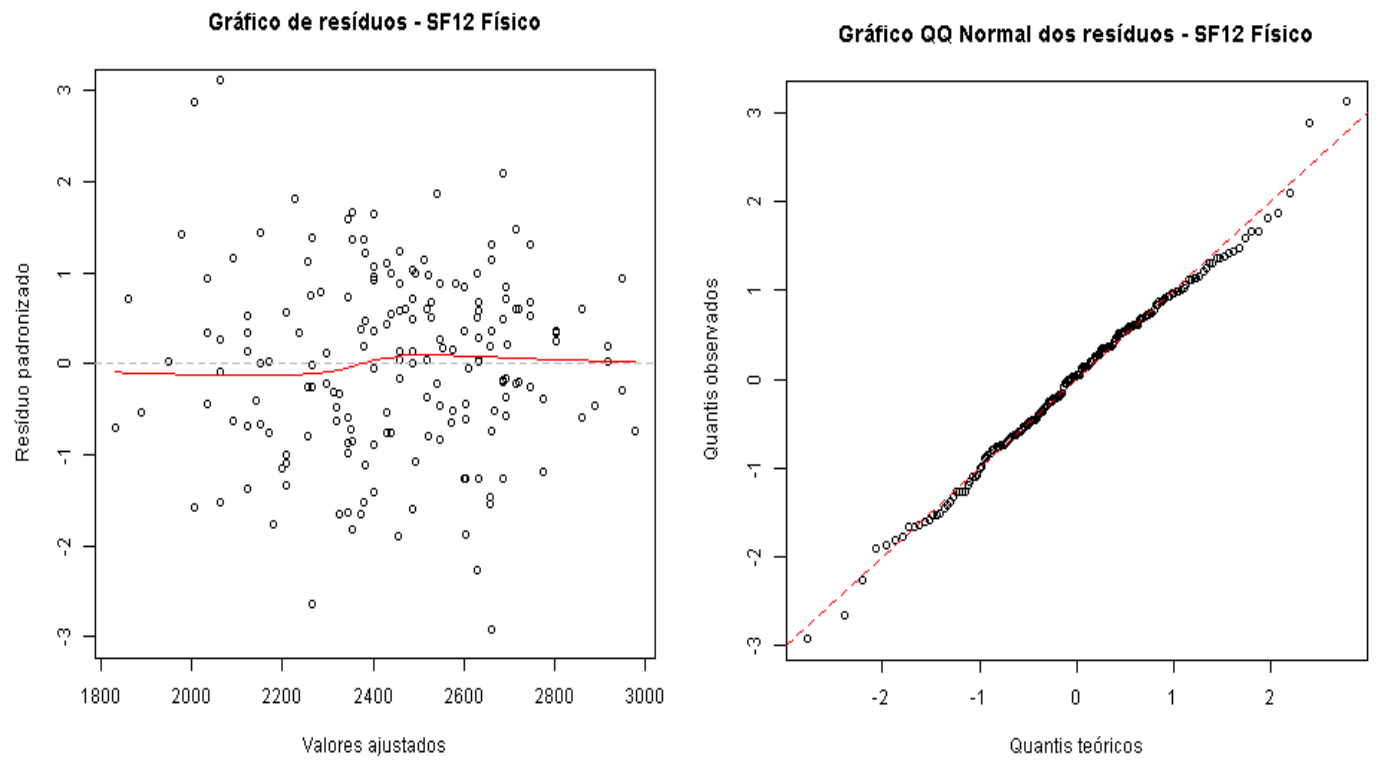

Resíduos do modelo estatístico final e da distribuição normal do CM- SF 12. São Paulo, 2012.
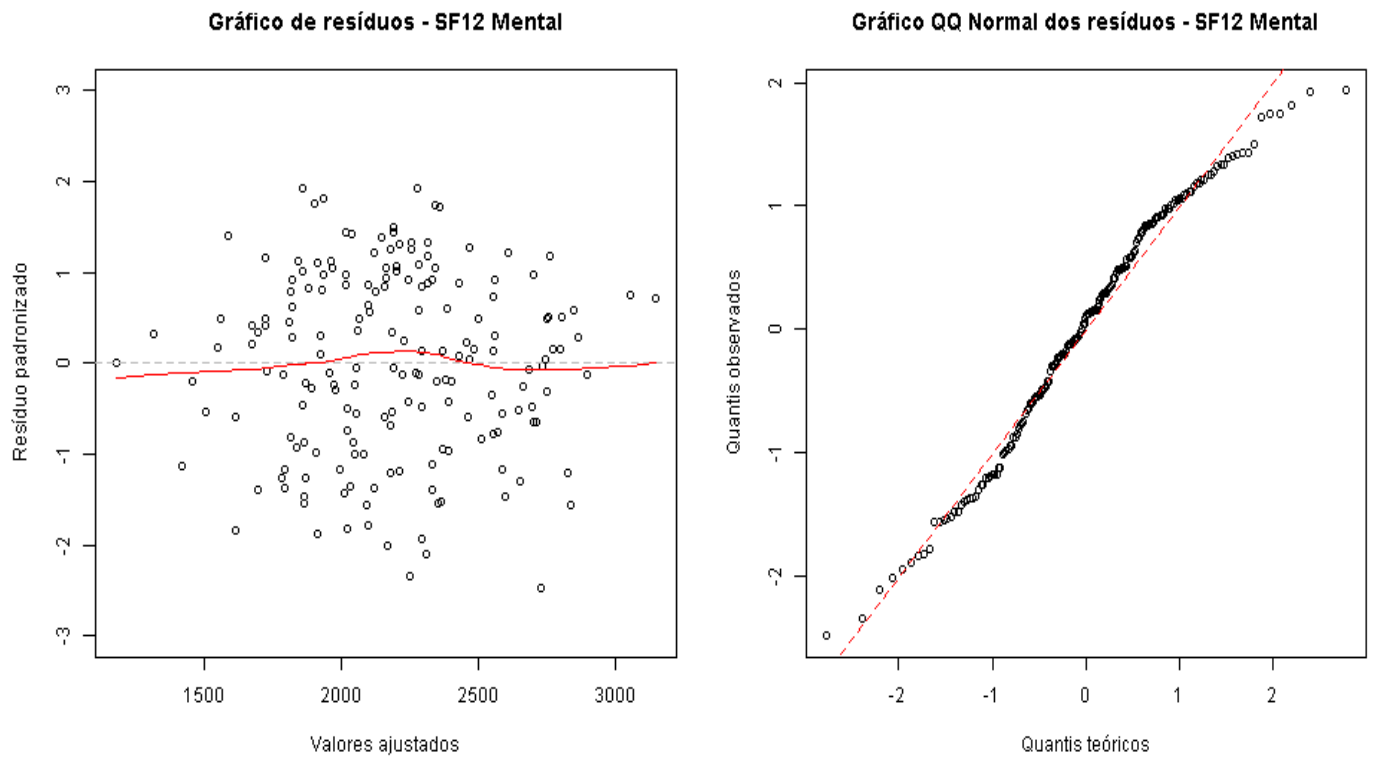
Apêndices 


\section{Apêndice I}

\section{TERMO DE CONSENTIMENTO LIVRE E ESCLARECIDO}

Título do projeto:

Qualidade de vida relacionada à saúde e condições de trabalho dos enfermeiros de Unidades de Terapia Intensiva do município de São Paulo

Responsável pelo projeto: Luciana Soares Costa Santos e Prof a ${ }^{\mathrm{D}}{ }^{\mathrm{a}}$ Miako Kimura

\section{Justificativa da pesquisa}

O ambiente de trabalho do enfermeiro na UTI pode ser influenciado por diferentes fatores e que podem repercutir na sua QV e seu status de saúde, o que pode levar ao comprometimento dos resultados de seu trabalho. Esta investigação se faz pertinente em função de buscarmos entender como o enfermeiro de UTI hoje, está inserido em seu ambiente de trabalho e em que condições este trabalho está sendo elaborado. Desta forma, este estudo permitirá revelar aspectos ainda pouco conhecidos na nossa realidade e que subsidiem o direcionamento de políticas institucionais capazes de produzir melhorias nas condições de trabalho dos enfermeiros e, em última instância, nos resultados para os pacientes e na qualidade do cuidado prestado.

\section{Objetivo da pesquisa}

Analisar a relação entre condições de trabalho e QVRS de enfermeiros em UTIs no município de São Paulo

\section{Procedimentos a que será submetido}

Estamos realizando um estudo para identificar a relação das condições de trabalho e QVRS dos enfermeiros de UTI no município de São Paulo.. Solicitamos sua colaboração em participar deste estudo, respondendo a um Kit contendo questionários que avaliam a QVRS, o estresse, a relação médico enfermeiro, autonomia e a qualidade de vida relacionada ao trabalho, além de um questionário com características sociodemográficas..

\section{Aspectos éticos}

Não haverá qualquer risco em sua participação neste estudo. Os resultados desta pesquisa poderão trazer informações importantes para que possamos caracterizar a QVRS dos enfermeiros e relacioná-las ao trabalho exercido na UTI. Todas as informações obtidas serão sigilosas e confidenciais, sendo divulgadas apenas em eventos e publicações científicas, preservando sempre a sua identidade.

\section{Outras informações}


Não haverá compensação financeira ou custos decorrentes de sua participação no estudo, pois a mesma é de caráter voluntário. Caso você não tenha interesse em participar, isto não acarretará nenhum prejuízo às suas atividades profissionais no hospital.

Você estará livre para desistir a qualquer momento, mesmo que inicialmente tenha concordado, sem que isso também prejudique o seu trabalho. Poderão tirar todas as dúvidas, mesmo aquelas que apareçam durante o estudo, havendo o compromisso do pesquisador em respondê-las.

\section{DECLARAÇÃO DE CONSENTIMENTO}

$\mathrm{Eu}$, idade anos,

RG................. , concordo em participar do presente estudo, após estar ciente dos propósitos da pesquisa, sendo a minha participação totalmente voluntária.

São Paulo, ..... de 2012.

\footnotetext{
Assinatura do participante
}

Ass. Pesquisador:

Luciana Soares Costa Santos

Fone (011) 32715625 / 99393024

Escola de Enfermagem - Universidade de São Paulo 


\section{Apêndice II}

\section{FICHA DE CARACTERIZAÇÃO SÓCIO-DEMOGRÁFICA E PROFISSIONAL DO ENFERMEIRO}

1. Idade (anos)

2. Sexo: Masculino $\square$ Feminino

3. Estado Civil: solteiro $\square$ Casado ou em união consensual $\square$ Viúvo $\square$ Separado $\square$

4. Ano da graduação em enfermagem:

5. Tempo de trabalho como enfermeiro de UTI: ___ anos

6. Qualificação profissional. Para cada tipo de curso a seguir, se a resposta for SIM, especifique no espaço correspondente a área do curso em andamento ou concluído.

a. Especialização : $\square$ Não $\square$ Sim.:

$\square$ Em andamento:

$\square$ Concluído:

b.Mestrado $\square$ Não $\square$ Sim.

Em andamento:

$\square$ Concluído:

\section{c. Doutorado $\square$ Não $\square$ Sim.}

Em andamento:

$\square$ Concluído:

\section{d. Outros cursos $\square$ Não $\square$ Sim:}

7. Qual o seu turno de trabalho nesta instituição?

$\square$ Manhã $\square$ Tarde $\square$ Noite

8. Além de trabalhar neste hospital, em quantos outros locais você trabalha atualmente? $\square$ Nenhum $\square 1 \square 2 \square 3 \square 4 \square 5 \square$ mais de 5

9. De quantos eventos científicos (congressos, simpósios, conferências, palestras, etc) você participou durante o ano passado? $\square$ Nenhum $\square 1 \square 2 \square 3 \square 4 \square$. Se mais de 5 , cite quantos:

10. Qual a sua carga horária de trabalho semanal? $\square<40$ horas $\square \geq 40$ horas

11. Remuneração mensal: $R \$$ 12. Possui religião? Qual 


\section{Apêndice III}

\section{FICHA DE CARACTERIZAÇÃO DA UNIDADE DE TERAPIA INTENSIVA}

Tipo de Instituição: Pública $\square$ Privada $\square$ Filantrópica $\square$

Procedimentos de alta complexidade: $\square$ não $\square$ sim.

Porte do hospital $\square$ médio $\square$ grande $\square$ extra

Tipo de atendimento $\square$ UTI geral $\square$ Especializada Tipo:

Número de leitos da UTI:

Número de UTIs na instituição:

Total de enfermeiros: Proporção paciente/enfermeiro por turno:

Total de técnicos de enfermagem: Proporção paciente/TE:

Total de médicos:

Taxa de mortalidade mensal: 